NBER WORKING PAPER SERIES

\title{
CAPITAL ALLOCATION AND PRODUCTIVITY IN SOUTH EUROPE
}

\author{
Gita Gopinath \\ Sebnem Kalemli-Ozcan \\ Loukas Karabarbounis \\ Carolina Villegas-Sanchez \\ Working Paper 21453 \\ http://www.nber.org/papers/w21453 \\ NATIONAL BUREAU OF ECONOMIC RESEARCH \\ 1050 Massachusetts Avenue \\ Cambridge, MA 02138 \\ August 2015
}

We are grateful to Mark Aguiar, Marios Angeletos, Pol Antras, Nick Bloom, Kinda Hachem, John Haltiwanger, Chang-Tai Hsieh, Oleg Itskhoki, Pete Klenow, Matteo Maggiori, Virgiliu Midrigan, Ben Moll, Brent Neiman, Ricardo Reis, Diego Restuccia, Richard Rogerson, John Van Reenen, Ivan Werning, five anonymous referees, and numerous participants in seminars and conferences for useful comments and helpful discussions. We thank Serdar Birinci, Laura Blattner, and Kurt Gerard See for excellent research assistance. Villegas-Sanchez thanks Banco Sabadell and AGAUR-Generalitat de Catalunya for financial support. The views expressed herein are those of the authors and not necessarily those of the Federal Reserve Bank of Minneapolis, the Federal Reserve System, or the National Bureau of Economic Research.

NBER working papers are circulated for discussion and comment purposes. They have not been peer-reviewed or been subject to the review by the NBER Board of Directors that accompanies official NBER publications.

(C) 2015 by Gita Gopinath, Sebnem Kalemli-Ozcan, Loukas Karabarbounis, and Carolina Villegas-Sanchez. All rights reserved. Short sections of text, not to exceed two paragraphs, may be quoted without explicit permission provided that full credit, including $\left({ }^{\circ}\right.$ notice, is given to the source. 
Capital Allocation and Productivity in South Europe

Gita Gopinath, Sebnem Kalemli-Ozcan, Loukas Karabarbounis, and Carolina Villegas-Sanchez NBER Working Paper No. 21453

August 2015, Revised March 2017

JEL No. D24,E22,F41,O16,O47

\begin{abstract}
Starting in the early 1990s, countries in southern Europe experienced low productivity growth alongside declining real interest rates. We use data for manufacturing firms in Spain between 1999 and 2012 to document a significant increase in the dispersion of the return to capital across firms, a stable dispersion of the return to labor, and a significant increase in productivity losses from capital misallocation over time. We develop a model with size-dependent financial frictions that is consistent with important aspects of firms' behavior in production and balance sheet data. We illustrate how the decline in the real interest rate, often attributed to the euro convergence process, leads to a significant decline in sectoral total factor productivity as capital inflows are misallocated toward firms that have higher net worth but are not necessarily more productive. We show that similar trends in dispersion and productivity losses are observed in Italy and Portugal but not in Germany, France, and Norway.
\end{abstract}

Gita Gopinath

Department of Economics

Harvard University

1875 Cambridge Street

Littauer 206

Cambridge, MA 02138

and NBER

gopinath@ harvard.edu

Sebnem Kalemli-Ozcan

Department of Economics

University of Maryland

Tydings Hall 4118D

College Park, MD 20742-7211

and CEPR

and also NBER

kalemli@econ.umd.edu
Loukas Karabarbounis

University of Minnesota

Department of Economics

Hanson Hall

Minneapolis, MN 55455

and NBER

loukas@umn.edu

Carolina Villegas-Sanchez

University of Houston

Office 211B

204 McElhinney Hall

Houston, TX 77204-5019

carolina.villegas@esade.edu 


\section{Introduction}

Beginning in the 1990s, so-called imbalances emerged across countries in Europe. Countries in the South received large capital inflows. During this period productivity diverged, with countries in the South experiencing slower productivity growth than other European countries. Economists and policymakers often conjecture that low productivity growth resulted from a misallocation of resources across firms or sectors in the South.

This paper has two goals. First, we bring empirical evidence to bear on the question of how the misallocation of resources across firms evolves over time. Between 1999 and 2012, we document a significant increase in the dispersion of the return to capital and a deterioration in the efficiency of resource allocation across Spanish manufacturing firms. Second, we develop a model with firm heterogeneity, financial frictions, and capital adjustment costs to shed light on these trends. We demonstrate how the decline in the real interest rate, often attributed to the euro convergence process, led to an increase in the dispersion of the return to capital and to lower total factor productivity (TFP) as capital inflows were directed to less productive firms operating within relatively underdeveloped financial markets.

Our paper contributes to the literatures of misallocation and financial frictions. Pioneered by Restuccia and Rogerson (2008) and Hsieh and Klenow (2009), the misallocation literature documents large differences in the efficiency of factor allocation across countries and the potential for these differences to explain observed TFP differences. But so far there is little systematic evidence on the dynamics of misallocation within countries. Models with financial frictions, such as Kiyotaki and Moore (1997), have natural implications for the dynamics of capital misallocation at the micro level. Despite this, there exists no empirical work that attempts to relate dynamics of capital misallocation at the micro level to firm-level financial decisions and to the aggregate implications of financial frictions. Our work aims to fill these gaps in the literature.

We use a firm-level dataset from ORBIS-AMADEUS that covers manufacturing firms in Spain between 1999 and 2012. Our data cover roughly 75 percent of the manufacturing economic activity reported in Eurostat (which, in turn, uses Census sources). Further, the share of economic activity accounted for by small and medium sized firms in our data is representative 
of that in Eurostat. Unlike datasets from Census sources, our data contain information on both production and balance sheet variables. This makes it possible to relate real economic outcomes to financial decisions at the firm level over time in a large and representative sample of firms.

We begin our analysis by documenting the evolution of misallocation measures within fourdigit level manufacturing industries. We examine trends in the dispersion of the return to capital, as measured by the log marginal revenue product of capital (MRPK), and the return to labor, as measured by the log marginal revenue product of labor (MRPL). As emphasized by Hsieh and Klenow (2009), an increase in the dispersion of a factor's return across firms could reflect increasing barriers to the efficient allocation of resources and be associated with a loss in TFP at the aggregate level. We document an increase in the dispersion of the MRPK in Spain in the pre-crisis period between 1999 and 2007 that further accelerated in the post-crisis period between 2008 and 2012. By contrast, the dispersion of the MRPL does not show a significant trend throughout this period. Importantly, we document that the increasing dispersion of the return to capital is accompanied by a significant decline in TFP relative to its efficient level.

To interpret these facts and evaluate quantitatively the role of capital misallocation for TFP in an environment with declining real interest rates, we develop a parsimonious small open economy model with heterogeneous firms, borrowing constraints, and capital adjustment costs. Firms compete in a monopolistically competitive environment and employ capital and labor to produce manufacturing varieties. They are heterogeneous in terms of their permanent productivity and also face transitory idiosyncratic productivity shocks. Firms save in a bond to smooth consumption over time and invest to accumulate physical capital.

The main novelty of our model is that financial frictions depend on firm size. We parameterize the borrowing constraint such that the model matches the positive relationship between firm leverage and size in the microdata. We compare the model to the data along various firmlevel moments not targeted during the parameterization. We show that the model generates within-firm and cross-sectional patterns that match patterns of firm size, productivity, MRPK, capital, and net worth in the data. A size-dependent borrowing constraint is important for understanding firms' behavior. Nested models, such as when financial frictions do not depend on firm size or are absent, do worse than our model in terms of matching firm-level moments. 
When subjected to the observed decline in the real interest rate that started in 1994, our model generates dynamics that resemble the trends in the manufacturing sector in Spain between 1999 and 2007 characterized by an inflow of capital, an increase in MRPK dispersion across firms, and a decline in sectoral TFP. In our model firms with higher net worth increase their capital in response to the decline in the cost of capital. For these unconstrained firms, the real interest rate drop generates a decline in their MRPK. On the other hand, firms that happen to have lower net worth despite being potentially productive delay their adjustment until they can internally accumulate sufficient funds. These firms do not experience a commensurate decline in their MRPK. Therefore, the dispersion of the MRPK between financially unconstrained and constrained firms increases. Capital flows into the sector, but not necessarily to the most productive firms, which generates a decline in sectoral TFP.

Quantitatively, our model generates large increases in firm capital, borrowing, and MRPK dispersion and a significant fraction of the observed decline in TFP relative to its efficient level between 1999 and 2007. We argue that a size-dependent borrowing constraint is crucial in generating these aggregate outcomes. We show that the model without a size-dependent borrowing constraint fails to generate significant changes in firm capital, borrowing, MRPK dispersion, and TFP in response to the same decline in the real interest rate.

To further corroborate the mechanism of our model, we present direct evidence that firms with higher initial net worth accumulated more capital during the pre-crisis period conditional on their initial productivity and capital. Our model generates an elasticity of capital accumulation with respect to initial net worth of similar magnitude to the elasticity estimated in the firmlevel data. Informatively for our mechanism, we additionally document that MRPK dispersion in the data does not increase in the subsample of larger firms. Our model also implies that MRPK dispersion does not increase within larger firms because, with a size-dependent borrowing constraint, larger firms are more likely to overcome their borrowing constraint than smaller firms.

We illustrate that alternative narratives of the pre-crisis period, such as a relaxation of borrowing constraints or transitional dynamics that arise purely from capital adjustment costs, do not generate the trends observed in the aggregate data. Additionally, we show that the increase in the dispersion of the MRPK in the pre-crisis period cannot be explained by changes in the 
stochastic process governing firm productivity. During this period, we actually find a decline in the dispersion of productivity shocks across firms. By contrast, changes in financial conditions and uncertainty shocks at the micro level may be important for the post-crisis dynamics characterized by reversals of capital flows and by even larger increases in the dispersion of the MRPK and declines in TFP relative to its efficient level. Indeed, we find that idiosyncratic shocks became significantly more dispersed across firms during the post-crisis period.

We conclude by extending parts of our empirical analyses to Italy (1999-2012), Portugal (2006-2012), Germany (2006-2012), France (2000-2012), and Norway (2004-2012). We find interesting parallels between Spain, Italy, and Portugal. As in Spain, there is a trend increase in MRPK dispersion in Italy before the crisis and a significant acceleration of this trend in the post-crisis period. Portugal also experiences an increase in MRPK dispersion during its sample period that spans mainly the post-crisis years. By contrast, MRPK dispersion is relatively stable in Germany, France, and Norway throughout their samples. Finally, we find significant trends in the loss in TFP due to misallocation in some samples in Italy and Portugal, but do not find such trends in Germany, France, and Norway. We find these differences suggestive, given that firms in the South are likely to operate in less well-developed financial markets.

Related Literature. Our paper contributes to a recent body of work that studies the dynamics of dispersion and misallocation. Oberfield (2013) and Sandleris and Wright (2014) document the evolution of misallocation during crises in Chile and Argentina respectively. Larrain and Stumpner (2013) document changes in resource allocation in several Eastern European countries during financial market liberalization episodes. Bartelsman, Haltiwanger, and Scarpetta (2013) examine the cross-country and time-series variation of the covariance between labor productivity and size as a measure of resource allocation. Kehrig (2015) presents evidence for a countercyclical dispersion of (revenue) productivity in U.S. manufacturing.

Asker, Collard-Wexler, and De Loecker (2014) show how risk and adjustment costs in capital accumulation can rationalize dispersion of firm-level revenue productivity. Following their observation, our model allows for the possibility that increases in the dispersion of firm-level outcomes are driven by changes in second moments of the stochastic process governing idiosyncratic 
productivity. Bloom, Floetotto, Jaimovich, Saporta-Eksten, and Terry (2012) demonstrate that increases in the dispersion of plant-level productivity shocks is an important feature of recessions in the United States.

Banerjee and Duflo (2005) discuss how capital misallocation can arise from credit constraints. An earlier attempt to link productivity and financial frictions to capital flows in an open economy is Mendoza (2010). Recently, several papers have endogenized TFP as a function of financial frictions in dynamic models (Midrigan and Xu, 2014; Moll, 2014; Buera and Moll, 2015). A typical prediction of these models is that a financial liberalization episode is associated with capital inflows, a better allocation of resources across firms, and an increase in TFP growth (see, for instance, Buera, Kaboski, and Shin, 2011; Midrigan and Xu, 2014). This shock, however, does not match the experience of countries in South Europe where TFP growth declined.

One important difference between our paper and these papers is that we focus on transitional dynamics generated by a decline in the real interest rate. Contrary to a financial liberalization shock, the decline in the real interest rate is associated with an inflow of capital and a decline in TFP in the short run of our model. ${ }^{1}$ Relative to the environment considered in these papers, our model produces larger TFP losses during the transitional dynamics because the borrowing constraint depends on firm size.

The problems associated with current account deficits and declining productivity growth in the euro area were flagged early on by Blanchard (2007) for the case of Portugal. Reis (2013) suggests that large capital inflows may have been misallocated to inefficient firms in Portugal in the 2000s. Benigno and Fornaro (2014) suggest that the decline in aggregate productivity growth resulted from a shift in resources from the traded sector, which is the source of endogenous productivity growth, to the non-traded sector following the consumption boom that accompanied the increase in capital inflows. In contemporaneous work, Dias, Marques, and Richmond (2014) and Garcia-Santana, Moral-Benito, Pijoan-Mas, and Ramos (2016) present

\footnotetext{
${ }^{1}$ Consistent with our narrative, Cette, Fernald, and Mojon (2016) provide VAR and panel-data evidence in a sample of European countries and industries linking lower real interest rates to lower productivity in the prerecession period. Fernandez-Villaverde, Garicano, and Santos (2013) also note the decline in interest rates and the inflow of capital fostered by the adoption of the euro and discuss sluggish performance in peripheral countries in the context of abandoned structural reforms. Buera and Shin (2016) study countries undergoing sustained growth accelerations and attribute capital outflows from countries with higher TFP growth to economic reforms that remove idiosyncratic distortions.
} 
descriptive statistics on trends in resource allocation within sectors, including construction and services, for Portugal (1996-2011) and Spain (1995-2007) respectively.

\section{Description of the Data}

Our data come from the ORBIS database. The database is compiled by the Bureau van Dijk Electronic Publishing (BvD). ORBIS is an umbrella product that provides firm-level data for many countries worldwide. Administrative data at the firm level are initially collected by local Chambers of Commerce and, in turn, relayed to BvD through roughly 40 different information providers including business registers. Given our paper's focus, we also use the AMADEUS dataset which is the European subset of ORBIS. One advantage of focusing on European countries is that company reporting is regulatory even for small private firms.

The dataset has financial accounting information from detailed harmonized balance sheets, income statements, and profit and loss accounts of firms. Roughly 99 percent of companies in the dataset are private. This crucially differentiates our data from other datasets commonly used in the finance literature such as Compustat for the United States, Compustat Global, and Worldscope that only contain information on large listed companies.

Our analysis focuses on the manufacturing sector for which challenges related to the estimation of the production function are less severe than in other sectors. In the countries that we examine, the manufacturing sector accounts for roughly 20 to 30 percent of aggregate employment and value added. The ORBIS database allows us to classify industries in the manufacturing sector according to their four-digit NACE Rev. 2 industry classification.

A well-known problem in ORBIS-AMADEUS is that, while the number of unique firm identifiers matches the number in official data sources, key variables, such as employment and materials, are missing once the data are downloaded. There are several reasons for this. Private firms are not required to report materials. Additionally, employment is not reported as a balance sheet item but in memo lines. Less often, there are other missing variables such as capital or assets. Variables are not always reported consistently throughout time in a particular disk or in a download, either from the BvD or the Wharton Research Data Services (WRDS) website. 
$\mathrm{BvD}$ has a policy by which firms that do not report during a certain period are automatically deleted from their later vintage products, creating an artificial survival bias in the sample. An additional issue that researchers face is that online downloads (BvD or WRDS) cap the amount of firms that can be downloaded in a given period of time. This cap translates into missing observations in the actual download job instead of termination of the download job.

We follow a comprehensive data collection process to address these problems and maximize the coverage of firms and variables for our six countries over time. ${ }^{2}$ Broadly, our strategy is to merge data available in historical disks instead of downloading historical data at once from the WRDS website. We rely on two BvD products, ORBIS and AMADEUS. These products have been developed independently and, therefore, they follow different rules regarding the companies and years that should be included. AMADEUS provides data for at most 10 recent years for the same company while ORBIS only reports data for up to 5 recent years. In addition, AMADEUS drops firms from the database if they did not report any information during the last 5 years while ORBIS keeps the information for these companies as long as they are active. We merge data across several vintages of these two products (ORBIS disk 2005, ORBIS disk 2009, ORBIS disk 2013, AMADEUS online 2010 from WRDS, and AMADEUS disk 2014). ${ }^{3}$

Finally, it is sometimes the case that information is updated over time and the value of variables that was not available in early disks is made available in later vintages. Additionally, because of reporting lags the coverage in the latest years of a certain disk can be poor. To maximize the number of firms in the sample and the coverage of variables we merge across all products using a unique firm identifier and we update information missing in early vintages by the value provided in later vintages. An issue when merging data across disks is that there can be changes in firm identifiers over time. We use a table with official identifiers changes provided by $\mathrm{BvD}$ to address this issue.

Table 1 summarizes the coverage in our data for Spain between 1999 and 2012. ${ }^{4}$ The columns

\footnotetext{
${ }^{2}$ See also Kalemli-Ozcan, Sorensen, Villegas-Sanchez, Volosovych, and Yesiltas (2015) for a description of how to use ORBIS to construct representative firm-level datasets for various countries.

${ }^{3}$ For example, consider a company that files information with BvD for the last time in year 2007. Suppose that BvD has information from the Business Registry that this company is still active. In AMADEUS disk 2014 this company will not be included in the database. However, information for the period 2002-2007 for this company will still be available when we combine ORBIS disks 2005 and 2009.

${ }^{4}$ We begin our analysis in 1999 as the coverage in ORBIS-AMADEUS between 1995 and 1998 is, in most
} 
Table 1: Coverage in ORBIS-AMADEUS Relative to Eurostat (SBS): Spain Manufacturing

\begin{tabular}{llcl}
\hline \hline & & & \\
& Employment & Wage Bill & Gross Output \\
& & & \\
\hline 1999 & 0.56 & 0.69 & 0.75 \\
2000 & 0.58 & 0.71 & 0.76 \\
2001 & 0.61 & 0.73 & 0.77 \\
2002 & 0.65 & 0.75 & 0.79 \\
2003 & 0.65 & 0.74 & 0.78 \\
2004 & 0.66 & 0.75 & 0.78 \\
2005 & 0.66 & 0.74 & 0.77 \\
2006 & 0.67 & 0.74 & 0.77 \\
2007 & 0.67 & 0.74 & 0.77 \\
2008 & 0.65 & 0.72 & 0.72 \\
2009 & 0.71 & 0.72 & 0.75 \\
2010 & 0.68 & 0.73 & 0.74 \\
2011 & 0.69 & 0.74 & 0.75 \\
2012 & 0.65 & 0.71 & 0.72 \\
\hline \hline
\end{tabular}

in the table represent the ratio of aggregate employment, wage bill, and gross output recorded in our sample relative to the same object in Eurostat as reported by its Structural Business Statistics (SBS). The data in Eurostat are from Census sources and represent the universe of firms. The coverage statistics we report are conservative because we drop observations with missing, zero, or negative values for gross output, wage bill, capital stock, and materials, that is the variables necessary for computing productivity at the firm level. ${ }^{5}$ As Table 1 shows the coverage in our sample is consistently high and averages roughly 75 percent for the wage bill and gross output and typically more than 65 percent for employment. ${ }^{6}$

Figure 1 plots the aggregate real wage bill and the aggregate real gross output in our ORBISAMADEUS dataset. It compares these aggregates to the same aggregates as recorded by Eurocases, extremely low. There is no representative dataset with financial information going back to the beginning of the 1990s. The ESEE (Encuesta Sobre Estrategias Empresariales) dataset for Spain has the required variables beginning in 1993 but surveys mostly large firms and, therefore, is not representative of the population of firms.

${ }^{5}$ Appendix A provides a detailed description of the process we follow to clean the data and presents summary statistics of the main variables used in our analysis. It also presents coverage statistics for the other countries.

${ }^{6}$ A difference between our sample and Eurostat is that we do not have data on the self-employed. While this has little impact on our coverage of the wage bill and gross output relative to Eurostat, it matters more for employment. 

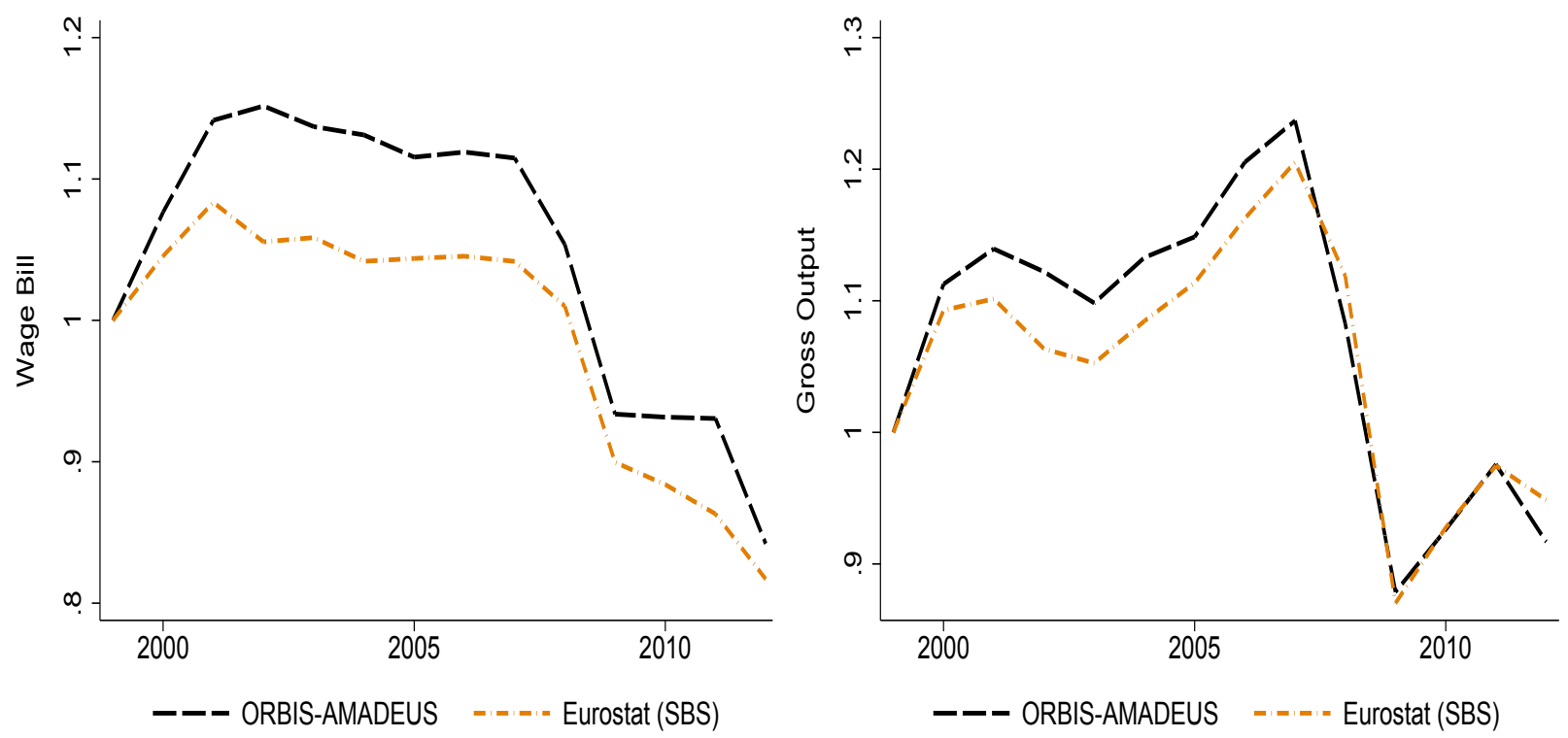

Figure 1: Aggregates in ORBIS-AMADEUS and Eurostat (SBS)

Table 2: Share of Total Manufacturing Economic Activity By Size Class in Spain (2006)

\begin{tabular}{lllcc}
\hline \hline & & & & \\
& & Employment & Wage Bill & Gross Output \\
& & & & \\
ORBIS-AMADEUS & $1-19$ employees & 0.24 & 0.19 & 0.14 \\
& $20-249$ employees & 0.50 & 0.47 & 0.42 \\
& $250+$ employees & 0.26 & 0.34 & 0.45 \\
& & & & 0.14 \\
Eurostat (SBS) & $0-19$ employees & 0.31 & 0.20 & 0.38 \\
& $20-249$ employees & 0.43 & 0.43 & 0.49 \\
& $250+$ employees & 0.26 & 0.37 & \\
\hline \hline
\end{tabular}

stat. Except for the wage bill in the first two years of the sample, these series track each other closely.

Table 2 presents the share of economic activity accounted for by firms belonging in three size categories in $2006 .{ }^{7}$ Each column presents a different measure of economic activity, namely

\footnotetext{
${ }^{7}$ The share of economic activity by size category in our sample relative to Eurostat is relatively stable over time. We show year 2006 in Table 2 for comparability with our analyses of other countries below that also start in 2006 .
} 
employment, wage bill, and gross output. The first three rows report statistics from ORBISAMADEUS and the next three from Eurostat. The entries in the table denote the fraction of total economic activity accounted for by firms belonging to each size class. For example, in our data from ORBIS-AMADEUS, firms with 1-19 employees account for 19 percent of the total wage bill, firms with 20-249 employees account for 47 percent of the total wage bill, and firms with 250 or more employees account for 34 percent of the total wage bill. The corresponding numbers provided by Eurostat's SBS are 20, 43, and 37 percent.

Our sample is mainly composed of small and medium sized firms that account for a significant fraction of economic activity in Europe and the majority of economic activity in the South. Table 2 illustrates that our sample is broadly representative in terms of contributions of small and medium sized firms to manufacturing employment, wage bill, and gross output. This feature is an important difference of our paper relative to the literature that works with both financial and real variables at the firm level. Most of this literature focuses on listed firms that account for less than 1 percent of the observations in our data.

\section{Dispersion and Misallocation Facts}

In this section we document the evolution of measures of dispersion and misallocation for the manufacturing sector in Spain. We build our measurements on the framework developed by Hsieh and Klenow (2009). We consider an industry $s$ at time $t$ populated by a large number $N_{s t}$ of monopolistically competitive firms. ${ }^{8}$ We define industries in the data by their four-digit industry classification.

Total industry output is given by a CES production function:

$$
Y_{s t}=\left[\sum_{i=1}^{N_{s t}} D_{i s t}\left(y_{i s t}\right)^{\frac{\varepsilon-1}{\varepsilon}}\right]^{\frac{\varepsilon}{\varepsilon-1}}
$$

where $y_{\text {ist }}$ denotes firm $i$ 's real output, $D_{i s t}$ denotes a demand shifter for firm $i$ 's variety, and $\varepsilon$ denotes the elasticity of substitution between varieties. We denote by $p_{i s t}$ the price of variety $i$

The sum of entries across rows within each panel and source may not add up to one because of rounding.

${ }^{8}$ In our analysis we model entrepreneurs as single-plant firms. In the ESEE dataset for Spain that generally covers only large firms, we find that firms with more than a single plant constitute roughly 15 percent of all firms in the data. Importantly, there is no time series variation in this share. Given that large firms tend to have more plants than small firms, we expect the share of multi-plant firms to be even smaller in our dataset. 
and by $P_{s t}$ the price of industry output $Y_{s t}$. Firms face an isoelastic demand for their output given by $y_{i s t}=\left(p_{i s t} / P_{s t}\right)^{-\varepsilon}\left(D_{i s t}\right)^{\varepsilon} Y_{s t}$.

Firms' output is given by a Cobb-Douglas production function:

$$
y_{i s t}=A_{i s t} k_{i s t}^{\alpha} \ell_{i s t}^{1-\alpha}
$$

where $k_{i s t}$ is capital, $\ell_{i s t}$ is labor, $A_{i s t}$ is physical productivity, and $\alpha$ is the elasticity of output with respect to capital. As a baseline and for comparability with our dynamic model below that features a single sector we set $\alpha=0.35$ for all industries, corresponding to the average capital share in a relatively undistorted economy such as the United States. Our measures of dispersion of factor returns are not affected by the assumption that $\alpha$ is homogeneous across industries because these measures use within-industry variation of firm outcomes. In Appendix $\mathrm{B}$ we show that our estimated trends in TFP losses do not change meaningfully when using either Spanish or U.S. factor shares to construct elasticities $\alpha_{s, t}$ that vary by sector and time.

We measure firm nominal value added, $p_{i s t} y_{i s t}$, as the difference between gross output (operating revenue) and materials. We measure real output, $y_{i s t}$, as nominal value added divided by an output price deflator. Given that we do not observe prices at the firm level, we use gross output price deflators from Eurostat at the two-digit industry level. We measure the labor input, $\ell_{i s t}$, with the firm's wage bill deflated by the same industry price deflator. We use the wage bill instead of employment as our measure of $\ell_{i s t}$ to control for differences in the quality of the workforce across firms. We measure the capital stock, $k_{i s t}$, with the book value of fixed assets and deflate this value with the price of investment goods. ${ }^{9}$ In fixed assets we include both tangible and intangible fixed assets. ${ }^{10}$

\footnotetext{
${ }^{9}$ Deflating fixed assets matters for our results only through our measures of capital and TFP at the aggregate level. We choose to deflate the book value of fixed assets because in this paper we are interested in measuring changes (rather than levels) of capital and TFP. Changes in book values across two years reflect to a large extent purchases of investment goods valued at current prices. For plots that cover the whole sample period until 2012, we use country-specific prices of investment from the World Development Indicators to deflate the book value of fixed assets, as we do not have industry-specific price of investment goods for the whole sample period. For our quantitative application to Spain between 1999 and 2007, we construct a manufacturing-specific investment deflator based on the prices of investment goods for eight types of assets provided from KLEMS.

${ }^{10}$ Our results do not change in any meaningful way if we measure $k_{i s t}$ with the book value of tangible fixed assets with one exception. In 2007 there was a change in the accounting system in Spain and leasing items that until 2007 had been part of intangible fixed assets were from 2008 included under tangible fixed assets. If we measure $k_{i s t}$ with tangible fixed assets, we observe an important discontinuity in some of our dispersion measures in Spain between 2007 and 2008 that is entirely driven by this accounting convention.
} 
Denoting the inverse demand function by $p\left(y_{i s t}\right)$, firms choose their price, capital, and labor to maximize their profits:

$$
\max _{p_{i s t}, k_{i s t}, \ell_{i s t}} \Pi_{i s t}=\left(1-\tau_{i s t}^{y}\right) p\left(y_{i s t}\right) y_{i s t}-\left(1+\tau_{i s t}^{k}\right)\left(r_{t}+\delta_{s t}\right) k_{i s t}-w_{s t} \ell_{i s t},
$$

where $w_{s t}$ denotes the wage, $r_{t}$ denotes the real interest rate, $\delta_{s t}$ denotes the depreciation rate, $\tau_{i s t}^{y}$ denotes a firm-specific wedge that distorts output, and $\tau_{i s t}^{k}$ denotes a firm-specific wedge that distorts capital relative to labor. For now we treat wedges as exogenous and endogenize them later in the model of Section 4.

The first-order conditions with respect to labor and capital are given by:

$$
\begin{aligned}
\operatorname{MRPL}_{i s t} & :=\left(\frac{1-\alpha}{\mu}\right)\left(\frac{p_{i s t} y_{i s t}}{\ell_{i s t}}\right)=\left(\frac{1}{1-\tau_{i s t}^{y}}\right) w_{s t}, \\
\mathrm{MRPK}_{i s t} & :=\left(\frac{\alpha}{\mu}\right)\left(\frac{p_{i s t} y_{i s t}}{k_{i s t}}\right)=\left(\frac{1+\tau_{i s t}^{k}}{1-\tau_{i s t}^{y}}\right)\left(r_{t}+\delta_{s t}\right),
\end{aligned}
$$

where $\mu=\varepsilon /(\varepsilon-1)$ denotes the constant markup of price over marginal cost. Equation (4) states that firms set the marginal revenue product of labor (MRPL) equal to the wage times the wedge $1 /\left(1-\tau_{i s t}^{y}\right)$. Similarly, in equation (5) firms equate the marginal revenue product of capital (MRPK) to the cost of capital times the wedge $\left(1+\tau_{\text {ist }}^{k}\right) /\left(1-\tau_{\text {ist }}^{y}\right)$. With CobbDouglas production function, the marginal revenue product of each factor is proportional to the factor's revenue-based productivity.

Following the terminology used in Foster, Haltiwanger, and Syverson (2008) and Hsieh and Klenow (2009), we define the revenue-based total factor productivity (TFPR) at the firm level as the product of price $p_{i s t}$ times physical productivity $A_{i s t}$ :

$$
\mathrm{TFPR}_{i s t}:=p_{i s t} A_{i s t}=\frac{p_{i s t} y_{i s t}}{k_{i s t}^{\alpha} \ell_{i s t}^{1-\alpha}}=\mu\left(\frac{\mathrm{MRPK}_{i s t}}{\alpha}\right)^{\alpha}\left(\frac{\mathrm{MRPL}_{i s t}}{1-\alpha}\right)^{1-\alpha} .
$$

Firms with higher output distortions $\tau_{i s t}^{y}$ or higher capital relative to labor distortions $\tau_{i s t}^{k}$ have higher marginal revenue products and, as equation (6) shows, a higher $\mathrm{TFPR}_{\text {ist }}$.

In this economy, resources are allocated optimally when all firms face the same (or no) distortions in output $\left(\tau_{i s t}^{y}=\tau_{s t}^{y}\right)$ and capital relative to labor $\left(\tau_{i s t}^{k}=\tau_{s t}^{k}\right)$. In that case, more factors are allocated to firms with higher productivity $A_{\text {ist }}$ or higher demand shifter $D_{i s t}$, but there is no dispersion of the returns to factors, that is the MRPL and the MRPK are equalized 


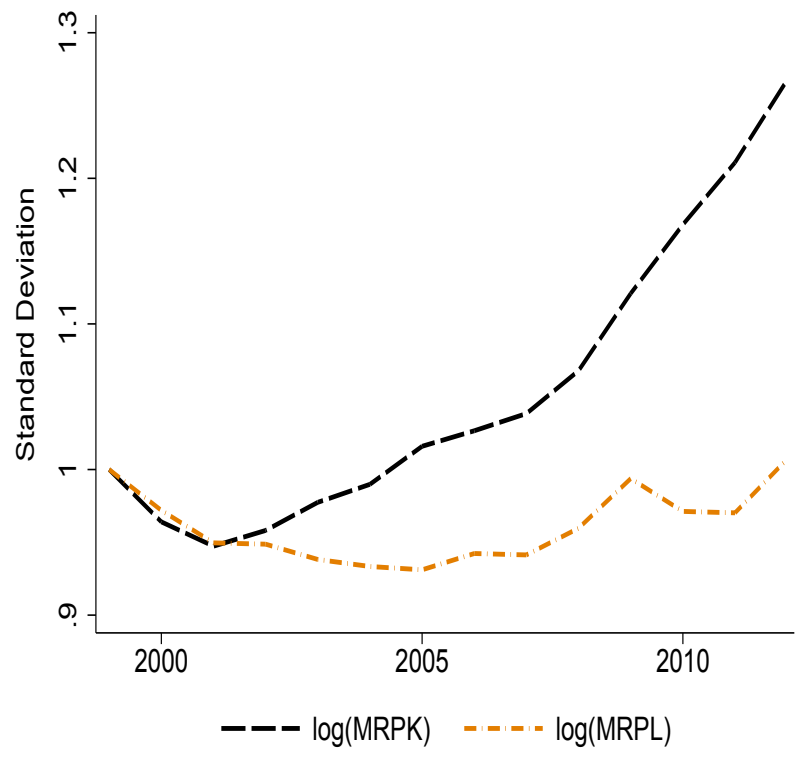

(a) Permanent Sample

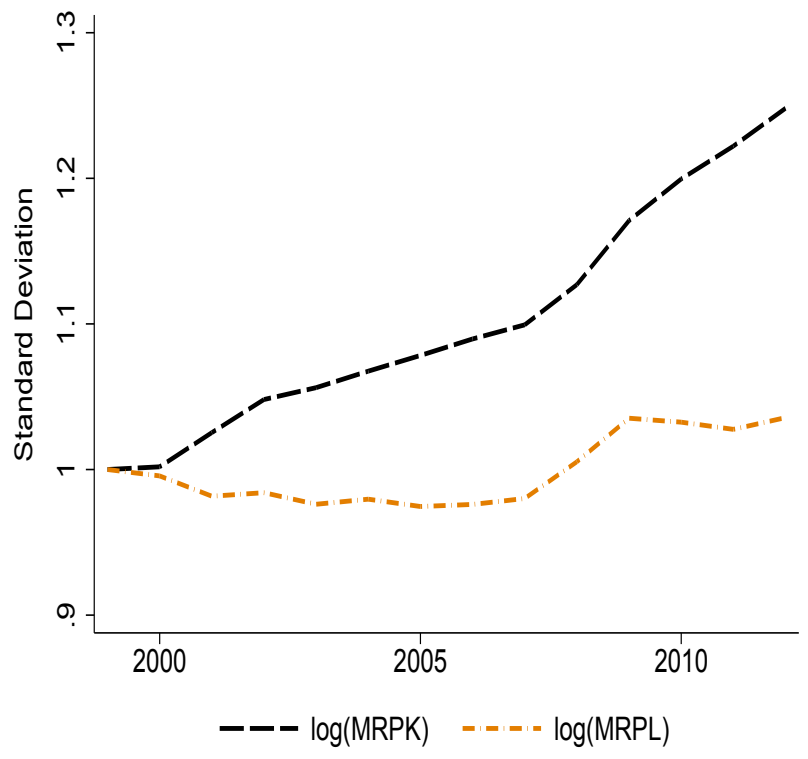

(b) Full Sample

Figure 2: Evolution of MRPK and MRPL Dispersion

across firms. ${ }^{11}$ On the other hand, the existence of idiosyncratic distortions, $\tau_{i s t}^{y}$ and $\tau_{i s t}^{k}$, leads to a dispersion of marginal revenue products and a lower sectoral TFP.

In Figure 2 we present the evolution of the dispersion of the $\log (\mathrm{MRPK})$ and $\log (\mathrm{MRPL})$ in Spain. To better visualize the relative changes over time, we normalize these measures to 1 in the first sample year. The left panel is based on the subset of firms that are continuously present in our data. We call this subset of firms the "permanent sample." The right panel is based on the "full sample" of firms. The full sample includes firms that enter or exit from the sample in various years and, therefore, comes closer to matching the coverage of firms observed in Eurostat. ${ }^{12}$

The time series of the dispersion measures are computed in two steps. First, we calculate a given dispersion measure across firms $i$ in a given industry $s$ and year $t$. Second, for each

\footnotetext{
${ }^{11}$ Without idiosyncratic distortions, $\mathrm{TFPR}_{i s t}=p_{\text {ist }} A_{\text {ist }}$ is equalized across firms since $p_{\text {ist }}$ is inversely proportional to physical productivity $A_{i s t}$ and does not depend on the demand shifter $D_{i s t}$. This also implies that capital-labor ratios are equalized across firms.

${ }^{12} \mathrm{We}$ calculate that in 2000 the entry rate among firms with at least one employee is 6.5 percent. The entry rate declines over time to 2 percent by the end of our sample. These numbers match closely the entry rates calculated from Eurostat. Our permanent sample of firms differs from the full sample both because of real entry and exit and because firms with missing reporting in at least one year are excluded from the permanent sample but are included in the full sample during years with non-missing reporting. See Appendix A for more details on the construction of the two samples.
} 

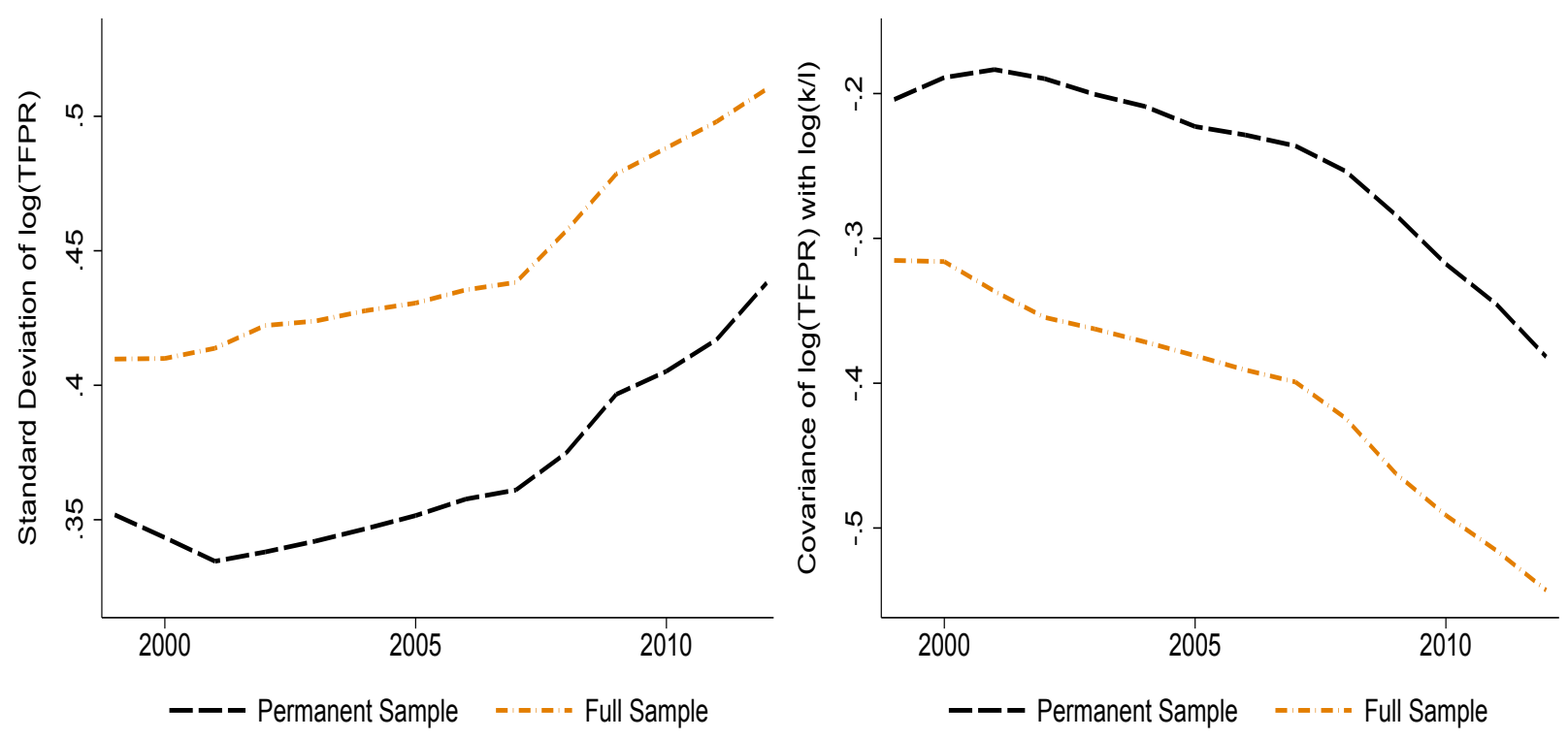

Figure 3: TFPR Moments

year we calculate dispersion for the manufacturing sector as the weighted average of dispersions across industries $s$. Each industry is given a time-invariant weight equal to its average share in manufacturing value added. We always use the same weights when aggregating across industries. Therefore, all of our estimates reflect purely variation within four-digit industries over time.

Figure 2 shows a large increase in the standard deviation of $\log (\mathrm{MRPK})$ over time. With the exception of the first two years in the permanent sample, we always observe increases in the dispersion of the $\log (\mathrm{MRPK})$. The increase in the dispersion of the $\log (\mathrm{MRPK})$ accelerates during the post-crisis period between 2008 and 2012. We emphasize that we do not observe similar trends in the standard deviation of $\log (\mathrm{MRPL}) .{ }^{13}$ The striking difference between the evolution of the two dispersion measures argues against the importance of changing distortions that affect both capital and labor at the same time. For example, this finding is not consistent with heterogeneity in price markups driving trends in dispersion because such an explanation would cause similar changes to the dispersion of both the $\log (\mathrm{MRPK})$ and the $\log (\mathrm{MRPL}) .{ }^{14}$ Finally, we note that while we use standard deviations of logs to represent dispersion, we obtain similar results when we measure dispersion with either the $90-10$ or the $75-25$ ratio.

\footnotetext{
${ }^{13}$ We obtain a similar result if we use employment instead of the wage bill to measure $\ell_{i s t}$.

${ }^{14}$ The relationship between markups and misallocation has been recently the focus of papers such as Fernald and Neiman (2011) and Peters (2013).
} 
The framework of Hsieh and Klenow (2009) that we adopt for measuring trends in the dispersion of returns to factors relies on the Cobb-Douglas production function. Under a CobbDouglas production function, an increasing dispersion of the $\log (\mathrm{MRPK})$ together with stable dispersion of the $\log (\mathrm{MRPL})$ implies that the covariance between $\log (\mathrm{TFPR})$ and $\log (k / \ell)$ across firms is decreasing over time. To see this point, write:

$$
\begin{gathered}
\operatorname{Var}(\operatorname{mrpk})=\operatorname{Var}(\operatorname{tfpr})+(1-\alpha)^{2} \operatorname{Var}\left(\log \left(\frac{k}{\ell}\right)\right)-2(1-\alpha) \operatorname{Cov}\left(\operatorname{tfpr}, \log \left(\frac{k}{\ell}\right)\right), \\
\operatorname{Var}(\operatorname{mrpl})=\operatorname{Var}(\mathrm{tfpr})+\alpha^{2} \operatorname{Var}\left(\log \left(\frac{k}{\ell}\right)\right)+2 \alpha \operatorname{Cov}\left(\operatorname{tfpr}, \log \left(\frac{k}{\ell}\right)\right),
\end{gathered}
$$

where we define $\operatorname{mrpk}=\log (\mathrm{MRPK}), \mathrm{mrpl}=\log (\mathrm{MRPL})$, and $\mathrm{tfpr}=\log (\mathrm{TFPR})$. Figure 3 confirms that the dispersion of tfpr is increasing over time and that the covariance between tfpr and $\log (k / \ell)$ is decreasing over time. The variance of the $\log$ capital-labor ratio (the second term) is also increasing over time.

We now discuss measures of productivity and misallocation. Total factor productivity at the industry level is defined as the wedge between industry output and an aggregator of industry inputs, $\mathrm{TFP}_{s t}:=Y_{s t} /\left(K_{s t}^{\alpha} L_{s t}^{1-\alpha}\right)$, where $K_{s t}=\sum_{i} k_{i s t}$ is industry capital and $L_{s t}=\sum_{i} \ell_{i s t}$ is industry labor. We can write TFP as: ${ }^{15}$

$$
\operatorname{TFP}_{s t}=\frac{Y_{s t}}{K_{s t}^{\alpha} L_{s t}^{1-\alpha}}=\frac{\overline{\operatorname{TFPR}}_{s t}}{P_{s t}}=\left[\sum_{i}(\underbrace{\left(D_{i s t}\right)^{\frac{\varepsilon}{\varepsilon-1}} A_{i s t}}_{Z_{i s t}} \frac{\overline{\mathrm{TFPR}}_{s t}}{\mathrm{TFPR}_{i s t}})^{\varepsilon-1}\right]^{\frac{1}{\varepsilon-1}} .
$$

We note that for our results it is appropriate to only track a combination of demand and productivity at the firm level. From now on we call "firm productivity," $Z_{i s t}=\left(D_{i s t}\right)^{\frac{\varepsilon}{\varepsilon-1}} A_{\text {ist }}$, a combination of firm productivity and the demand shifter.

To derive a measure that maps the allocation of resources to TFP performance, we follow Hsieh and Klenow (2009) and define the "efficient" level of TFP as the TFP level we would observe in the first-best allocation in which there is no dispersion of the MRPK, MRPL, and TFPR across firms. Plugging $\mathrm{TFPR}_{i s t}=\overline{\mathrm{TFPR}}_{s t}$ into equation (9), we see that the efficient

\footnotetext{
${ }^{15}$ To derive equation (9), we substitute into the definition of TFP the industry price index $P_{s t}=$ $\left(\sum_{i}\left(D_{i s t}\right)^{\varepsilon}\left(p_{i s t}\right)^{1-\varepsilon}\right)^{1 /(1-\varepsilon)}$, firms' prices $p_{i s t}=\mathrm{TFPR}_{i s t} / A_{i s t}$, and an industry-level TFPR measure, $\overline{\mathrm{TFPR}}_{s t}=$ $P_{s t} Y_{s t} /\left(K_{s t}^{\alpha} L_{s t}^{1-\alpha}\right)$. Equation (9) is similar to the one derived in Hsieh and Klenow (2009), except for the fact that we also allow for idiosyncratic demand shifters $D_{i s t}$.
} 


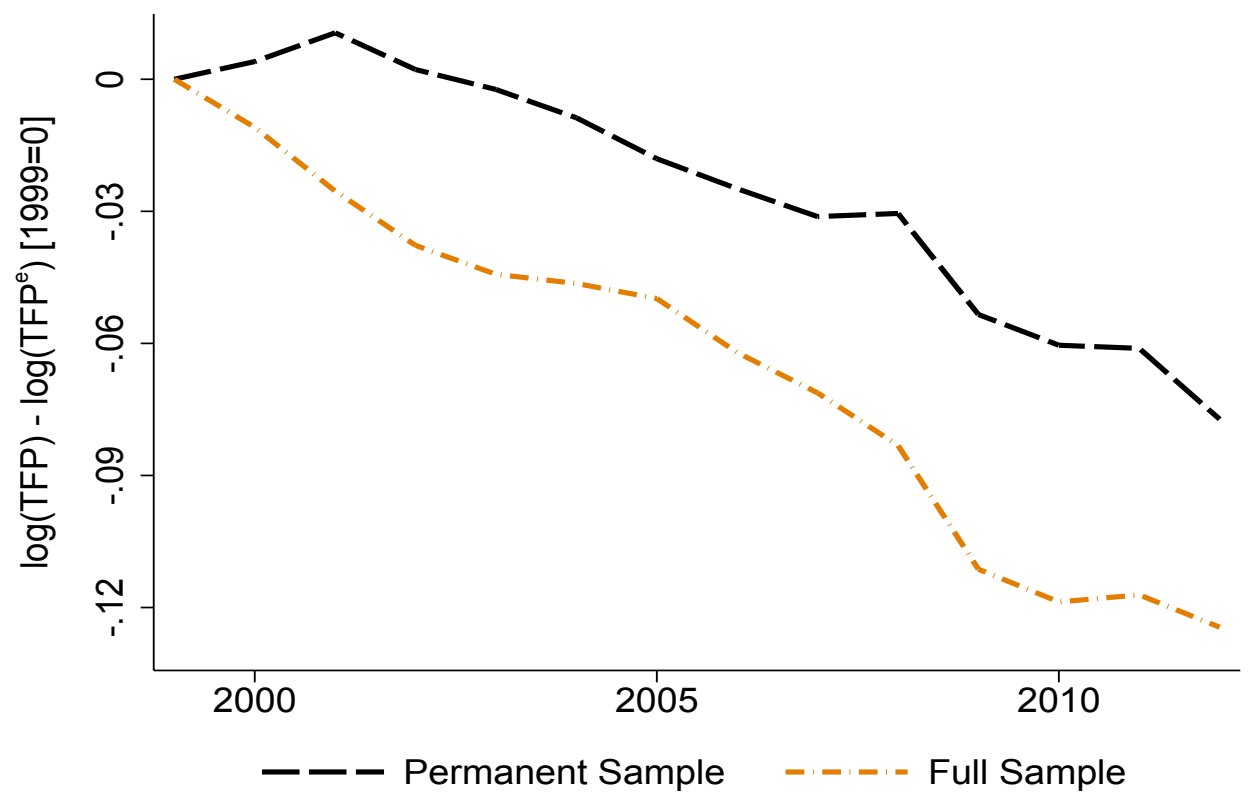

Figure 4: Evolution of TFP Relative to Efficient Level

level of TFP is given by $\mathrm{TFP}_{s t}^{e}=\left[\sum_{i} Z_{i s t}^{\varepsilon-1}\right]^{\frac{1}{\varepsilon-1}}$. The difference in $\log (\mathrm{TFP})$ arising from misallocation, $\Lambda_{s t}=\log \left(\mathrm{TFP}_{s t}\right)-\log \left(\mathrm{TFP}_{s t}^{e}\right)$, can be expressed as:

$$
\begin{aligned}
\Lambda_{s t}= & \frac{1}{\varepsilon-1}\left[\log \left(\mathbb{E}_{i} Z_{\text {ist }}^{\varepsilon-1} \mathbb{E}_{i}\left(\frac{\overline{\mathrm{TFPR}}}{\mathrm{TFPR}_{\text {ist }}}\right)^{\varepsilon-1}+\operatorname{Cov}_{i}\left(Z_{\text {ist }}^{\varepsilon-1},(\overline{\overline{\mathrm{TFPR}}})^{\varepsilon-1}\right)\right)\right] \\
& -\frac{1}{\varepsilon-1} \log \left(\mathbb{E}_{i} Z_{\text {ist }}^{\varepsilon-1}\right) .
\end{aligned}
$$

To construct this measure of misallocation, we need estimates of $Z_{i s t}$. Employing the structural assumptions on demand and production used to arrive at equation (10), we estimate firm productivity as: ${ }^{16}$

$$
\tilde{Z}_{i s t}=\left(\frac{\left(P_{s t} Y_{s t}\right)^{-\frac{1}{\varepsilon-1}}}{P_{s t}}\right)\left(\frac{\left(p_{i s t} y_{i s t}\right)^{\frac{\varepsilon}{\varepsilon-1}}}{k_{i s t}^{\alpha} \ell_{i s t}^{1-\alpha}}\right)
$$

where $p_{i s t} y_{i s t}$ denotes firm nominal value added and $P_{s t} Y_{s t}=\sum_{i} p_{i s t} y_{i s t}$ denotes industry nominal value added.

Figure 4 plots changes relative to 1999 in the difference in $\log$ (TFP) relative to its efficient level. For comparability with Hsieh and Klenow (2009), we use an elasticity of substitution between varieties equal to $\varepsilon=3$. As with our measures of dispersion, we first estimate the

\footnotetext{
${ }^{16}$ To derive equation (11), first use the production function to write $\tilde{Z}_{i s t}=A_{i s t} D_{\text {ist }}^{\frac{\varepsilon}{\varepsilon-1}}=D_{i s t}^{\frac{\varepsilon}{\varepsilon-1}} y_{i s t} /\left(k_{i s t}^{\alpha} \ell_{i s t}^{1-\alpha}\right)$. Then, from the demand function substitute in $D_{i s t}^{\frac{\varepsilon}{\varepsilon-1}}=\left(p_{i s t} / P_{s t}\right)^{\frac{\varepsilon}{\varepsilon-1}}\left(y_{i s t} / Y_{s t}\right)^{\frac{1}{\varepsilon-1}}$.
} 


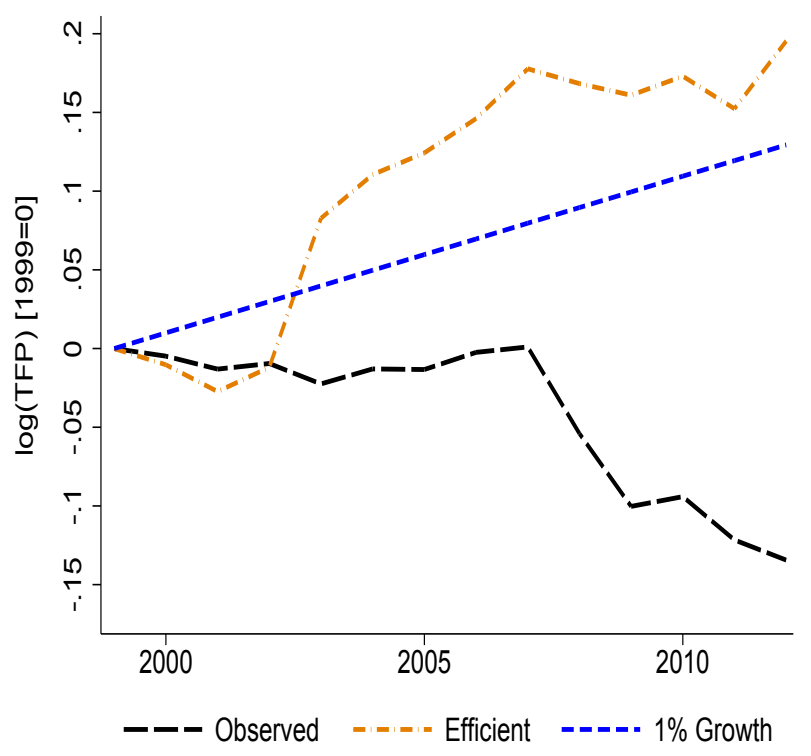

(a) Permanent Sample

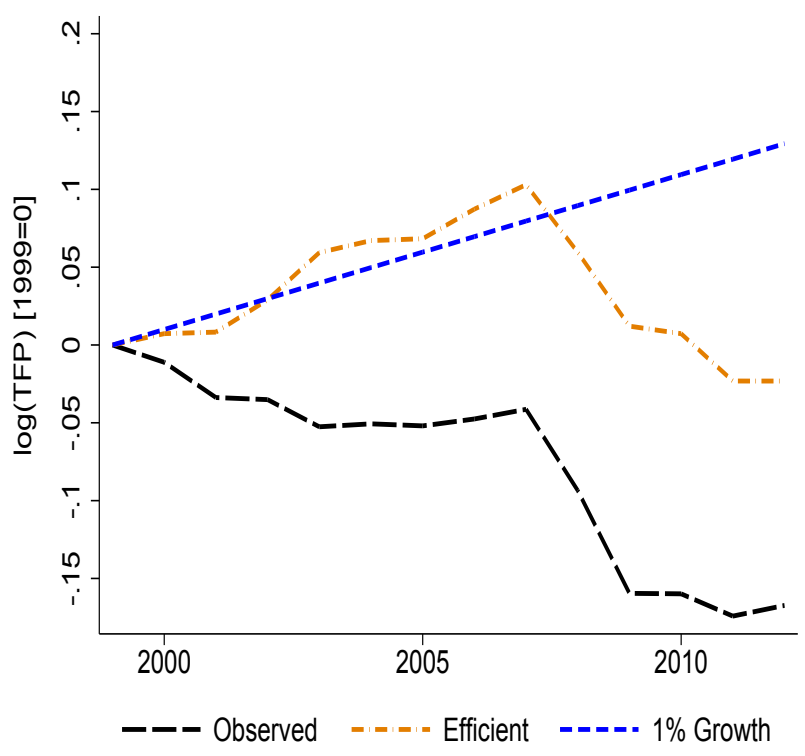

(b) Full Sample

Figure 5: Evolution of Observed TFP Relative to Benchmarks

difference $\Lambda_{s t}$ within every industry $s$ and then use the same time-invariant weights to aggregate across industries. Between 1999 and 2007, we document declines in TFP relative to its efficient level of roughly 3 percentage points in the permanent sample and 7 percentage points in the full sample. By the end of the sample in 2012, we observe declines in TFP relative to its efficient level of roughly 7 percentage points in the permanent sample and 12 percentage points in the full sample. ${ }^{17}$

In Figure 5 we plot changes in manufacturing $\log (\mathrm{TFP})$ in the data. We measure $\log (\mathrm{TFP})$ for each industry as $\log \left(\mathrm{TFP}_{s t}\right)=\log \left(\sum_{i} y_{i s t}\right)-\alpha \log \left(K_{s t}\right)-(1-\alpha) \log \left(L_{s t}\right)$ and use the same time-invariant weights to aggregate across industries $s$. Manufacturing TFP could be changing over time for reasons other than changes in the allocation of resources (for example, labor hoarding, capital utilization, entry, and technological change). We, therefore, compare observed $\log (\mathrm{TFP})$ in the data to two baseline $\log (\mathrm{TFP})$ paths. The first path is the efficient path implied by the model, $\log \left(\mathrm{TFP}_{s t}^{e}\right)=\left(\frac{1}{\varepsilon-1}\right)\left(\log \left(N_{s t}\right)+\log \left(\mathbb{E}_{i} \tilde{Z}_{i s t}^{\varepsilon-1}\right)\right)$. The second path

\footnotetext{
${ }^{17}$ The 1999 level of the difference $\Lambda_{s t}$ is roughly -0.21 in the permanent sample and -0.28 in the full sample. We also note that for an elasticity $\varepsilon=5$ we obtain declines of roughly 4 and 10 percentage points for the permanent and the full sample between 1999 and 2007 and declines of roughly 13 and 19 percentage points between 1999 and 2012. For an elasticity $\varepsilon=5$, the 1999 level of $\Lambda_{s t}$ is roughly -0.36 in the permanent sample and -0.46 in the full sample.
} 
corresponds to a hypothetical scenario in which TFP grows at a constant rate of one percent per year. Figure 5 documents that observed $\log (\mathrm{TFP})$ lies below both baseline paths. Our loss measures in Figure 4 suggest that an increase in the misallocation of resources across firms is related to the observed lower productivity performance relative to these benchmarks. ${ }^{18}$

To explain the joint trends in MRPK dispersion and TFP relative to its efficient level, our model relates the decline in the real interest rate to inflows of capital that are directed to some less productive firms. We now present some first evidence supporting this narrative. It is useful to express the dispersion of the log (MRPK) in terms of dispersions in firm log productivity and log capital and the covariance between these two:

$$
\operatorname{Var}_{i}\left(\log \mathrm{MRPK}_{i s t}\right)=\gamma_{1} \operatorname{Var}_{i}\left(\log Z_{i s t}\right)+\gamma_{2} \operatorname{Var}_{i}\left(\log k_{i s t}\right)-\gamma_{3} \operatorname{Cov}_{i}\left(\log Z_{i s t}, \log k_{i s t}\right)
$$

for some positive coefficients $\gamma^{\prime}$ s. $^{19}$ Loosely, equation (12) says that the dispersion of the $\log (\mathrm{MRPK})$ increases if capital becomes more dispersed across firms for reasons unrelated to their underlying productivity. More formally, holding constant $\operatorname{Var}_{i}\left(\log Z_{i s t}\right)$, an increase in $\operatorname{Var}_{i}\left(\log k_{i s t}\right)$ or a decrease in $\operatorname{Cov}_{i}\left(\log Z_{i s t}, \log k_{i s t}\right)$ is associated with higher $\operatorname{Var}_{i}\left(\log \operatorname{MRPK}_{i s t}\right)$.

The left panel of Figure 6 shows an increase in the dispersion of capital over time. The right panel shows the unconditional correlation between firm productivity (as estimated by $\tilde{Z}_{i s t}$ ) and capital in the cross section of firms. In general, more productive firms invest more in capital. However, the correlation between productivity and capital declines significantly over time. This fact suggests that capital inflows may have been allocated inefficiently to less productive firms. ${ }^{20}$

\footnotetext{
${ }^{18}$ The path of model-based TFP, as constructed in the last part of equation (9), does not in general coincide with the path of "Observed" TFP in Figure 5. We make use of the CES aggregator to move from the definition of TFP as a wedge between output and an aggregator of inputs to the last part of equation (9). The divergence between the two series is a measurement issue because "Observed" TFP does not use the CES aggregator or the price index. We use Figure 5 to only show that a measure of TFP in the data lies below some benchmarks and do not wish to make any quantitative statements about allocative efficiency based on this figure. Finally, we note that in Figure 5 the larger increase in $\log \left(\mathrm{TFP}_{s t}^{e}\right)$ in the permanent sample relative to the full sample is explained by the fact that the latter includes new entrants that typically have lower productivity.

${ }^{19}$ The coefficients are given by $\gamma_{1}=\left(\frac{\varepsilon-1}{1+\alpha(\varepsilon-1)}\right)^{2}, \gamma_{2}=\left(\frac{1}{1+\alpha(\varepsilon-1)}\right)^{2}$, and $\gamma_{3}=\frac{2(\varepsilon-1)}{(1+\alpha(\varepsilon-1))^{2}}$. Equation $(12)$ is derived by substituting the solution for labor $\ell_{i s t}$ into the definition of MRPK and treating the choice of $k_{i s t}$ as given. In our model we justify treating $k_{i s t}$ as a predetermined variable with a standard technology that implies that investment becomes productive after one period.

${ }^{20}$ We present the correlation between log productivity and log capital to make the interpretation of the figure transparent. Both the covariance between log productivity and log capital and the elasticity of capital with respect

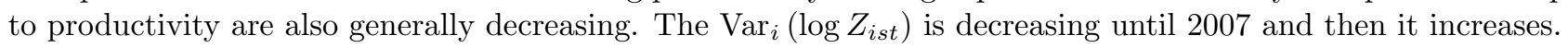



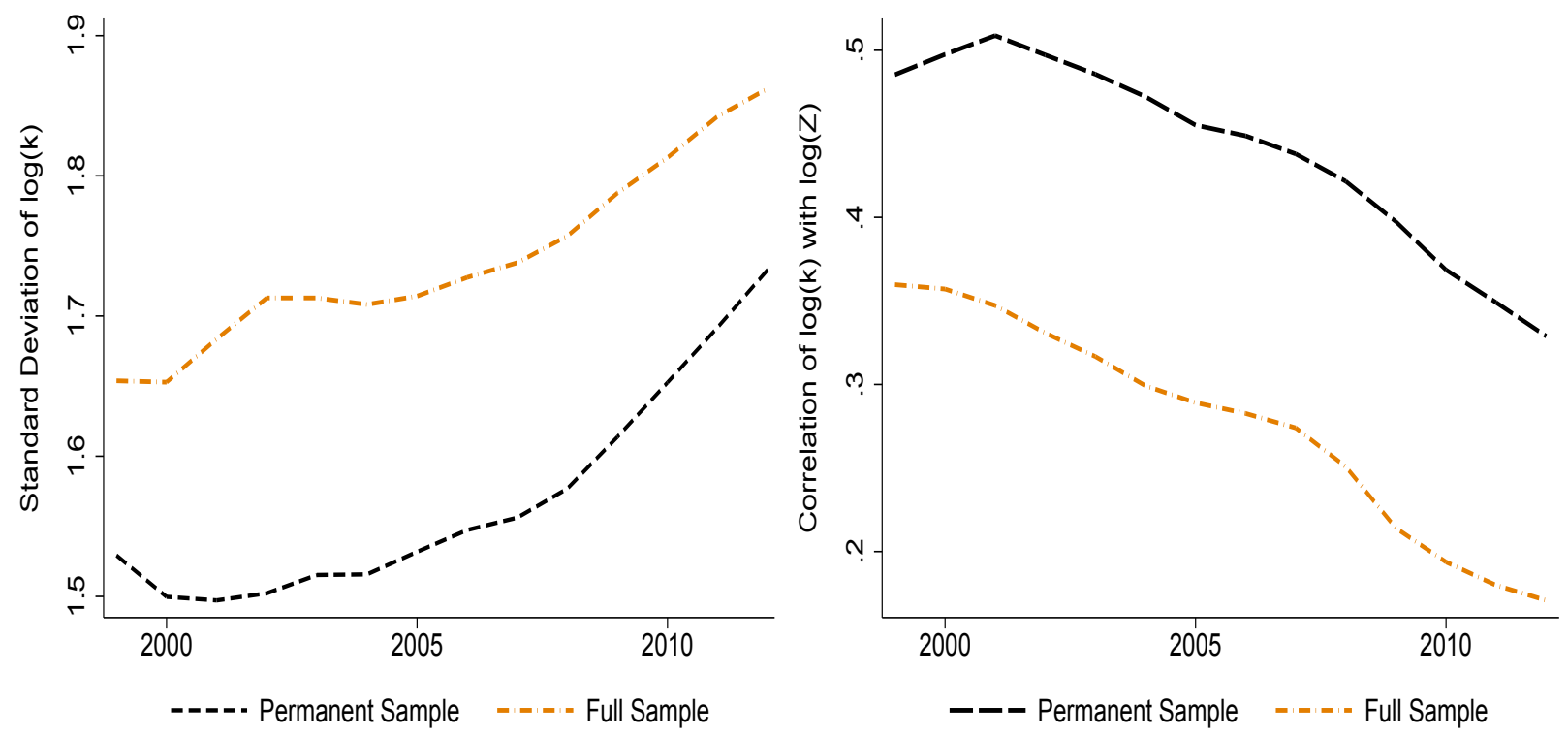

Figure 6: Log Capital Moments

\section{Model of MRPK Dispersion, TFP, and Capital Flows}

To evaluate quantitatively the role of capital misallocation for TFP in an environment with declining real interest rates, we consider a small open economy populated by a large number of infinitely-lived firms $i=1, \ldots, N$ that produce differentiated varieties of manufacturing goods. The three elements of the model that generate dispersion of the MRPK across firms are a borrowing constraint that depends on firm size, risk in capital accumulation, and capital adjustment costs. Motivated by the fact that we did not find significant trends in the MRPL dispersion in the data, in our baseline model there is no MRPL dispersion across firms. We allow for MRPL dispersion in an extension of the baseline model.

\subsection{Firms' Problem}

Firms produce output with a Cobb-Douglas production function $y_{i t}=Z_{i t} k_{i t}^{\alpha} \ell_{i t}^{1-\alpha}$, where $Z_{i t}$ is firm productivity, $k_{i t}$ is the capital stock, and $\ell_{i t}$ is labor. Labor is hired in a competitive market at an exogenous wage $w_{t}$. Varieties of manufacturing goods are supplied monopolistically to the global market. Each firm faces a downward sloping demand function for its product, $y_{i t}=p_{i t}^{-\varepsilon}$, where $p_{i t}$ is the price of the differentiated product and $\varepsilon$ is the absolute value of the elasticity 
of demand. We denote by $\mu=\varepsilon /(\varepsilon-1)$ the markup of price over marginal cost. ${ }^{21}$

Firms can save and borrow in a bond traded in the international credit market at an exogenous real interest rate $r_{t}$. Denoting by $\beta$ the discount factor, firms choose consumption of tradeables $c_{i t}$, debt $b_{i t+1}$, investment $x_{i t}$, labor $\ell_{i t}$, and the price $p_{i t}$ of their output to maximize the expected value of the sum of discounted utility flows:

$$
\max _{\left\{c_{i t}, b_{i t+1}, x_{i t}, \ell_{i t}, p_{i t}\right\}_{t=0}^{\infty}} \mathbb{E}_{0} \sum_{t=0}^{\infty} \beta^{t} U\left(c_{i t}\right)
$$

The utility function is given by $U\left(c_{i t}\right)=\left(c_{i t}^{1-\gamma}-1\right) /(1-\gamma)$, where $\gamma$ denotes the inverse of the elasticity of intertemporal substitution. This maximization problem is subject to the sequence of budget constraints:

$$
c_{i t}+x_{i t}+\left(1+r_{t}\right) b_{i t}+\frac{\psi\left(k_{i t+1}-k_{i t}\right)^{2}}{2 k_{i t}}=p_{i t} y_{i t}-w_{t} \ell_{i t}+b_{i t+1},
$$

and the capital accumulation equation:

$$
k_{i t+1}=(1-\delta) k_{i t}+x_{i t}
$$

where $\delta$ denotes the depreciation rate of capital. Firms face quadratic costs of adjusting their capital. The parameter $\psi$ in the budget constraint controls for the magnitude of these costs.

Firms own the capital stock and augment it through investment. This setup differs from the setup in Hsieh and Klenow (2009) where firms rent capital in a static model. We do not adopt the convenient assumption in Moll (2014), Midrigan and Xu (2014), and Buera and Moll (2015) that exogenous shocks during period $t+1$ are known at the end of $t$ before capital and borrowing decisions are made for $t+1$. This timing assumption effectively renders the choice of capital static and generates an equivalence with the environment in Hsieh and Klenow (2009). Instead, in our model firms face idiosyncratic investment risk which makes capital and debt imperfect substitutes in firms' problem. Risk in capital accumulation is an additional force generating MRPK dispersion across firms in the model.

\footnotetext{
${ }^{21}$ Since our model is partial equilibrium, we normalize both the demand shifter and the sectoral price index to one in the demand function $y_{i t}=p_{i t}^{-\varepsilon}$. It is appropriate to abstract from the determination of the sectoral price index because manufacturing in a small open economy accounts for a small fraction of global manufacturing production. Similarly to our analysis in Section 3, we call a combination of idiosyncratic productivity and demand "firm productivity" and denote it by $Z_{i t}$.
} 
The main novelty of our model is to introduce a borrowing constraint that depends on firm size. $^{22}$ The amount of debt that firms can borrow is constrained by:

$$
b_{i t+1} \leq \theta_{0} k_{i t+1}+\theta_{1} \Psi\left(k_{i t+1}\right)=\underbrace{\left[\theta_{0}+\theta_{1} \Psi\left(k_{i t+1}\right) / k_{i t+1}\right]}_{\theta\left(k_{i t+1}\right)} k_{i t+1},
$$

where $\Psi(k)=\exp (k)-1$ is an increasing and convex function of capital and $\theta_{0}$ and $\theta_{1}$ are parameters characterizing the borrowing constraint. In Appendix $\mathrm{C}$ we write explicitly a model that yields the constraint (16) from the requirement that firms do not default in equilibrium. In this microfoundation, the $\Psi($.$) function denotes an increasing and convex cost that firms incur$ from the disruption of their productive capacity if they decide to default.

The constraint (16) nests the standard model in the literature (Moll, 2014; Midrigan and Xu, 2014; Buera and Moll, 2015) when $\theta_{1}=0$. In this case the maximum fraction of capital that can be borrowed, $\theta\left(k_{i t+1}\right)=\theta_{0}$, is exogenous. Because $\Psi($.$) is a convex function, a positive value for$ $\theta_{1}$ implies that larger firms are more leveraged. We discipline the value of $\theta_{1}$ from the positive cross-sectional relationship between leverage $b_{i t+1} / k_{i t+1}$ and firm size that we find in our data. A key finding of our analysis is that a size-dependent borrowing constraint, with larger firms being more leveraged, is crucial for the ability of the model to account for the cross-sectional patterns of the return to capital in the data. ${ }^{23}$

We write firm productivity $Z_{i t}=Z_{t}^{A} z_{i}^{P} \exp \left(z_{i t}^{T}\right)$ as the product of an aggregate effect $Z_{t}^{A}$, an idiosyncratic permanent effect $z_{i}^{P}$, and an idiosyncratic transitory effect $z_{i t}^{T}$. Idiosyncratic transitory productivity follows an $\mathrm{AR}(1)$ process in logs:

$$
z_{i t}^{T}=-\frac{\sigma^{2}}{2(1+\rho)}+\rho z_{i t-1}^{T}+\sigma u_{i t}^{z}, \quad \text { with } \quad u_{i t}^{z} \sim \mathrm{N}(0,1) .
$$

In equation (17), $\rho$ parameterizes the persistence of the process and $\sigma$ denotes the standard

\footnotetext{
${ }^{22}$ Guner, Ventura, and Xu (2008) examine the effects of size-dependent input taxes on the size distribution of firms and argue that such taxes reduce significantly steady state capital accumulation and TFP.

${ }^{23}$ Arellano, Bai, and Zhang (2012) also document a positive cross-sectional relationship between firm leverage and size for less financially developed European countries. In a sample of U.S. manufacturing firms with access to corporate bond markets, Gilchrist, Sim, and Zakrajsek (2013) document that larger firms face lower borrowing costs. In the European survey on the access to finance of enterprises (European Central Bank, 2013), small and medium sized firms were more likely than larger firms to mention access to finance as one of their most pressing problems. In addition to disruptions in productive capacity that increase in size, there may be other reasons why larger firms have easier access to finance. Khwaja and Mian (2005) show that politically connected firms receive preferential treatment from government banks and Johnson and Mitton (2003) present evidence that ties market values of firms to political connections and favoritism.
} 
deviation of idiosyncratic productivity shocks $u_{i t}^{z}$. The constant term in equation (17) normalizes the mean of transitory productivity to $\mathbb{E} \exp \left(z_{i t}^{T}\right)=1$ for any choice of $\rho$ and $\sigma$.

We define firm net worth in period $t$ as $a_{i t}:=k_{i t}-b_{i t} \geq 0$. Using primes to denote nextperiod variables and denoting by $\mathbf{X}$ the vector of exogenous aggregate shocks, we rewrite the firm's problem in recursive form as:

$$
V\left(a, k, z^{P}, z^{T}, \mathbf{X}\right)=\max _{a^{\prime}, k^{\prime}, \ell, p}\left\{U(c)+\beta \mathbb{E} V\left(a^{\prime}, k^{\prime}, z^{P},\left(z^{T}\right)^{\prime}, \mathbf{X}^{\prime}\right)\right\},
$$

subject to the budget constraint:

$$
c+a^{\prime}+\frac{\psi\left(k^{\prime}-k\right)^{2}}{2 k}=p(y) y-w \ell-(r+\delta) k+(1+r) a,
$$

the production function $y=Z k^{\alpha} \ell^{1-\alpha}$ and the demand function $y=p^{-\varepsilon}$. The borrowing constraint becomes:

$$
k^{\prime} \leq \lambda_{0} a^{\prime}+\lambda_{1} \Psi\left(k^{\prime}\right)=\underbrace{\left[\lambda_{0}+\lambda_{1} \Psi\left(k^{\prime}\right) / a^{\prime}\right]}_{\lambda\left(k^{\prime}, a^{\prime}\right)} a^{\prime},
$$

where $\lambda_{0}=1 /\left(1-\theta_{0}\right)$ and $\lambda_{1}=\theta_{1} /\left(1-\theta_{0}\right)$ with $\lambda_{0}+\lambda_{1} \geq 1$. The reformulation of the borrowing constraint in equation (20) shows that large firms are less constrained by their net worth in accumulating capital than small firms. The standard model is nested by equation (20) under $\lambda_{1}=0$, in which case $\lambda\left(k^{\prime}, a^{\prime}\right)=\lambda_{0}$ becomes exogenous.

\subsection{Dispersion in Factor Returns}

We first solve for labor $\ell$ for a given state vector $\left(a, k, z^{P}, z^{T}, \mathbf{X}\right)$. Labor demand is given by:

$$
\ell=Z^{\frac{\varepsilon-1}{1+\alpha(\varepsilon-1)}} \mu^{\frac{-\varepsilon}{1+\alpha(\varepsilon-1)}}\left(\frac{w}{1-\alpha}\right)^{\frac{-\varepsilon}{1+\alpha(\varepsilon-1)}} k^{\frac{\alpha(\varepsilon-1)}{1+\alpha(\varepsilon-1)}} .
$$

Labor is increasing in capital $k$ and productivity $Z$ and decreasing in the wage $w$ and the markup $\mu .{ }^{24}$ The marginal revenue product of labor is equalized across firms, that is for any firm with a state vector $\left(a, k, z^{P}, z^{T}, \mathbf{X}\right)$ we obtain MRPL $:=((1-\alpha) / \mu)(p y / \ell)=w$. Therefore, the allocation of labor across firms is undistorted.

\footnotetext{
${ }^{24}$ To obtain equation (21), we combine the first-order condition for labor $((1-\alpha) p y / \ell=\mu w)$ with the demand function, the production function, the expression for the marginal cost $\mathrm{MC}=(1 / Z)(w /(1-\alpha))(\ell / k)^{\alpha}$, and the solution for prices $p=\mu \mathrm{MC}$. Given that capital is predetermined at some level $k$, at the beginning of each period firms face decreasing returns to scale with respect to the variable input $\ell$. Therefore, the marginal cost MC is increasing in the scale of production. To solve for prices we substitute the solution for labor in equation (21) into $p=\mu \mathrm{MC}$. Firms with high $k$ and low $Z$ have lower marginal cost $\mathrm{MC}$ and lower price $p$.
} 
In general, the MRPK is not equalized across firms. We define MRPK $:=(\alpha / \mu)(p y / k):=$ $\left(1+\tau^{k}\right)(r+\delta)$, where $\tau^{k}$ denotes the percent deviation of MRPK from $r+\delta$. To illustrate the sources of MRPK dispersion, denote by $\chi$ the multiplier on the borrowing constraint $(20)$ and by $\mathrm{AC}=(\psi / 2)\left(k^{\prime}-k\right)^{2} / k$ the adjustment cost technology and consider the first-order condition with respect to capital for a firm characterized by some state vector $\left(a, k, z^{P}, z^{T}, \mathbf{X}\right)$ :

$$
\mathbb{E}\left[\frac{\beta U^{\prime}\left(c^{\prime}\right)}{U^{\prime}(c)}\right]\left[\mathrm{MRPK}^{\prime}-\left(r^{\prime}+\delta\right)-\frac{\partial \mathrm{AC}^{\prime}}{\partial k^{\prime}}\right]=\frac{\chi\left(1-\lambda_{1} \Psi^{\prime}\left(k^{\prime}\right)\right)}{U^{\prime}(c)}+\frac{\partial \mathrm{AC}}{\partial k^{\prime}} .
$$

In the absence of borrowing constraints, risk in capital accumulation, and capital adjustment costs, there would be no dispersion of the MRPK across firms. More productive firms would choose higher capital stocks but would lower their price $p$ one-to-one with their productivity $Z$, leading to an equalization of the MRPK across firms. Under these assumptions, equation (22) simplifies to MRPK $=r+\delta$ for all firms $\left(a, k, z^{P}, z^{T}, \mathbf{X}\right)$.

By contrast, binding borrowing constraints, risk in capital accumulation, or capital adjustment costs introduce dispersion of the MRPK across firms. Binding borrowing constraints are captured by a positive multiplier $\chi$ in equation (22). Adjustment costs are captured by the derivatives of the adjustment cost function $\mathrm{AC}$ and $\mathrm{AC}^{\prime}$. Finally, similar to the analysis of Asker, Collard-Wexler, and De Loecker (2014), a capital stock determined in some previous period may not be optimal ex-post, that is after productivity is realized. As a result, part of the dispersion of the MRPK across firms would also arise in an undistorted economy in which the capital stock is chosen under uncertainty and becomes productive in the next period.

\subsection{The Real Interest Rate Decline}

We associate the secular decline in the real interest rate $r_{t}$ to trends in MRPK dispersion, TFP losses, and capital flows in the pre-crisis period between 1999 and 2007. The decline in $r_{t}$ started prior to 1999 and could reflect expectations of a reduction in exchange rate risk as countries converged to a common currency, declines in default risk from an implicit assumption that euro countries would be bailed out in a crisis, and the removal of barriers to capital mobility within the euro area. Following the small open economy literature, we model these forces as an exogenous decline in the real interest rate. 


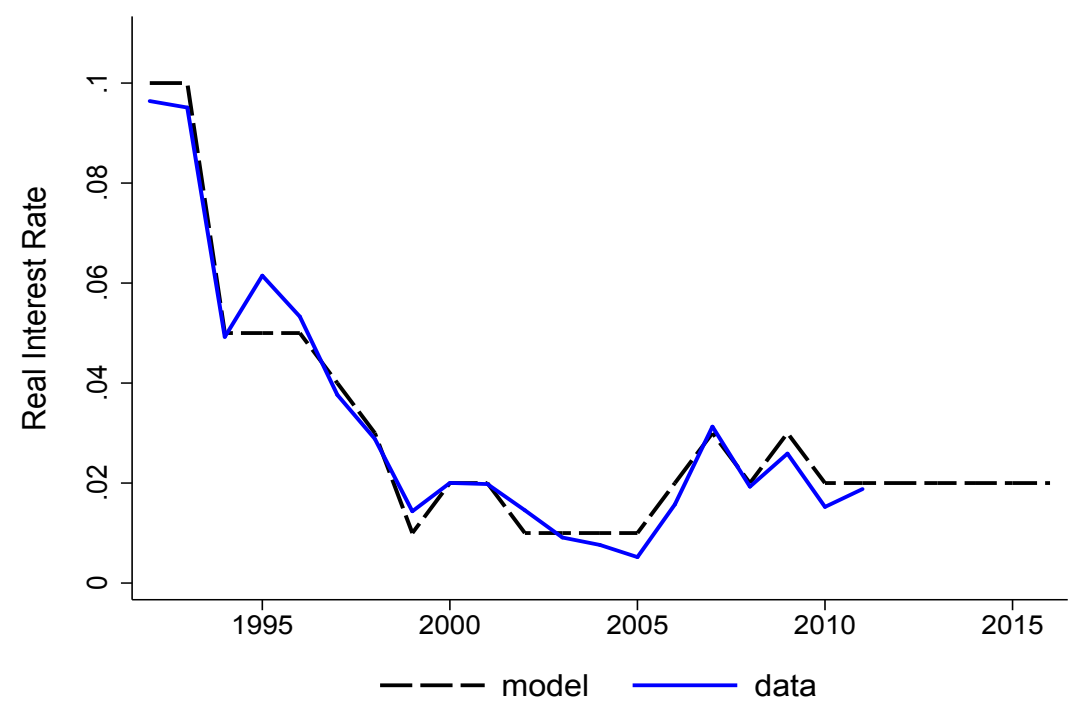

Figure 7: Evolution of Real Interest Rate

The blue solid line in Figure 7 presents the evolution of the real interest rate $r_{t}$ since the early 1990s in the data. We measure $r_{t}$ as the difference between the nominal corporate lending rate to non-financial firms and next year's expected inflation. The lending rate comes from Eurostat and refers to loans with size less than one million euros that mature within one year. Expected inflation is given by the fitted values from an estimated AR(1) process for inflation.

The black dashed line is the real interest rate that we feed as the driving process into the model. We start the economy in a stochastic steady state that corresponds to the period before 1994 with a constant $r=0.10$. We define the stochastic steady state as an equilibrium of the model in which all aggregate shocks are constant, but firms are hit by idiosyncratic productivity shocks and change their production, savings, and investment decisions over time. Starting from the stochastic steady state, we then introduce the path of the real interest rate $r_{t}$ depicted in Figure 7. In the baseline results we assume that firms have perfect foresight and are continuously surprised by shocks to $r_{t}$, that is any change in $r_{t}$ is perceived by firms as an unexpected and permanent shock. In our robustness checks shown below, we obtain similar results when we assume that firms perceive that the real interest rate follows an $\mathrm{AR}(1)$ process that we estimate in the data after $1994 . .^{25}$

\footnotetext{
${ }^{25}$ We solve the model with standard value function iteration methods. We discretize the space of net worth, capital, permanent productivity, transitory productivity, and the real interest rate into 120,120, 2, 11, and 6 points respectively. In figure 7 we do not match exactly the path of the real interest rate in the data because, to economize
} 
Table 3: Baseline Parameters

\begin{tabular}{ccccccccccccc}
\hline \hline$\beta$ & $\gamma$ & $\delta$ & $\varepsilon$ & $\alpha$ & $\rho$ & $\sigma$ & $\pi$ & $z_{L}$ & $z_{H}$ & $\psi$ & $\lambda_{0}$ & $\lambda_{1}$ \\
\hline 0.87 & 2.00 & 0.06 & 3.00 & 0.35 & 0.59 & 0.13 & 0.80 & 0.785 & 1.86 & 3.20 & 0.98 & 0.047 \\
\hline \hline
\end{tabular}

\subsection{Parameterization}

Table 3 lists parameter values for the baseline version of our model. ${ }^{26}$ There are three types of parameters. First, we choose conventional values for five parameters $(\beta, \gamma, \delta$, $\varepsilon$, and $\alpha)$ before solving the model. Second, the productivity parameters $\left(\rho, \sigma, \pi, z_{L}\right.$, and $\left.z_{H}\right)$ are estimated directly from the data without solving the model. Third, we calibrate the three remaining parameters $\left(\psi, \lambda_{0}\right.$, and $\left.\lambda_{1}\right)$ by requiring that the model matches three moments in the data.

To estimate firm productivity, we use the Wooldridge (2009) extension of the Levinsohn and Petrin (2003) methodology and denote this estimate by $\hat{Z}_{i s t} \cdot{ }^{27}$ In the estimation, we allow the elasticities of value added with respect to inputs to vary at the two-digit industry level. We discuss our estimates in more detail in Appendix D. Here we note that we estimate reasonable elasticities, with their sum ranging from 0.75 to 0.91 . Our estimate $\hat{Z}_{i s t}$ uncovers a combination of idiosyncratic productivity and demand as we do not separately observe firm prices. ${ }^{28}$

We estimate the productivity process at the firm level using the regression:

$$
\log \left(\hat{Z}_{i s t}\right)=d_{i}+d_{s t}+\rho \log \left(\hat{Z}_{i s t-1}\right)+u_{i s t}^{z}
$$

where $d_{i}$ denotes the firm permanent effect and $d_{s t}$ denotes a four-digit industry-year fixed effect.

on computational speed for our many extensions and robustness checks, we define the grid for the real interest rate on 6 points. Our baseline results (labeled "HeF Model" below) remained unchanged in simulations in which we matched exactly the path of the real interest rate in the data by solving the model on a grid of 20 points for the real interest rate.

${ }^{26}$ We have fixed the aggregate wage to $w=1$ and the aggregate component of firm productivity to $Z^{A}=1$.

${ }^{27}$ Olley and Pakes (1996) and Levinsohn and Petrin (2003) use a two-step method to estimate production functions in which investment and intermediate inputs respectively proxy for unobserved productivity. Ackerberg, Caves, and Frazer (2015) highlight that if a variable input (e.g. labor) is chosen as a function of unobserved productivity, then the coefficient on the variable input is not identified. Wooldridge (2009) suggests a generalized method of moments estimation to overcome some of the limitations of previous methods.

${ }^{28}$ For this reason our elasticities are more appropriately defined as revenue elasticities. The correlation between $\log \left(\hat{Z}_{i s t}\right)$ and $\log \left(\tilde{Z}_{i s t}\right)$, which was defined in equation (11), in the cross section of firms ranges between 0.8 and 0.9 and is stable over time. Unless otherwise noted, we now use the $\hat{Z}_{i s t}$ to construct moments in the data. 
Using this regression, we find that $\rho=0.59 .^{29}$ We use the cross-sectional standard deviation of residuals $u_{i s t}^{z}$ from regression (23) to choose a value for $\sigma$. The value of $\sigma=0.13$ corresponds to the average standard deviation over time.

The permanent component of productivity is drawn from the following distribution:

$$
z_{i}^{P}=\left\{\begin{array}{ll}
z_{L}, & \text { with probability } \pi \\
z_{H}, & \text { with probability } 1-\pi
\end{array},\right.
$$

We normalize the average $z_{i}^{P}$ to one and choose the values $\pi=0.80, z_{L}=0.785$, and $z_{H}=1.86$ such that, together with our estimated $\rho=0.59$ and $\sigma=0.13$, the standard deviation of $\log \left(Z_{i t}\right)$ equals 0.38 as in the data. ${ }^{30}$

Finally, we calibrate the three remaining parameters, $\psi$ in the adjustment cost technology and $\lambda_{0}$ and $\lambda_{1}$ in the borrowing constraint, to match three informative moments in the data between 1999 and 2007. We view the data as generated from transitional dynamics of our model following the decline in the real interest rate that started in 1994 . We choose the three parameters such that our model generates:

Moment 1. Within-firm regression coefficient of capital growth $\left(k^{\prime}-k\right) / k$ on productivity $\log Z$ equal to 0.10 .

Moment 2. Fraction of firms that borrow equal to 0.90 .

Moment 3. Cross-sectional regression coefficient of firm leverage $b / k$ on capital $\log k$ equal to 0.15 .

For our baseline model this procedure yields $\psi=3.20, \lambda_{0}=0.98$, and $\lambda_{1}=0.047 .{ }^{31}$

\footnotetext{
${ }^{29}$ Including firm fixed effects in a regression with a lagged dependent variable and a short time series leads to a downward bias in the estimated persistence of a process. When we estimate the AR(1) process in equation (23) we obtain an estimated persistence parameter of 0.46 . Therefore, we set $\rho=0.59$ such that, in model-generated data of 14 sample periods, the estimated persistence parameter equals 0.46 . To maximize the length of the sample, our estimates of the productivity process are obtained from the permanent sample of firms between 1999 and 2012 .

${ }^{30}$ We have experimented with values of $\pi$ ranging from 0.50 to 0.90 and found that, conditional on matching the same moments in the data, such alternative values for $\pi$ do not alter significantly the dynamics of TFP following the decline in the real interest rate. Our choice of $\pi=0.80$ implies a natural comparison between the model and the data in terms of the share of aggregate variables accounted for by the top 20 percent of firms.

${ }^{31}$ During the transitional dynamics generated by our model between 1999 and 2007, the mean adjustment cost equals 2.8 percent of value added conditional on adjusting the capital stock and the mean frequency of adjustment is 20 percent. The value of 2.8 percent lies within the wide range of estimates that Bachmann, Caballero, and Engel (2013) report from the literature and is close to their preferred estimate of 3.6 percent.
} 


\subsection{Model Evaluation}

We evaluate the performance of our model by comparing it with two nested benchmark models. In our model with a size-dependent borrowing constraint, we choose three parameters, $\left(\psi, \lambda_{0}, \lambda_{1}\right)=(3.2,0.98,0.047)$ to match the three moments discussed above. Because the borrowing constraint depends on firm size, financial frictions are heterogeneous across firms and in what follows we label the baseline model by "HeF." The first comparison is with the standard model with $\lambda_{1}=0$. In this model, financial frictions are homogeneous across firms (so we call this model "HoF") and we choose $\left(\psi, \lambda_{0}, \lambda_{1}\right)=(3.2,1.06,0)$ to match the first two moments discussed above. Finally, we compare our model to a model without financial frictions (which we call "NoF"). We choose $\left(\psi, \lambda_{0}, \lambda_{1}\right)=(3.6, \infty, \infty)$ to match only the first moment.

We evaluate the performance of our model by comparing it to these two nested models along moments that are not targeted during the parameterization of each model. Therefore, comparing HeF to HoF informs us by how much untargeted moments change when we ignore the cross-sectional relationship between leverage and size during the parameterization of the model. Comparing HoF to NoF informs us by how much untargeted moments change when we ignore the fact that financial frictions prevent some firms from borrowing.

\section{$5 \quad$ Firm-Level Implications of the Model}

In this section we document the success of our model to generate firm-level outcomes that resemble those observed in the data. We summarize firm-level outcomes in the data in terms of statistics estimated during the pre-recession period of 1999 to 2007 for the permanent sample of firms. We construct these statistics similarly to the dispersion and misallocation measures presented in Section 3. We compute the same statistics in the model during the transitional dynamics between 1999 and 2007 in response to the decline in the real interest rate shown in Figure 7. Summary statistics both in data and the model are averaged between 1999 and 2007. In Appendix E.1 we show that our conclusions remain unchanged if we evaluate the model in terms of moments generated from the full sample instead of the permanent sample of firms. 
A. Distributional Moments. Panel A of Table 4 shows statistics related to the distribution of firm size in the data and in the various models. Row 1 shows that all models feature the same standard deviation of $\log Z$ by construction. Our model with a size-dependent borrowing constraint $(\mathrm{HeF})$ generates roughly 70 percent of the standard deviation of $\log l$ observed in the data (row 2) and roughly 60 percent of the standard deviation of $\log k$ observed in the data (row $3)$. Rows 4 and 5 show that the model generates roughly 90 percent of the share of aggregate labor or capital accruing to the top 20 percent of firms.

The size-dependent borrowing constraint in model HeF implies that some firms find it profitable to accumulate a significant amount of capital in order to relax their borrowing limit in response to the decline in the real interest rate. Therefore, our model HeF generates more dispersion in labor and capital than the model with a homogeneous borrowing constraint (HoF) and the model without financial frictions (NoF).

B. Within-Firm Moments. Panel B of Table 4 focuses on the dynamics of capital, debt, and productivity at the firm level. We present results from two regressions that use within-firm variation over time. Rows 6 to 8 show estimated coefficients from a regression of capital growth on productivity, net worth, and capital:

$$
\frac{k_{i s t+1}-k_{i s t}}{k_{i s t}}=d_{i}+d_{s t}+\beta_{z} \log \left(Z_{i s t}\right)+\beta_{a} \log \left(a_{i s t}\right)+\beta_{k} \log \left(k_{i s t}\right)+u_{i s t}^{k},
$$

where $d_{i}$ denotes a firm fixed effect and $d_{s t}$ denotes a four-digit industry-year fixed effect. The second regression in rows 9 to 11 is a similar regression but uses the change in (net) debt to capital ratio $\left(b_{i s t+1}-b_{i s t}\right) / k_{i s t}$ as the left-hand side variable. The choice of regressors is motivated by our model in which productivity, net worth, and capital are the state variables summarizing firm capital and debt decisions. The first two regressors resemble sales and cash flow, commonly used by the finance literature in investment regressions. In Appendix E.2 we report such regressions. ${ }^{32}$

In the data column, we document that firm capital growth $\left(k^{\prime}-k\right) / k$ is positively related

\footnotetext{
${ }^{32}$ We measure firm net worth $a$ in the data as the difference between the book value of total assets and total liabilities and deflate this difference with the industry output price deflators previously described in Section 3 . We measure (net) debt $b$ with the book value of current liabilities minus cash holdings and also deflate this difference with the same price deflators. This short-term measure of debt is our preferred one because our model abstracts from a maturity choice of debt and savings in long-term assets.
} 
Table 4: Firm-Level Moments: Model vs. Data (1999-2007)

\begin{tabular}{|c|c|c|c|c|}
\hline Moment & Data & $\mathrm{HeF}$ & HoF & NoF \\
\hline \multicolumn{5}{|c|}{ A. Distributional Moments } \\
\hline 1. $\mathrm{SD}(\log Z)$ & 0.37 & 0.38 & 0.38 & 0.38 \\
\hline 2. $\mathrm{SD}(\log \ell)$ & 1.13 & 0.80 & 0.74 & 0.71 \\
\hline 3. $\mathrm{SD}(\log k)$ & 1.52 & 0.91 & 0.75 & 0.66 \\
\hline 4. Top $20 \%$ Share of Aggregate Labor & 0.69 & 0.63 & 0.59 & 0.58 \\
\hline 5. Top 20\% Share of Aggregate Capital & 0.79 & 0.71 & 0.61 & 0.56 \\
\hline \multicolumn{5}{|c|}{ B. Within-Firm Moments } \\
\hline 6. Coefficient of $\left(k^{\prime}-k\right) / k$ on $\log Z$ & 0.10 & 0.10 & 0.10 & 0.10 \\
\hline 7. Coefficient of $\left(k^{\prime}-k\right) / k$ on $\log a$ & 0.09 & 0.04 & 0.27 & 0.01 \\
\hline 8. Coefficient of $\left(k^{\prime}-k\right) / k$ on $\log k$ & -0.46 & -0.07 & -0.46 & -0.19 \\
\hline 9. Coefficient of $\left(b^{\prime}-b\right) / k$ on $\log Z$ & -0.38 & -0.04 & -0.06 & 0.03 \\
\hline 10. Coefficient of $\left(b^{\prime}-b\right) / k$ on $\log a$ & 0.15 & 0.09 & 0.72 & 0.02 \\
\hline 11. Coefficient of $\left(b^{\prime}-b\right) / k$ on $\log k$ & -0.34 & 0.07 & -0.74 & -0.22 \\
\hline \multicolumn{5}{|c|}{ C. Cross-Sectional Moments } \\
\hline 12. Fraction Borrowing & 0.90 & 0.90 & 0.90 & 1.00 \\
\hline 13. Coefficient of $b / k$ on $\log k$ & 0.15 & 0.15 & 0.03 & 0.00 \\
\hline 14. $\operatorname{Corr}(\log Z, \log k)$ & 0.62 & 0.88 & 0.89 & 0.91 \\
\hline 15. $\operatorname{Corr}(\log Z, \log a)$ & 0.75 & 0.84 & 0.90 & 0.43 \\
\hline 16. Corr $(\log M R P K, \log Z)$ & 0.03 & -0.08 & 0.28 & 0.51 \\
\hline 17. Corr $(\log \mathrm{MRPK}, \log k)$ & -0.62 & -0.54 & -0.18 & 0.10 \\
\hline 18. Corr $(\log \mathrm{MRPK}, \log a)$ & -0.14 & -0.36 & -0.15 & 0.20 \\
\hline \multicolumn{5}{|c|}{$\underline{\text { D. Model Evaluation }}$} \\
\hline 19. Root Mean Squared Error & & 0.28 & 0.35 & 0.41 \\
\hline 20. Mean Absolute Error & & 0.22 & 0.29 & 0.34 \\
\hline
\end{tabular}

to productivity $\log Z$ (row 6 ) and to net worth $\log a$ (row 7 ). In row 8, the estimated coefficient of $\left(k^{\prime}-k\right) / k$ on $\log k$ is negative and greater than minus one, which indicates that log capital is a persistent process. Rows 9 to 11 document that the change in firm debt to capital ratio, 
$\left(b^{\prime}-b\right) / k$, is negatively related to $\log Z$, positively related to $\log a$, and negatively related to $\log k$. Given the large sample size with more than 100,000 observations, all estimated coefficients in rows 6 to 11 are statistically significant at levels below 1 percent. We present the standard errors of our estimates in Appendix E.2.

Row 6 shows that all models match the responsiveness of $\left(k^{\prime}-k\right) / k$ to $\log Z$ by construction. An increase in current productivity leads to an increase in next period's capital because productivity is a persistent process and firms expect the marginal product of capital to be higher in future periods. Capital adjustment costs ameliorate the responsiveness of capital growth and, thus, the choice of the adjustment cost parameter $\psi$ in each model reflects the magnitude of adjustment costs that allow models to match the responsiveness of capital growth to productivity in the data. In row 9 we see that the change in debt is weakly negatively correlated with $\log Z$ in models HoF and HeF and weakly positively correlated with $\log Z$ in model NoF. The change in debt, $b^{\prime}-b$, equals the difference between the flow of investment and saving. A persistent but mean-reverting increase in $\log Z$ increases investment because firms expect a higher marginal product of capital in future periods and also saving because firms desire to smooth consumption. The negative coefficient in models $\mathrm{HoF}$ and $\mathrm{HeF}$ reflects the fact that, similarly to the data, firm saving responds more than investment to changes in productivity.

Contrary to the data, we find that net worth in model NoF is not a significant determinant of the within-firm variation in capital growth (row 7) and change in debt (row 10). Models with financial frictions will, in general, imply a more important role of net worth for capital and debt accumulation. Our model HeF comes close to matching quantitatively the role of net worth for capital growth and change in debt, while model HoF assigns a much stronger role to net worth than observed in the data. Net worth is a less important determinant of capital and debt decisions on average in model HeF than in model HoF because in model HeF some firms accumulate a significant amount of capital and become effectively unconstrained in response to the decline in the real interest rate. ${ }^{33}$

C. Cross-Sectional Moments. Panel C of Table 4 presents correlations between firm

\footnotetext{
${ }^{33}$ Rows 8 and 11 show that model HeF fails to match the coefficient on $\log k$ and performs worse than HoF and NoF in that dimension. Recalling that $\left(k^{\prime}-k\right) / k \approx \log \left(k^{\prime}\right)-\log (k)$, the estimated coefficient in the HeF model implies that log capital becomes a more persistent process when we allow for size-dependent borrowing constraints.
} 
size, productivity, leverage, net worth, and MRPK in the cross section of firms. Row 12 shows the fraction of firms that are borrowing $(b>0)$, a moment which both model HoF and model HeF match by construction. Row 13 shows the cross-sectional relationship between leverage $b / k$ and $\log k$. In the data, we find that larger firms are more leveraged. ${ }^{34}$ We calibrated the parameter $\lambda_{1}$ in the borrowing constraint (20) such that model HeF generates the cross-sectional relationship between $b / k$ and $\log k$ observed in the data.

Rows 14 to 18 of Panel C show other (untargeted) cross-sectional moments. Rows 14 and 15 show that all models reproduce the positive relationship between firm productivity and capital in the data. ${ }^{35}$ As shown in rows 16 to 18 , the key difference between models is in their cross-sectional patterns of the return to capital. In the data, $\log (\mathrm{MRPK})$ is essentially uncorrelated with $\log Z$ and negatively correlated with $\log k$ and $\log a$ in the cross section of firms. ${ }^{36}$ However, model NoF implies that $\log (\mathrm{MRPK})$ is positively correlated with $\log Z, \log k$, and $\log a$. In Model HoF, the distance between model-generated moments and the corresponding moments in the data is smaller. Model HeF comes closer than all models in matching the crosssectional patterns of the return to capital, as it generates a weak negative correlation between $\log (\mathrm{MRPK})$ and $\log Z$ and negative correlations of $\log (\mathrm{MRPK})$ with $\log k$ and $\log a$.

To understand these differences, first we note that risk in capital accumulation tends to generate a positive correlation between $\log (\mathrm{MRPK})$ and either $\log Z$ or measures of firm size. As an example, consider two firms that start with the same state vector $\left(a, k, z^{P}, z^{T}, \mathbf{X}\right)$ in some period and, therefore, choose the same capital for next period $k^{\prime}$. If in next period one of these firms receives a higher productivity shock, then that firm will have higher revenues and MRPK ex-post. This explains the high correlation between $\log (\mathrm{MRPK})$ and either $\log Z$ or $\log k$ in the

\footnotetext{
${ }^{34}$ We obtain a similar result in the data when we use other measures of firm size such as the wage bill. Since our model does not consider the distinction between short-term and long-term liabilities or assets, the regressions in the data control for the difference between long-term liabilities and long-term assets (current assets minus cash). Additionally, cross-sectional regressions control for firm age. We define firm age in period $t$ as $t$ minus the date of incorporation plus one. Firm age is a firm-specific linear time trend and, therefore, is absorbed by the firm fixed effect in regressions that use within-firm variation over time.

${ }^{35}$ All models successfully replicate the positive and high correlation between log productivity and firm size (measured either by log labor or log capital) and the positive and high correlation between firm log productivity and share in sectoral economic activity (measured either by labor or capital). The correlations between log productivity and firm share in economic activity resemble the measures of resource allocation emphasized by Bartelsman, Haltiwanger, and Scarpetta (2013).

${ }^{36} \mathrm{Hsieh}$ and Olken (2014) report that smaller firms in India, Indonesia, and Mexico have lower average product of capital than larger firms. We do not find this pattern in Spain.
} 
NoF model. Model HeF differs crucially from the other models because, with a size-dependent borrowing constraint, some highly productive firms accumulate a significant amount of capital in order to relax their borrowing limit. These firms become effectively unconstrained and have a low $\log (\mathrm{MRPK})$. The existence of large firms with low MRPK accounts for the negative correlation between $\log (\mathrm{MRPK})$ and either $\log Z$ or $\log k$ in the HeF model. The correlations in the HoF model are between those in the NoF model and those in the HeF model.

Finally, in the two models with financial frictions, HoF and HeF, higher net worth firms are less constrained and, therefore, tend to have a lower return to capital. The two models are successful in generating the negative correlation between $\log (\mathrm{MRPK})$ and $\log a$ observed in the data. By contrast, model NoF generates a positive correlation.

D. Model Evaluation. Panel D of Table 4 compares the models in terms of their distance from data moments not targeted during the parameterization of each model. These moments are in rows 2 to 5, 7 to 11, and 14 to 18. In rows 19 and 20 we present the Root Mean Squared Error and the Mean Absolute Error of the three models. We find that the HeF model performs better than the HoF model and that the HoF model performs better than the NoF model.

\section{Macroeconomic Implications}

Having documented the success of the model to match aspects of firm-level behavior, we now present the evolution of aggregate outcomes in response to the decline in the real interest rate.

\subsection{Aggregate Responses}

Table 5 summarizes the aggregate responses. The first column shows changes in various statistics between 1999 and 2007 in the data for the permanent sample of firms. ${ }^{37}$ In Section 3 we documented a decline in TFP relative to its efficient level and an increase in the dispersion of the $\log (\mathrm{MRPK})$ over time. We reproduce these changes in the first two rows of Table 5 that show a 3.1 percentage points decline in TFP relative to its efficient level and a 3.4 percentage

\footnotetext{
${ }^{37}$ In a previous version of this paper we considered an extension of the model with endogenous entry and exit. The model with endogenous entry and exit generates a decline in mean firm productivity over time when less productive firms choose to enter manufacturing in response to the decline in the real interest rate. See Lagos (2006) for a formalization of the idea that TFP depends on the productivity composition of firms that are active in equilibrium which, in turn, responds to labor market policy.
} 
Table 5: Aggregate Responses: Data vs. Baseline HeF Model (1999-2007)

\begin{tabular}{lcc}
\hline \hline & Data & Model HeF \\
\hline \hline 1. $\Delta \Lambda$ & -0.031 & -0.023 \\
2. $\Delta($ Dispersion $)$ & 0.034 & 0.074 \\
3. $\Delta \log \left(\sum y\right)$ & 0.14 & 0.26 \\
4. $\Delta \log K$ & 0.22 & 0.38 \\
5. $\Delta B / \Delta K$ & 1.28 & 1.24 \\
\hline \hline
\end{tabular}

Notes: All changes are calculated between 1999 and 2007. $\Delta \Lambda$ denotes the percentage point change in TFP relative to its efficient level, that is the difference between $\log \left(\mathrm{TFP}_{07}\right)-\log \left(\mathrm{TFP}_{07}^{e}\right)$ and $\log \left(\mathrm{TFP}_{99}\right)-\log \left(\mathrm{TFP}_{99}^{e}\right)$. $\Delta$ (Dispersion) is the $\Delta[\mathrm{SD}(\log (\mathrm{MRPK}))] . \Delta \log \left(\sum y\right)$ is the change in the $\log$ of the sum of output and $\Delta \log K$ is the change in the log of aggregate capital. $\Delta B / \Delta K$ is the change in aggregate debt between 1999 and 2007 divided by the change in the aggregate capital between 1999 and 2007.

points increase in the standard deviation of $\log (\mathrm{MRPK})$. The data column of the table also documents the evolution of total output and capital flows to the manufacturing sector from our dataset. Between 1999 and 2007, we observe significant aggregate capital accumulation financed by an increase in short-term debt and a significant increase in aggregate output. Additionally, as the last row shows, debt increased more than one-to-one with capital over that time period (that is, $\Delta B / \Delta K>1$ ).

The second column of Table 5 shows the aggregate responses in the HeF model. Figure 8 plots some of the transitions to better visualize the dynamics generated by the model. Similarly to the data, our model driven by a decline in the real interest rate generates capital and debt accumulation, an increase in the dispersion of the $\log (\mathrm{MRPK})$, and a decline in TFP relative to its efficient level. ${ }^{38}$ Quantitatively, the model generates roughly three-quarters of the observed decline in TFP relative to its efficient level. Consistently with the data, debt increases more than capital in the model following the decline in the real interest rate. The model generates

\footnotetext{
${ }^{38}$ In Figure 6 we documented that the increase in the dispersion of log capital was associated with a declining correlation between $\log$ capital and $\log$ productivity. We obtain a similar prediction in the HeF model. In the model, the standard deviation of $\log k$ increases by roughly 20 percentage points and the correlation between $\log k$ and $\log Z$ declines by roughly 3 percentage points.
} 

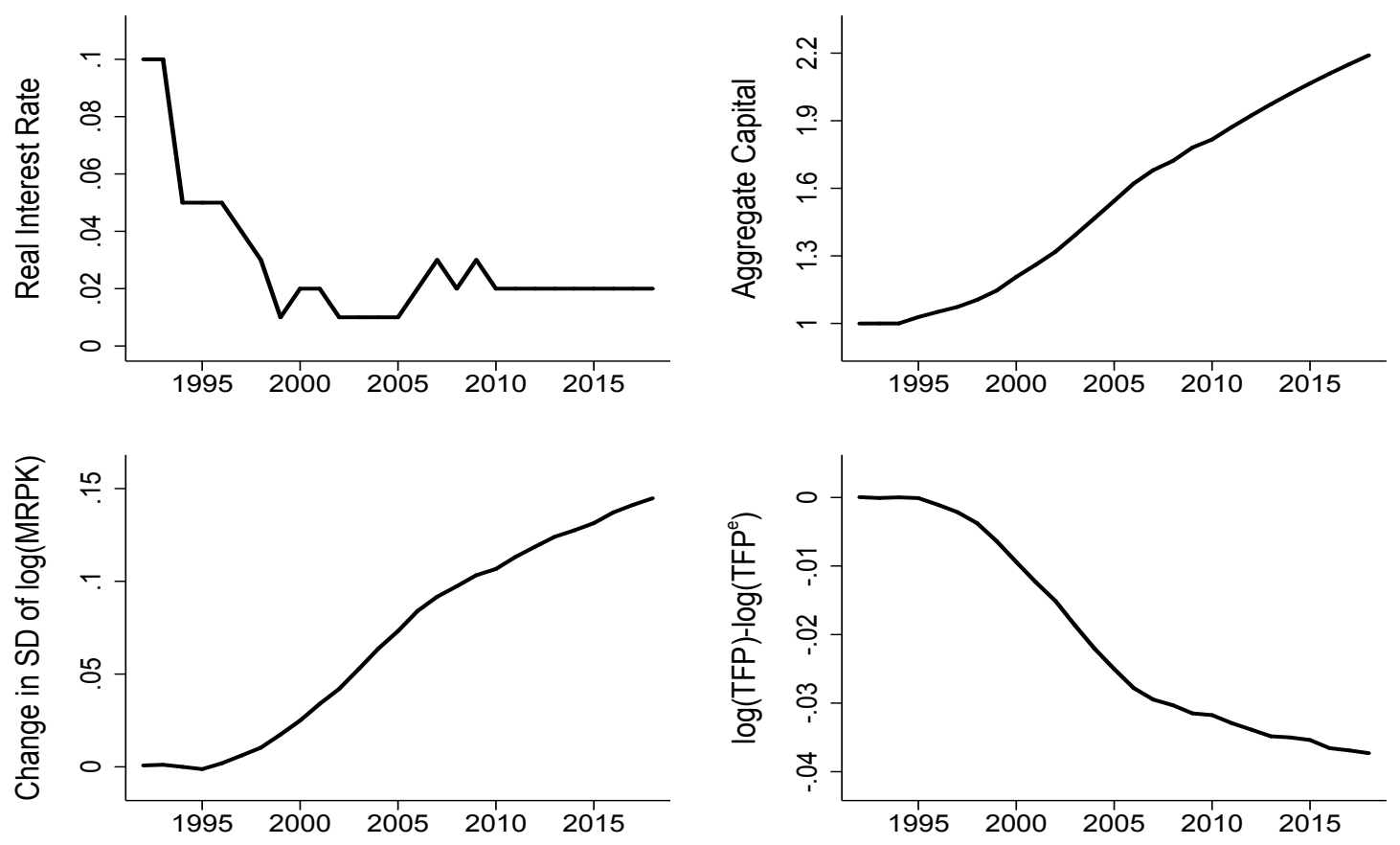

Figure 8: Evolution of Aggregate Variables in Baseline HeF Model

a somewhat larger increase in the dispersion of $\log (\mathrm{MRPK})$, in capital, and in output than observed in the data. ${ }^{39}$ Below we show that increasing the magnitude of adjustment costs, so that the model reproduces the observed changes in capital and output, does not affect much the ability of the model to generate a significant decline in TFP.

\subsection{Inspecting the Mechanism: Capital Allocation Across Firms}

To understand these aggregate responses, we begin with a simple example that illustrates the mechanism generating misallocation in our model in response to the decline in $r_{t}$. Figure 9 depicts outcomes for two firms in model HeF. We label one firm as "unconstrained" and the other as "constrained." The initial state variables for the two firms in 1994 are drawn from the stationary distribution of the model. As the first panel of the figure shows, the two firms have the same constant productivity in all periods. The firms, however, differ in their initial net worth and debt.

\footnotetext{
${ }^{39}$ In the table and the figure we show the change in the level of the standard deviation of log (MRPK) rather than the percent change in this standard deviation. The reason is that the baseline model generates only roughly $1 / 3$ of the level of dispersion relative to the data, which makes percent comparisons uninformative. Below we show that adding measurement error in capital in order to match the level of MRPK dispersion does not change significantly the quantitative predictions of the model.
} 

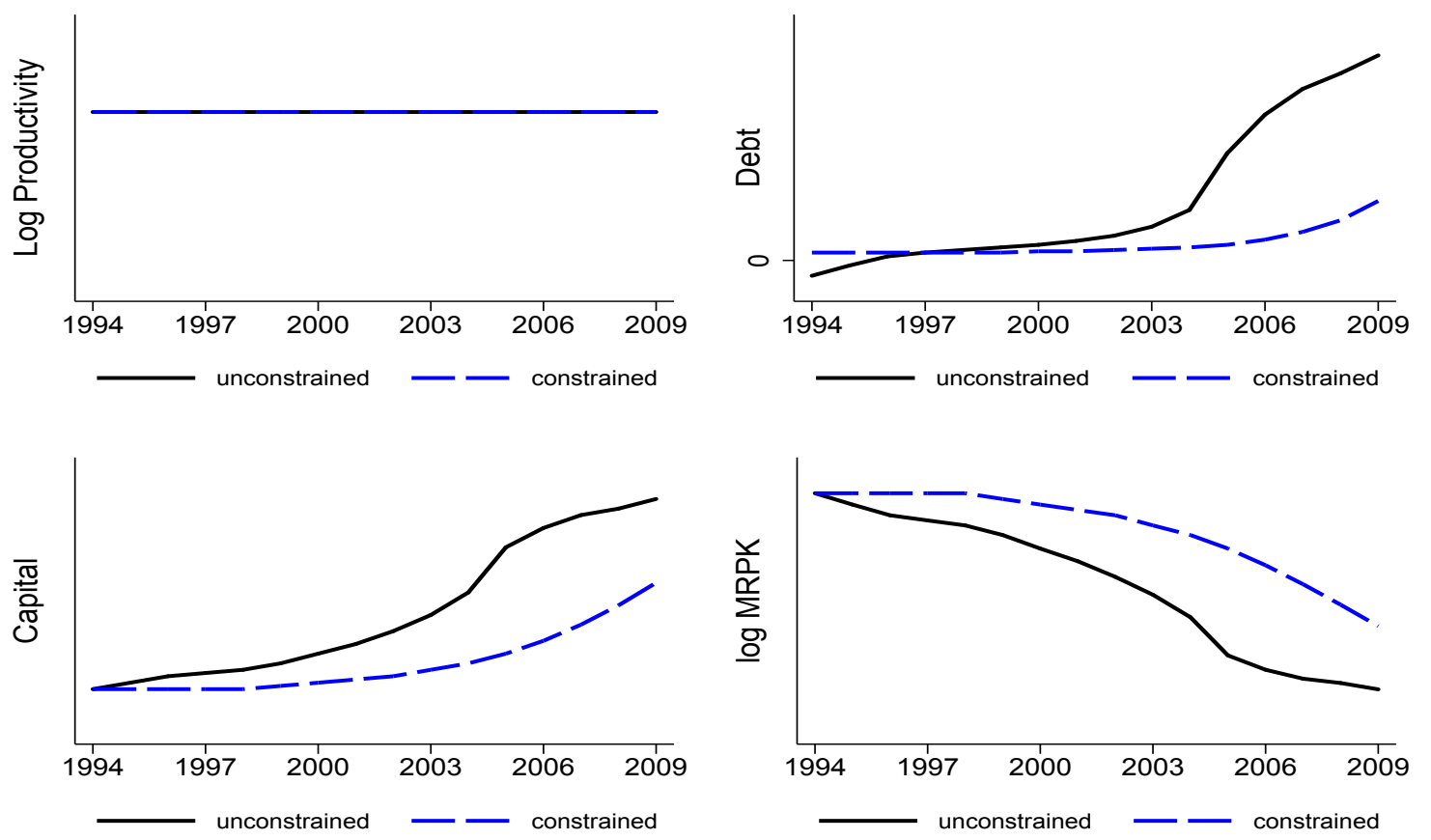

Figure 9: Real Interest Rates and Misallocation: An Illustrative Example (HeF Model)

The unconstrained firm is initially saving $(b<0)$ and, therefore, its borrowing constraint is not binding when the $r_{t}$ shock hits. The decline in $r_{t}$ increases desired investment. In the first few periods after the shock, the firm uses internal savings to finance capital accumulation and adjustment costs. With a size-dependent borrowing limit, the borrowing constraint of this firm is relaxed as capital accumulates over time. As a result, the unconstrained firm borrows more over time and uses the inflow of debt to increase its capital even more and to finance its consumption. As the last panel of the figure shows, the decline in the real interest rate causes a decline in the MRPK of the unconstrained firm.

By contrast, the constrained firm has initially lower net worth and its borrowing constraint is binding when the $r_{t}$ shock hits. This firm also desires to increase its capital. However, the lack of sufficient funds prevents the firm from doing so in the first few periods after the shock. Over time, the firm uses internal funds to increase its capital stock but, even 15 years after the initial decline in the real interest rate, the constrained firm's capital is significantly lower than the desired level. The financially constrained firm experiences a smaller decline in its MRPK and, therefore, the dispersion of the MRPK between the two firms increases over time.

This example illustrates how a decline in the real interest rate in an environment with size- 
dependent borrowing constraints and adjustment costs causes capital inflows to be misallocated. Misallocation here means that capital is unequally allocated across firms despite both firms being equally productive. It is not crucial that both firms are equally productive. We would obtain the same result even if the unconstrained firm experienced a few negative productivity shocks along its transition.

This mechanism explains the results in Table 5. Firms with higher initial wealth are more able to finance capital accumulation. As these firms grow, they gradually overcome their borrowing constraints and accumulate a significant amount of debt. TFP declines because capital is not allocated to its most efficient use as some productive but financially constrained firms with low net worth are not able to grow in the short run.

We now provide direct evidence that supports this mechanism. We run the cross-sectional regression in the data:

$$
\frac{k_{i s, 07}-k_{i s, 99}}{k_{i s, 99}}=d_{s}+\beta_{z} \log \left(Z_{i s, 99}\right)+\beta_{a} \log \left(a_{i s, 99}\right)+\beta_{k} \log \left(k_{i s, 99}\right)+u_{i s}^{k},
$$

where the left-hand side denotes firm capital growth between 1999 and 2007. The result we want to emphasize is our estimate $\beta_{a}=0.17$ which implies that, conditional on initial productivity and capital, firms that in 1999 had a one percent higher net worth invested 0.17 percent more in capital by 2007. Appendix E.2 shows that all estimated coefficients in regression (26) are statistically significant.

Model HeF comes close to matching the relationship between initial net worth and subsequent capital accumulation in the data. Running the same regression in model-generated data yields an estimated coefficient of $\beta_{a}^{\mathrm{HeF}}=0.21$. To set a benchmark for this estimate, we report that the corresponding coefficients in the two nested models are quite different as we obtain $\beta_{a}^{\mathrm{NoF}}=-0.03$ and $\beta_{a}^{\mathrm{HoF}}=0.11$.

At the core of the mechanism amplifying the misallocation of capital in our model is that larger firms are more likely than small firms to overcome their borrowing constraints. As a result, the increase in the dispersion of the MRPK should be found primarily between small and large firms and not within large firms. The left panel of Figure 10 shows that, in response to the decline in the real interest rate, MRPK dispersion does not increase in our model when 


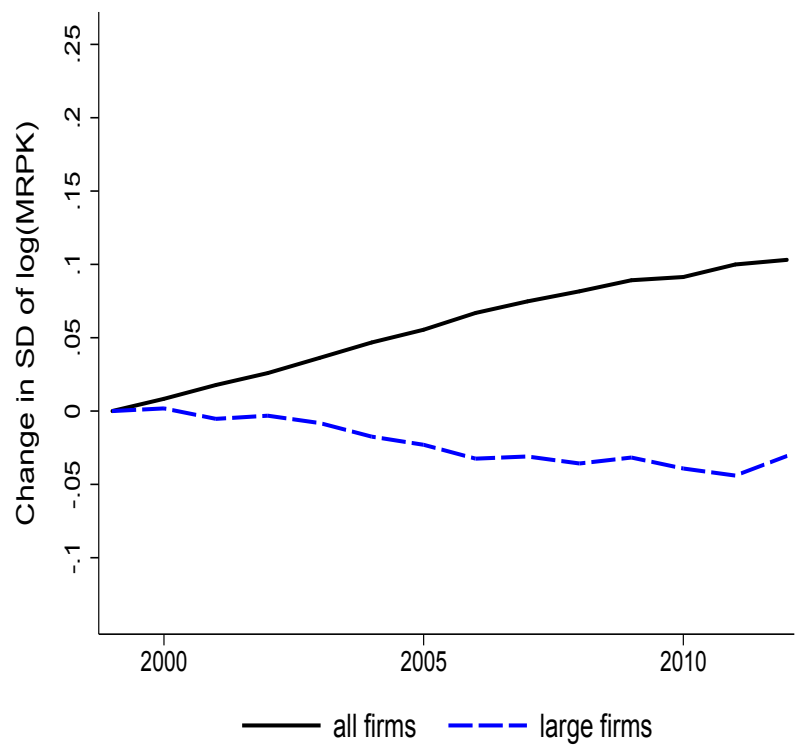

(a) Model

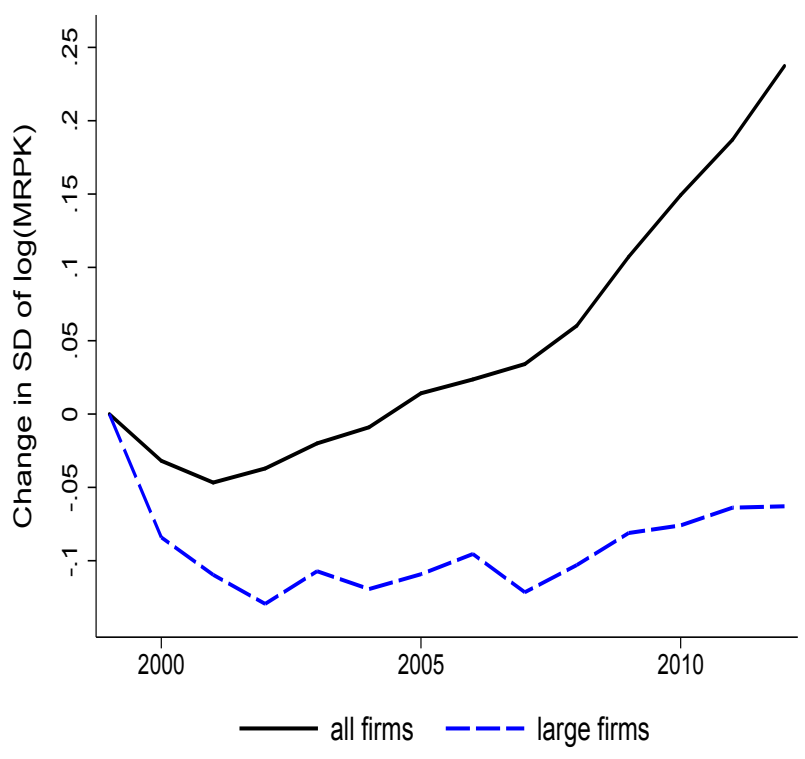

(b) Data

Figure 10: MRPK Dispersion and Large Firms

we condition on the subsample of large firms. We define large firms as firms with capital in the top 5 percent of the capital distribution. The right panel confirms that in the data MRPK dispersion also does not increase in the subsample of large firms. This result highlights the importance of having smaller firms in the sample. ${ }^{40}$

\subsection{Impact of Misallocation on Aggregate Dynamics}

The inflow of capital in our model is associated with a deterioration in the allocation of resources across firms. We now ask what is the additional impact of this deterioration on aggregate dynamics following the decline in the real interest rate. To answer this question, we compare the transitional dynamics generated by the HeF model to the transitional dynamics generated by a model without financial frictions. This comparison allows us to isolate the effect of financial frictions on aggregate dynamics, holding constant the other two factors that generate MRPK dispersion (risk in capital accumulation and adjustment costs).

Figure 11 shows that the transitional dynamics in the HeF model with parameters $\left(\psi, \lambda_{0}, \lambda_{1}\right)=$

\footnotetext{
${ }^{40}$ We find a divergence in the change in MRPK dispersion between the whole sample and the subsample of large firms for various alternative definitions of large firms (firms in the top 1, 3, or 10 percent of the capital distribution or firms with more than 100 or 250 employees). We also note that we fail to detect significant increases in the MRPK dispersion in the ESEE dataset that includes mostly large firms.
} 

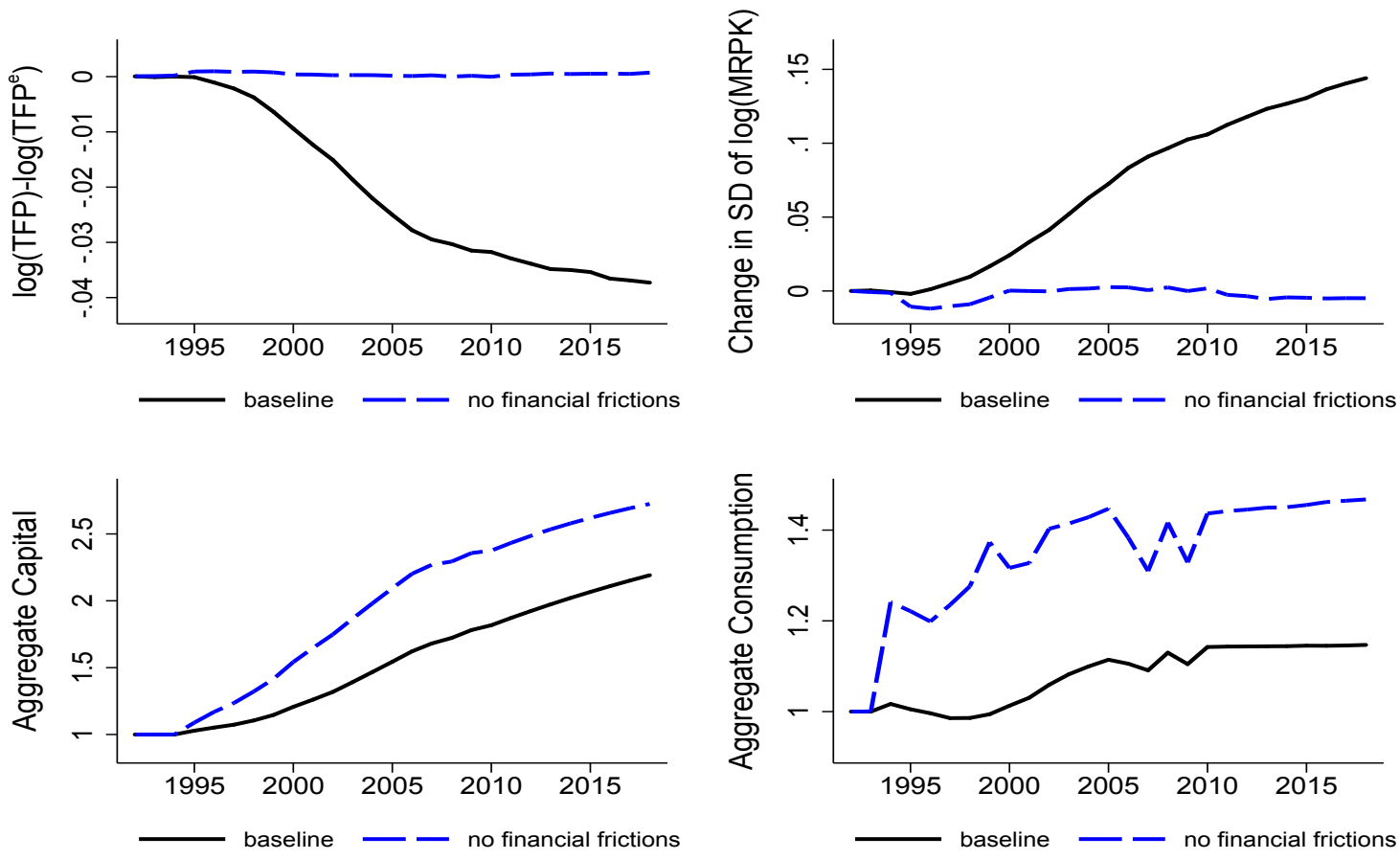

Figure 11: Impact of Misallocation on Evolution of Aggregate Variables

$(3.2,0.98,0.047)$ differ significantly from the transitional dynamics generated by a model without financial frictions and parameters $\left(\psi, \lambda_{0}, \lambda_{1}\right)=(3.2, \infty, \infty)$. Output and capital grow by significantly less in the model with financial frictions. We also note an important difference in the initial growth of aggregate consumption. Consumption grows by substantially more in the model without financial frictions because permanent income grows by more in this model than in the HeF model. We conclude that, in response to the decline in the real interest rate, there is an important quantitative effect of misallocation due to size-dependent financial frictions on the transitional dynamics of aggregate variables. ${ }^{41}$

\subsection{Extensions}

We next present aggregate responses to the real interest rate decline in the nested models HoF and NoF and in various extensions of the baseline HeF model. We summarize our results in

\footnotetext{
${ }^{41}$ Consistently with the findings of Moll (2014) and Midrigan and Xu (2014), in our model the TFP loss due to financial frictions in the stochastic steady state is small because firm productivity is a persistent process. Our baseline experiment is a decline in the real interest rate in a model with financial frictions, rather than a change in financial frictions per se. The decline in the real interest rate generates a loss in TFP along the transitional dynamics that is substantially larger than the steady state TFP loss. Additionally, we show that there is a substantial impact of financial frictions on the transitional dynamics of aggregate variables in response to a decline in the real interest rate.
} 
Table 6: Aggregate Responses: Data vs. Various Models (1999-2007)

\begin{tabular}{lccccc}
\hline \hline & $\Delta \Lambda$ & $\Delta$ (Dispersion) & $\Delta \log \left(\sum y\right)$ & $\Delta \log K$ & $\Delta B / \Delta K$ \\
\hline 1. Data & -0.031 & 0.034 & 0.14 & 0.22 & 1.28 \\
\hline 2. Heterogeneous Frictions & -0.023 & 0.074 & 0.26 & 0.38 & 1.24 \\
3. Homogeneous Frictions & 0.000 & 0.003 & 0.01 & 0.01 & 0.86 \\
4. No Frictions & 0.000 & 0.002 & 0.27 & 0.43 & 1.06 \\
5. Higher Adjustment Costs & -0.019 & 0.050 & 0.13 & 0.22 & 0.88 \\
6. Exogenous Labor Wedges & -0.026 & 0.057 & 0.27 & 0.39 & 1.17 \\
7. Overhead Labor & -0.023 & 0.075 & 0.26 & 0.38 & 1.24 \\
8. Unmeasured Capital & -0.027 & 0.048 & 0.31 & 0.47 & 1.29 \\
9. Alternative $r$ Process & -0.018 & 0.056 & 0.19 & 0.28 & 1.25 \\
\hline \hline
\end{tabular}

Notes: All changes are calculated between 1999 and 2007. $\Delta \Lambda$ denotes the percentage point change in TFP relative to its efficient level, that is the difference between $\log \left(\mathrm{TFP}_{07}\right)-\log \left(\mathrm{TFP}_{07}^{e}\right)$ and $\log \left(\mathrm{TFP}_{99}\right)-\log \left(\mathrm{TFP}_{99}^{e}\right)$. $\Delta$ (Dispersion) is the $\Delta[\mathrm{SD}(\log (\mathrm{MRPK}))] . \Delta \log \left(\sum y\right)$ is the change in the $\log$ of the sum of output and $\Delta \log K$ is the change in the log of aggregate capital. $\Delta B / \Delta K$ is the change in aggregate debt between 1999 and 2007 divided by the change in the aggregate capital between 1999 and 2007.

Table 6. The first two rows of Table 6 repeat the aggregate responses in the data and the HeF model. For each extension, we present more details about the model environment, our choice of parameters, the firm-level moments, and metrics of model performance in Appendix E.3.

Models HoF and NoF. Rows 3 and 4 of Table 6 show the responses of aggregate variables in the model with homogeneous frictions and the model without frictions. The most important result is that both models fail to generate any significant change in TFP and MRPK dispersion over time. This result is striking considering that the two models generate very different output and capital dynamics in response to the decline in the real interest rate. Output and capital barely change in model HoF whereas they increase significantly in model NoF.

To understand the difference between the $\mathrm{HeF}$ and the $\mathrm{HoF}$ model, Figure 12 repeats in model HoF the example with the two firms first presented in Figure 9 for model HeF. We keep 

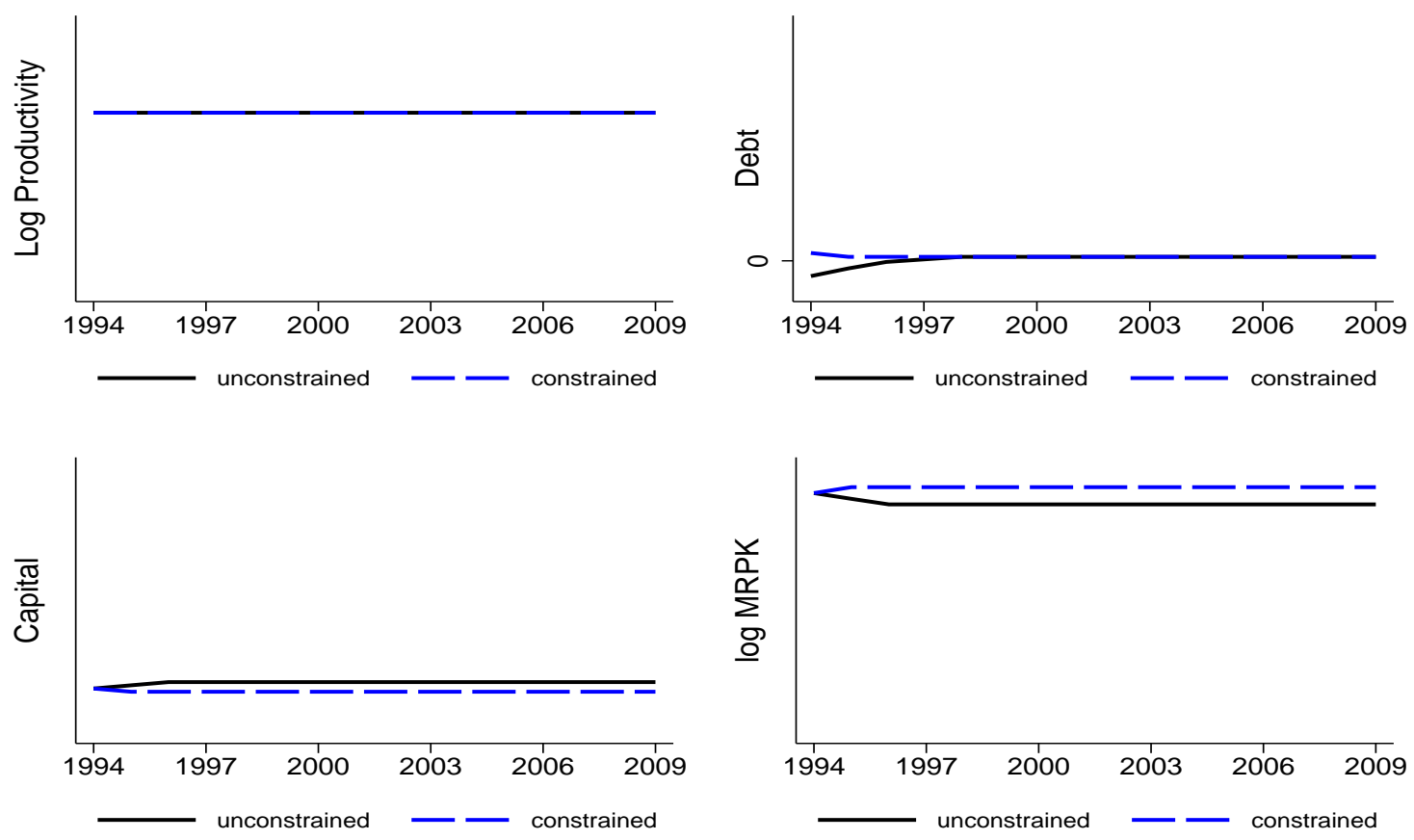

Figure 12: Real Interest Rates and Misallocation: An Illustrative Example (HoF Model)

the scale of the axes the same between the two figures to ease the comparisons. Figure 12 shows muted differences in capital and debt accumulation between the two types of firms. Contrary to the HeF model, in the HoF model the initially unconstrained firm is not able to overcome its borrowing constraint over its transition. Therefore, capital and debt accumulation are relatively similar across firms. The small dispersion in firm outcomes explains why the HoF model fails to generate significant movements in TFP and MRPK dispersion following the decline in the real interest rate.

In response to the decline in the real interest rate, the NoF model generates significant capital and debt accumulation. In that respect, the NoF model is different from the HoF model. In the HoF model, most firms remain constrained and do not grow significantly. In the NoF model, all firms are unconstrained and grow significantly. Therefore, both models generate too little heterogeneity in firm capital and debt accumulation. This explains why both models fail to generate significant changes in TFP and MRPK dispersion over time.

Higher Adjustment Costs. The baseline HeF model generates larger increases in aggregate output, capital, and debt relative to the data. The magnitude of these increases is directly affected by the parameter $\psi$ that controls for the magnitude of adjustment costs in capital accu- 
mulation. In the baseline $\mathrm{HeF}$ model we choose $\psi$ such that the model replicates the within-firm responsiveness of capital growth to productivity observed in the microdata. To examine the robustness of our conclusions to alternative calibration strategies, we now choose $\psi=7.6$ such that the model reproduces the increase in aggregate capital observed in the data. ${ }^{42}$

Row 5 of Table 6 shows that the model with higher adjustment costs generates a somewhat smaller decline in TFP relative to its efficient level than the baseline HeF model. The model with higher adjustment costs comes closer than the HeF model to matching the changes in MRPK dispersion, output, and debt observed in the data. We note, however, that the model with higher adjustment costs performs worse than the baseline HeF model in terms of matching firm-level moments (see Appendix E.3).

Exogenous Labor Wedges. We now extend the baseline HeF model to allow for MRPL dispersion across firms. We begin our analysis with a model of MRPL dispersion arising from exogenous labor wedges. The labor wedge takes the form of a time-varying proportional tax that firms pay on their compensation to labor. The stochastic process for the labor wedge is independent of calendar time and, as a result, MRPL dispersion is constant in the model. We calibrate this process to match the standard deviation and the first-order autocorrelation of $\log (\mathrm{MRPL})$ in the firm-level data.

Row 6 of Table 6 shows that the model with exogenous labor wedges performs better than the baseline HeF model in terms of generating a larger decline in TFP relative to its efficient level and a smaller increase in the dispersion of the $\log (\mathrm{MRPK})$. The responses of aggregate output, capital, and debt are similar between the two models. We also note that the model with exogenous labor wedges performs roughly as well as the baseline model in terms of matching the micro moments in the data.

Overhead Labor. A model with overhead labor endogenously generates MRPL dispersion across firms. Such a model would, however, imply changes in MRPL dispersion over time in response to shocks. We, therefore, started with the simpler approach of specifying exogenous labor wedges at the firm level and assumed that the dispersion of these wedges is constant over

\footnotetext{
${ }^{42}$ In the model with $\psi=7.6$, the mean adjustment cost equals 1.8 percent of value added conditional on adjusting the capital stock, which is lower than the 2.8 percent we found with $\psi=3.2$. This is because firms choose to adjust by less conditional on adjusting. With $\psi=7.6$, the mean frequency of adjustment is 14 percent.
} 
time. To confirm the robustness of our results to the modeling choice that generates MRPL dispersion, we now adopt the production function in Bartelsman, Haltiwanger, and Scarpetta (2013) given by $y_{i t}=Z_{i t} k_{i t}^{\alpha}\left(\ell_{i t}-\phi_{\ell}\right)^{1-\alpha}$, where $\phi_{\ell}$ denotes overhead labor. With this production function, the measured marginal revenue product of labor varies across firms and over time.

Row 7 of Table 6 shows that the model with overhead labor generates nearly identical aggregate responses as the baseline model. Overhead labor does not interact in a significant quantitative way with firm investment and debt decisions and, therefore, moments related to leverage, net worth, capital, and MRPK are similar between the model with overhead labor and the baseline model without MRPL dispersion.

Unmeasured Capital. The standard deviation of $\log (\mathrm{MRPK})$ in the baseline HeF model (0.26) is much lower than in the data (0.88). We incorporate measurement error in firms' capital in order to generate the higher level of MRPK dispersion in the data. We consider the production function $y_{i t}=Z_{i t}\left(k_{i t}+q_{i t}\right)^{\alpha} \ell_{i t}^{1-\alpha}$, where $q_{i t}$ denotes measurement error in firms' capital reflecting, for example, unmeasured intangible assets or overhead capital in production.

Row 8 of Table 6 shows aggregate responses in the model with measurement error in capital. The model matches closer the observed changes in TFP relative to its efficient level and in the dispersion of the $\log (\mathrm{MRPK})$ than the baseline model. However, the model also generates a stronger response in aggregate output, capital, and debt. In terms of matching untargeted firmlevel moments, the model with unmeasured capital performs similarly to the baseline model.

Alternative $r$ Process. In the baseline HeF model, all changes in the real interest rate $r_{t}$ were unexpected to firms and perceived as permanent. We examine the robustness of our results to an alternative stochastic process for $r_{t}$. We assume that the initial decline in $r_{t}$ in 1994 was unexpected but that from that date on firms expect $r_{t}$ to evolve according to an $\mathrm{AR}(1)$ process, $r_{t}=\left(1-\rho^{r}\right) \bar{r}+\rho^{r} r_{t-1}+\sigma^{r} \epsilon_{t}^{r}$, where $\bar{r}$ denotes the mean real interest rate, $\rho^{r}$ denotes the persistence of the process, and $\sigma^{r}$ denotes the standard deviation of shocks to the real interest rate. Using data from our sample period, we estimate $\bar{r}=0.03, \rho^{r}=0.50$, and $\sigma^{r}=0.009$. We continue to feed into the model the path of $r_{t}$ shown in Figure 7 .

Row 9 of Table 6 shows that, relative to our baseline model, the model with the alternative process for $r_{t}$ generates a somewhat smaller decline in TFP relative to its efficient level but 
Table 7: Aggregate Responses and Various Shocks

\begin{tabular}{lcccc}
\hline \hline & $\mathrm{TFP} / \mathrm{TFP}^{e}$ & $\mathrm{SD}(\log \mathrm{MRPK})$ & $K$ & $B-K$ \\
\hline 1. Data (Pre-Crisis Period) & $\downarrow$ & $\uparrow$ & $\uparrow$ & $\uparrow$ \\
2. Real Interest Rate Decline $(\downarrow r)$ & $\downarrow$ & $\uparrow$ & $\uparrow$ & $\uparrow$ \\
3. Financial Liberalization $\left(\uparrow \lambda_{0}\right.$ or $\left.\uparrow \lambda_{1}\right)$ & $\uparrow$ & $\downarrow$ & $\uparrow$ & $\uparrow$ \\
4. Uncertainty Decline $(\downarrow \sigma)$ & $\uparrow$ & $\downarrow$ & - & $\uparrow$ \\
5. Data (Post-Crisis Period) & $\downarrow$ & $\uparrow$ & $\downarrow$ & $\downarrow$ \\
\hline \hline
\end{tabular}

comes closer to matching the change in MRPK dispersion observed in the data. The model also generates smaller responses of output, capital, and debt relative to the baseline model. Finally, firm-level moments generated by the model with the alternative $r_{t}$ process are similar to those in the baseline model. Our conclusion is that changing the process for the real interest rate process does not affect significantly our results.

\subsection{Other Shocks and Post-Crisis Dynamics}

We next compare the decline in the real interest rate to other shocks in terms of their ability to generate changes in MRPK dispersion, TFP, and capital flows that resemble the changes observed in the data. We do not assess quantitatively the performance of the model under these other shocks because we simply wish to make the qualitative point that the decline in the real interest rate generates directional responses of dispersion, TFP, and capital flows similar to those observed in the data whereas these other shocks do not.

Table 7 summarizes the results. In the pre-crisis period (row 1), we observe a decline in TFP relative to its efficient level, an increase in the dispersion of the return to capital, and capital inflows. As discussed before, our model with size-dependent financial frictions matches the dynamics of these variables over time (row 2).

It is often conjectured that countries in the South received large capital inflows following a financial liberalization associated with the euro convergence process. Row 3 of Table 7 evaluates 
the implications of such a development through the lens of our baseline HeF model. A financial liberalization episode in our model, modeled as a relaxation of the borrowing constraint (an increase in either $\lambda_{0}$ or $\lambda_{1}$ ), is associated with an increase in borrowing that allows previously constrained firms to increase their capital accumulation. Therefore, this shock captures the common view that the adoption of the euro was associated with capital inflows to the South.

The relaxation of the borrowing constraint generates a more efficient allocation of resources and is associated with increases in TFP relative to its efficient level and a decrease in the dispersion of the return to capital. This contradicts the key fact that capital inflows in Spain were accompanied by a decline in TFP relative to its efficient level and an increase in MRPK dispersion. The prediction that financial liberalization episodes are associated with increasing productivity is common in models with financial frictions (see, for instance, Buera, Kaboski, and Shin, 2011; Midrigan and Xu, 2014). ${ }^{43}$ While we do not deny that such a financial liberalization may have taken place, our results point out that the decline in the real interest rate is more important for understanding the evolution of productivity in Spain in the first few years after the adoption of the euro. ${ }^{44}$

Can changes in the process governing firm productivity explain Spain's pre-crisis experience? In a model with risky capital accumulation and adjustment costs, a higher dispersion of productivity across firms leads to higher MRPK dispersion (Asker, Collard-Wexler, and De Loecker, 2014). However, we find that the standard deviation of productivity shocks across firms, $\sigma$, was generally decreasing between 1999 and 2007. ${ }^{45}$ As row 4 of Table 7 shows, a decrease in $\sigma$ generates an increase in debt as the precautionary saving motive weakens but is associated

\footnotetext{
${ }^{43}$ The directional response of the dispersion of the $\log (\mathrm{MRPK})$ to various shocks is a general feature of these models with financial frictions and not an artifact of specific features of our model. In Appendix $\mathrm{F}$ we examine a similar model to Midrigan and Xu (2014), Moll (2014), and Buera and Moll (2015) without a size-dependent borrowing constraint, risky capital accumulation, and adjustment costs. Within this simpler environment, we derive closed-form solutions for the response of the dispersion of the $\log (\mathrm{MRPK})$ to various shocks and show that all responses have the same sign as the responses generated by our richer model.

${ }^{44}$ Our results relate to Aoki, Benigno, and Kiyotaki (2010) who develop a model in which financial liberalization may lead to a decline in TFP. With an underdeveloped financial system, TFP in their model declines because capital inflows are intermediated by unproductive entrepreneurs who expand relative to productive entrepreneurs.

${ }^{45}$ To obtain idiosyncratic productivity shocks, we follow Bloom, Floetotto, Jaimovich, Saporta-Eksten, and Terry (2012) and estimate the firm-level AR(1) process shown in equation (23). We find that the dispersion of productivity shocks is decreasing between 1999 and 2007 using either the productivity measure $\log \hat{Z}$ estimated with the Wooldridge (2009) extension of the Levinsohn and Petrin (2003) methodology or the productivity measure $\log \tilde{Z}$ defined in equation (11). We find these patterns both in the permanent sample and the full sample of firms.
} 
with a lower dispersion of MRPK and a higher TFP relative to its efficient level.

To summarize, our model shows that the decline in the real interest rate generates dynamics in capital flows, dispersion, and TFP that resemble the dynamics observed in the data. Changes in financial frictions or in the productivity process are not able to match even qualitatively the trends observed in the data between 1999 and $2007{ }^{46}$

Uncertainty and deleveraging are likely to be important factors in the post-crisis period between 2008 and 2012. In Section 3 we documented an acceleration of the increase in the dispersion of the $\log (\mathrm{MRPK})$ in the post-crisis period and a continuation of the decline in TFP relative to its efficient level. Further, row 5 of Table 7 shows a reversal of capital flows during the post-crisis period. While some changes in dispersion and TFP can plausibly reflect transitional dynamics from the decline in the real interest rate, the reversal of capital flows implies an important role for other shocks during the post-crisis period. Indeed, we find that the dispersion of productivity shocks $\sigma$ increased sharply after 2007. Additionally, borrowing constraints were tightened during the crisis. As rows 3 and 4 of Table 7 show, an increase in $\sigma$ and a decline in $\lambda_{0}$ or $\lambda_{1}$ lead to capital outflows, higher MRPK dispersion, and lower TFP relative to its efficient level. We leave for future research an evaluation of the quantitative role of uncertainty and deleveraging shocks for the post-crisis dynamics.

\section{Evidence From Other Euro Countries}

In this section we extend parts of our empirical analyses to Italy (1999-2012), Portugal (20062012), Germany (2006-2012), France (2000-2012), and Norway (2004-2012). To preview our results, countries in the South share some similar trends in the MRPK dispersion and the TFP loss due to misallocation. By contrast, these trends differ significantly in the North.

In Appendix A we present coverage statistics and the size distribution of firms for all countries. The coverage is high and averages from roughly 60 to more than 90 percent of the coverage observed in Eurostat. The exception is Germany, for which we have roughly one-third of the wage bill starting in 2006. As with the case of Spain, our sample for other countries is also

\footnotetext{
${ }^{46} \mathrm{An}$ increase in the mean level of firm productivity or demand $Z^{A}$ generates an increase in capital accumulation, a higher dispersion of the MRPK, and lower TFP relative to its efficient level. However, the increase in $Z^{A}$ would generate an increase in the level of TFP, which contradicts the fact that TFP in the data did not increase.
} 
broadly representative in terms of contributions of small and medium sized firms to economic activity.

Figures 13 and 14 present the evolution of the standard deviation of $\log (\mathrm{MRPK})$ and $\log (\mathrm{MRPL})$ for each country in the permanent sample and the full sample respectively. The figures show a significant increase in the standard deviation of $\log (\mathrm{MRPK})$ in Spain and Italy before the crisis. During the same period, France experienced a smaller increase. We document significant increases in the dispersion of the $\log (\mathrm{MRPK})$ in all countries of the South during and after the crisis. By contrast, we do not observe such trends in the North. Additionally, we do not see significant changes in the dispersion of the $\log (\mathrm{MRPL})$ in any country in our sample. This holds both during the pre-crisis period and during the post-crisis period.

Figure 15 plots the evolution of the loss in TFP due to misallocation, previously defined in equation (10). Similarly to Spain, we observe significant declines in $\log (\mathrm{TFP})$ in Italy's full sample throughout the period, in Italy's permanent sample during the crisis, and in Portugal's permanent sample that mostly covers the crisis period. We do not observe trend declines in Germany, France, or Norway.

\section{Conclusions}

The aim of this paper is to shed light on the joint dynamics of capital flows, dispersion of factor returns, and productivity in South Europe following the adoption of the euro. The first contribution of our work is to bring empirical evidence on the dynamics of misallocation over time. Employing a large and representative sample of Spanish manufacturing firms, we document a significant increase in MRPK dispersion over time and a decline in TFP relative to its efficient level. Interestingly, we do not find an important role for a changing dispersion of the returns to labor.

Our second contribution is to link patterns of capital misallocation at the micro level to firm-level financial decisions and to the macroeconomic implications of financial frictions. We have developed a model with heterogeneous firms, financial frictions that depend on firm size, and capital adjustment costs that matches closely various moments estimated from production 


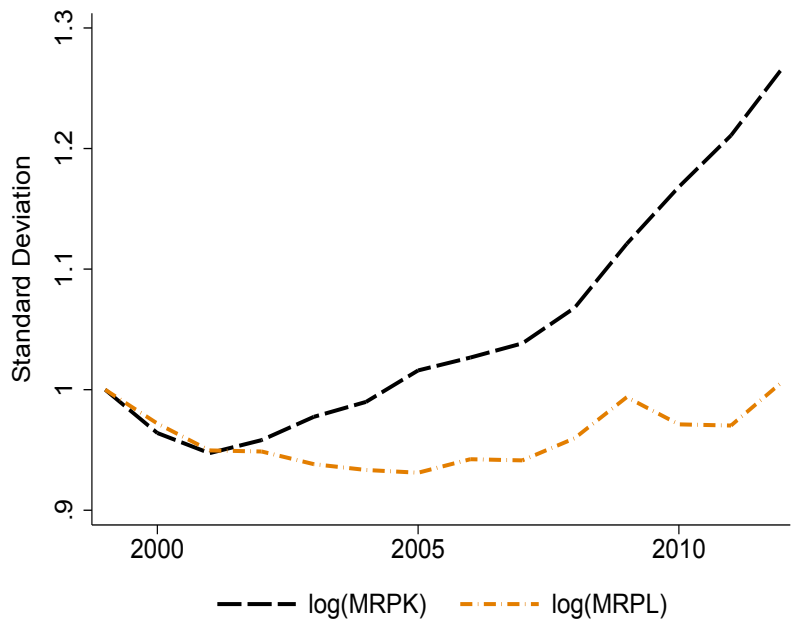

(a) Spain

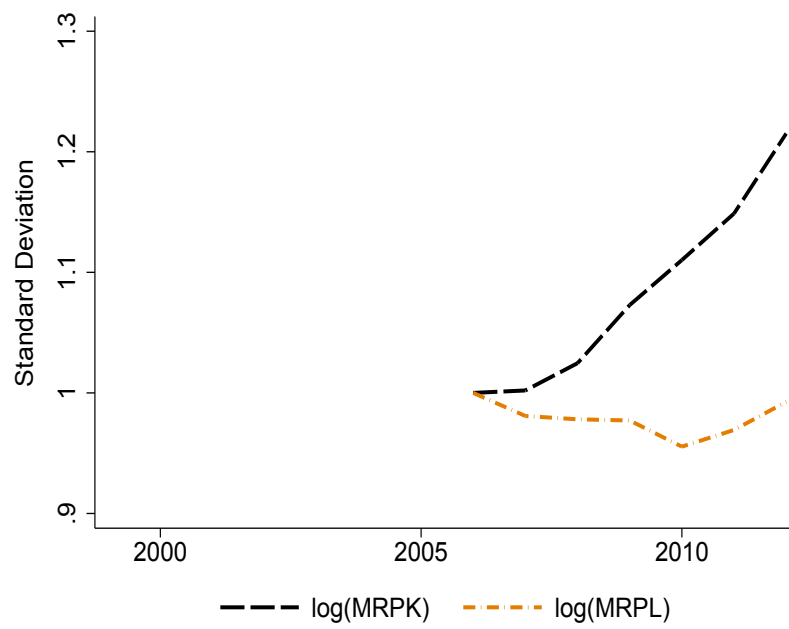

(c) Portugal

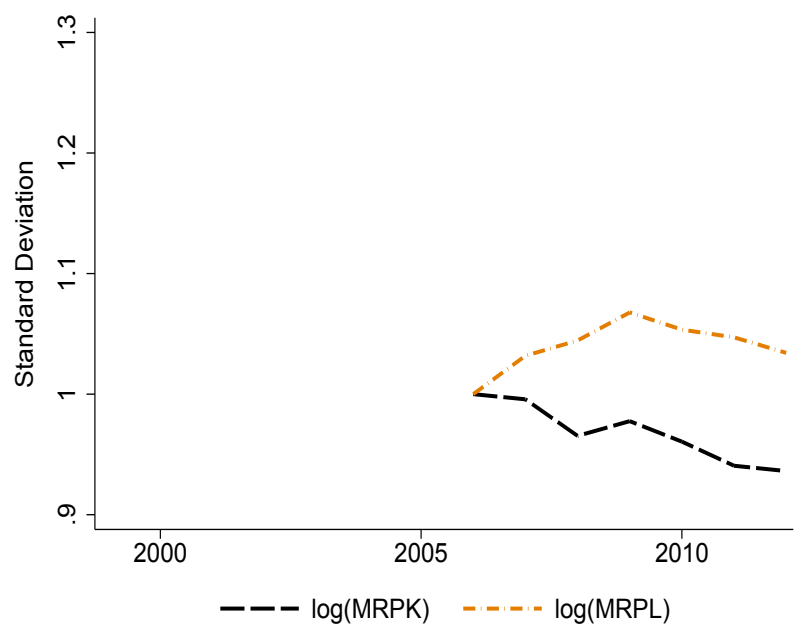

(e) Germany

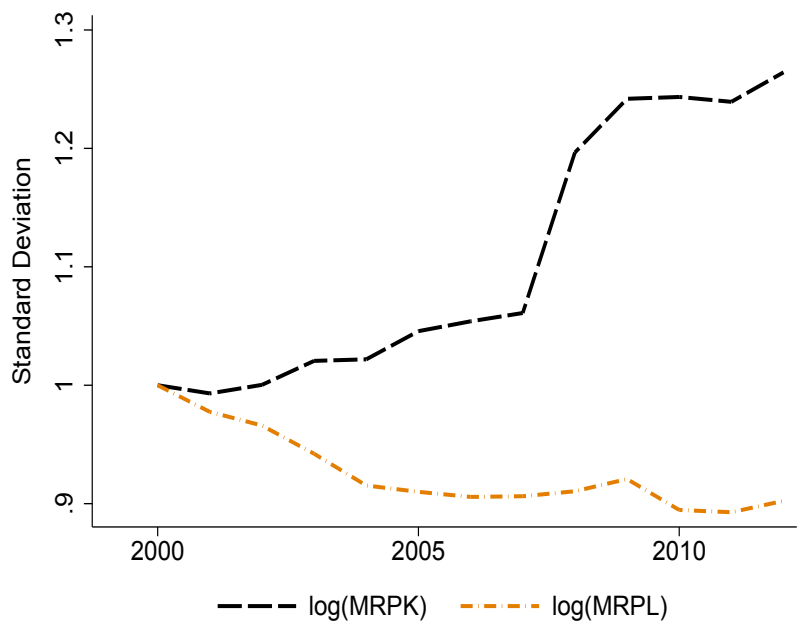

(b) Italy

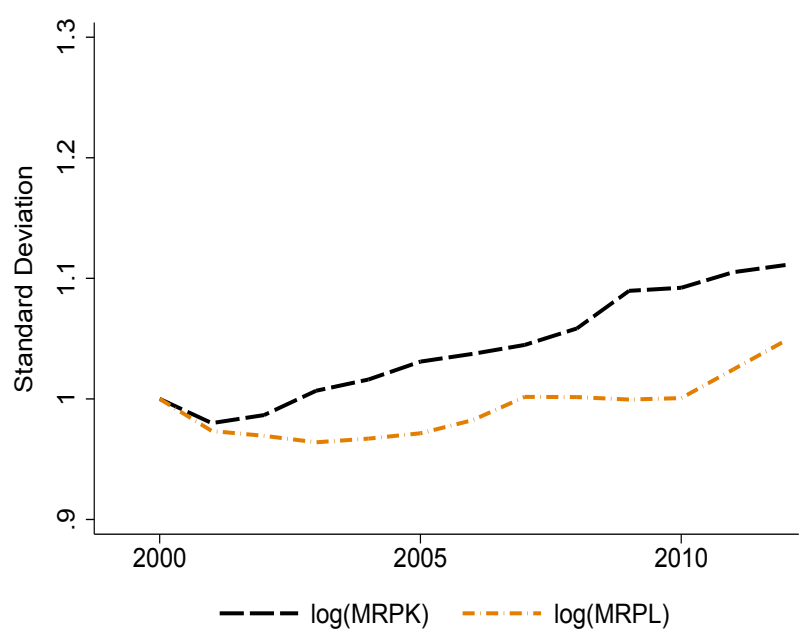

(d) France

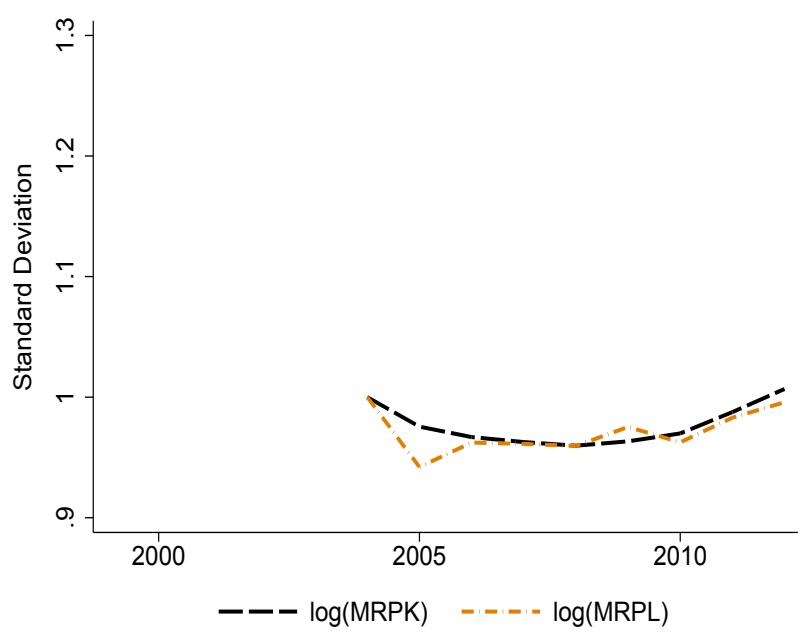

(f) Norway

Figure 13: Evolution of MRPK and MRPL Dispersion in Permanent Sample 


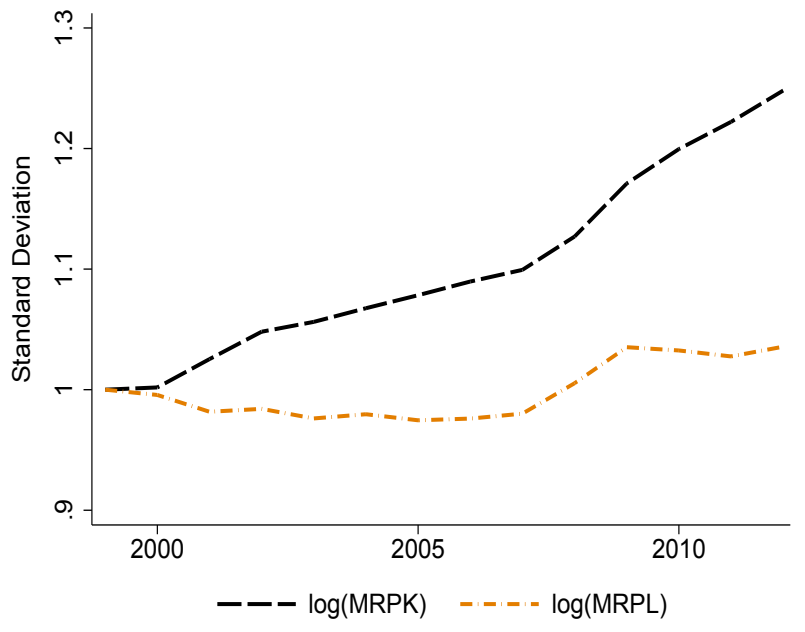

(a) Spain

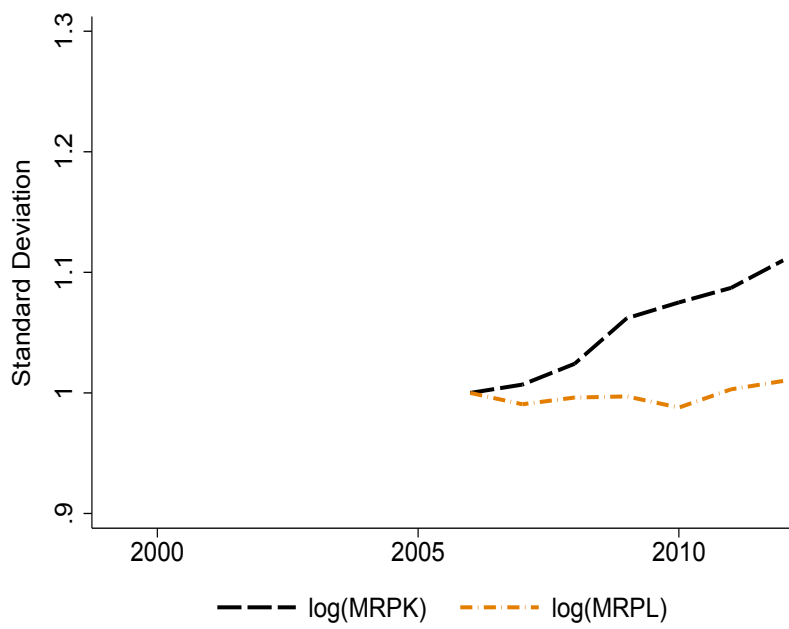

(c) Portugal

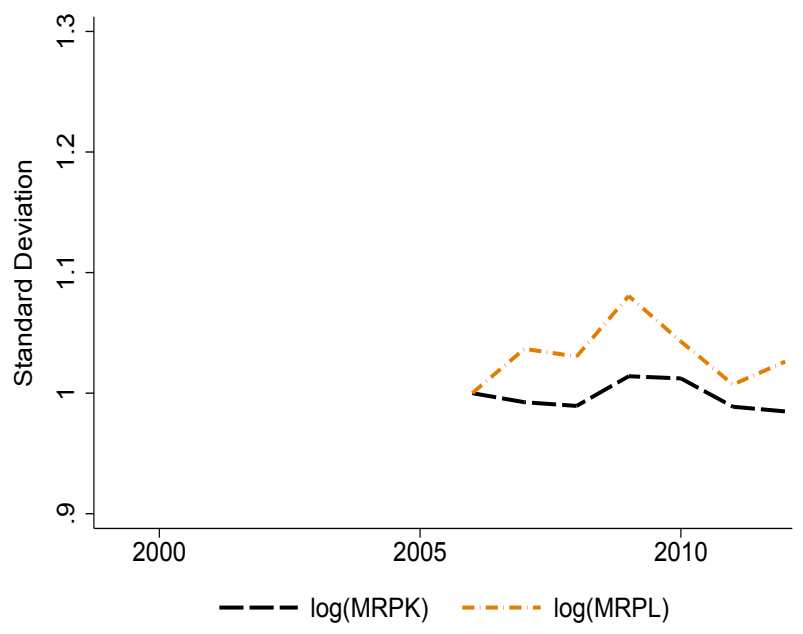

(e) Germany

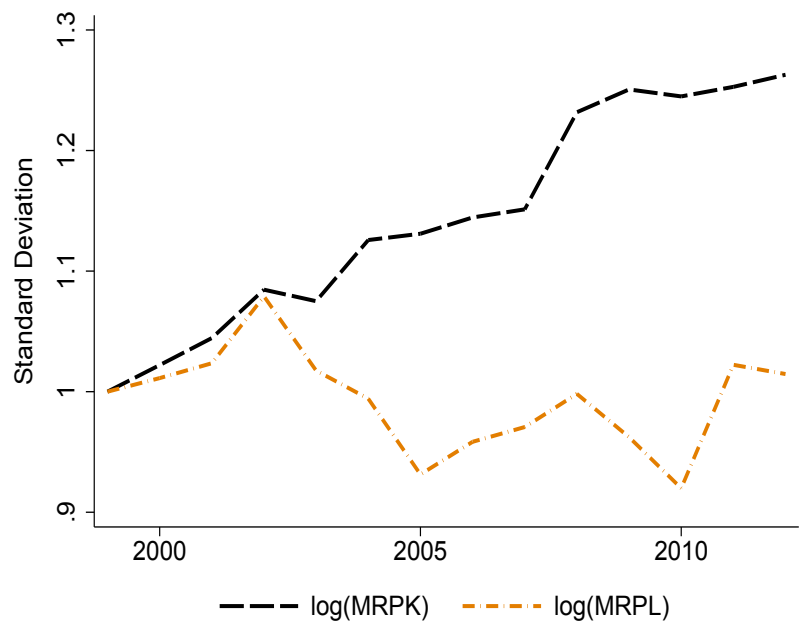

(b) Italy

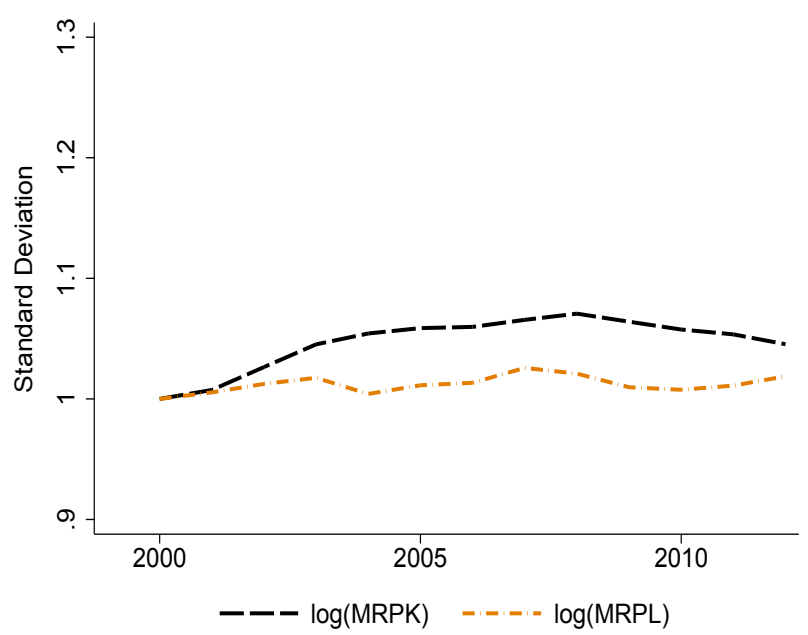

(d) France

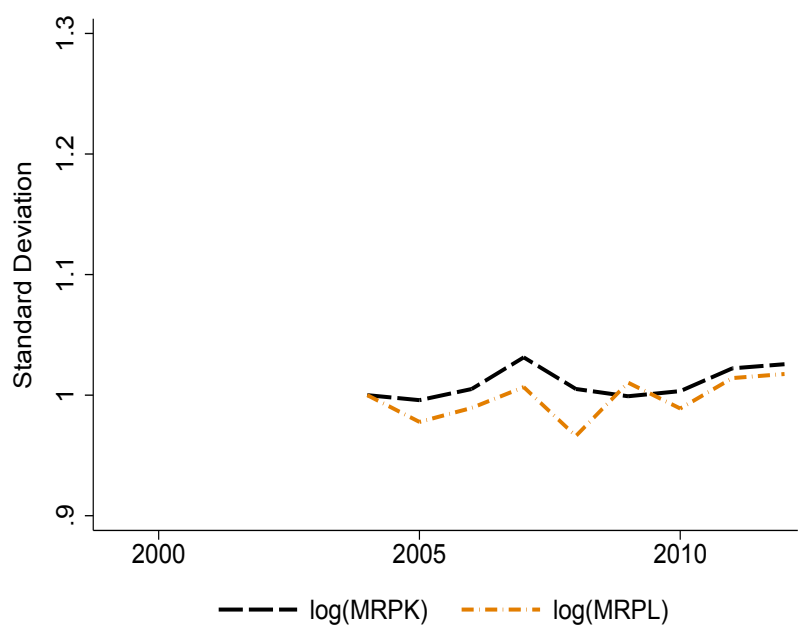

(f) Norway

Figure 14: Evolution of MRPK and MRPL Dispersion in Full Sample 


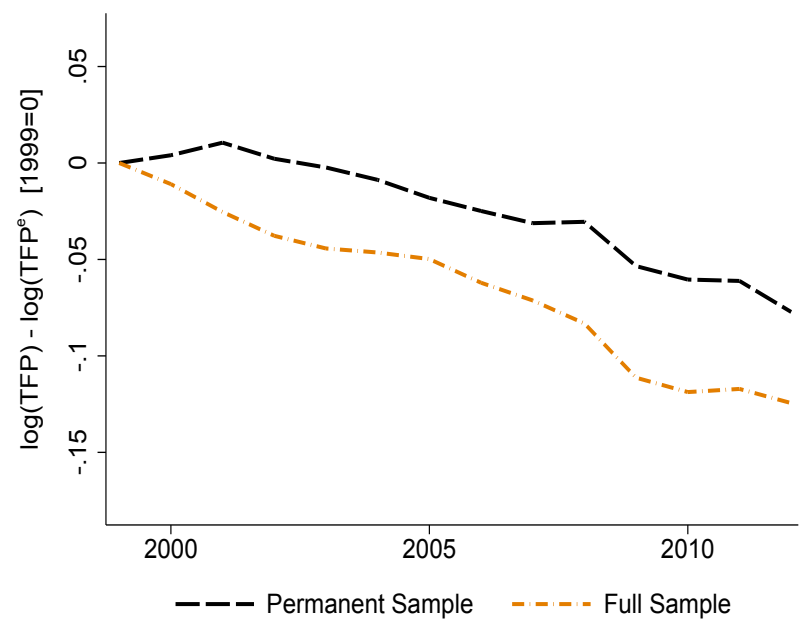

(a) Spain

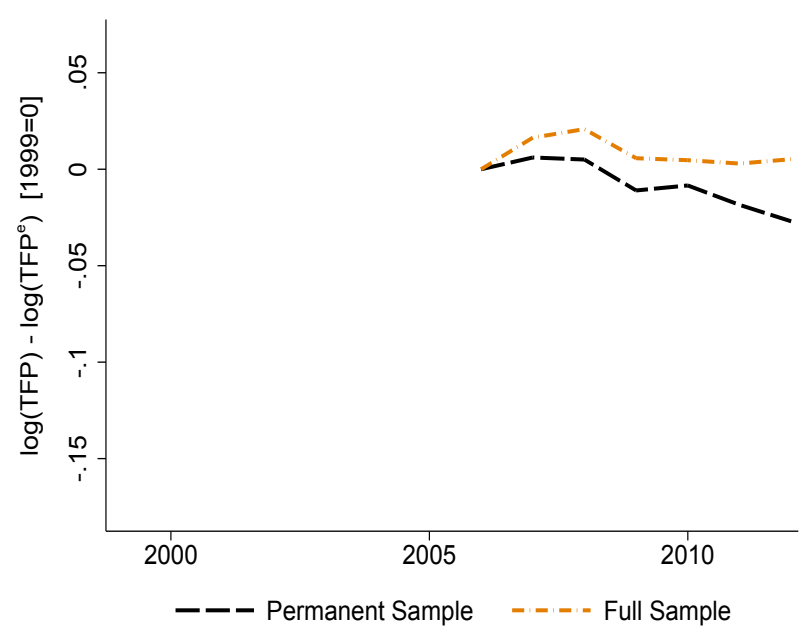

(c) Portugal

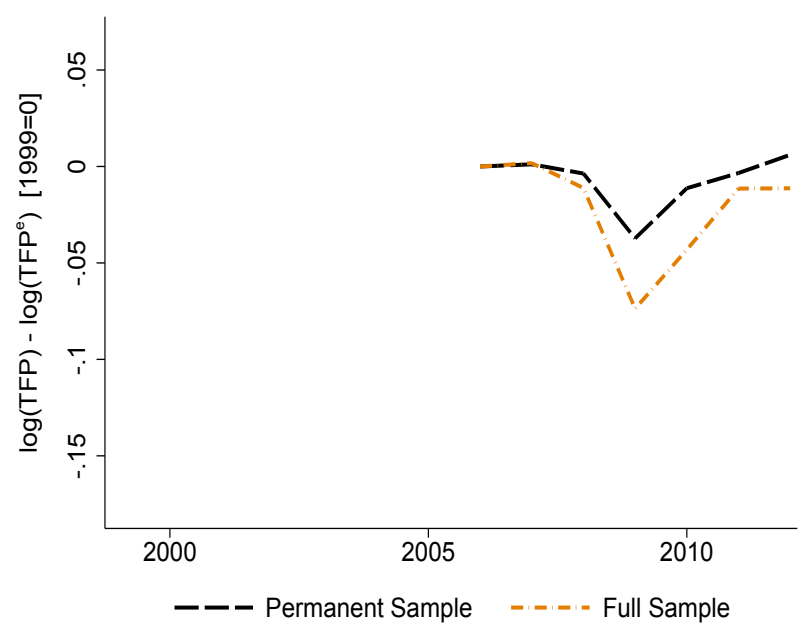

(e) Germany

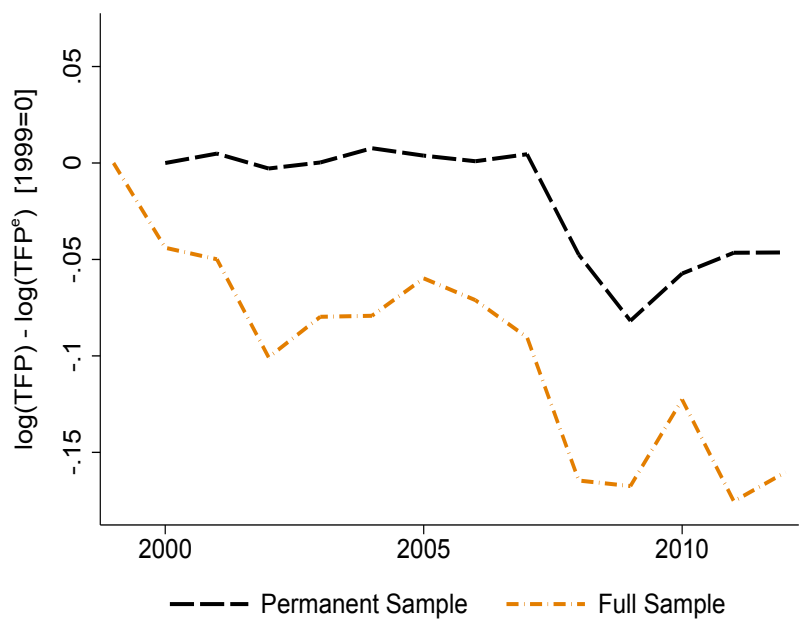

(b) Italy

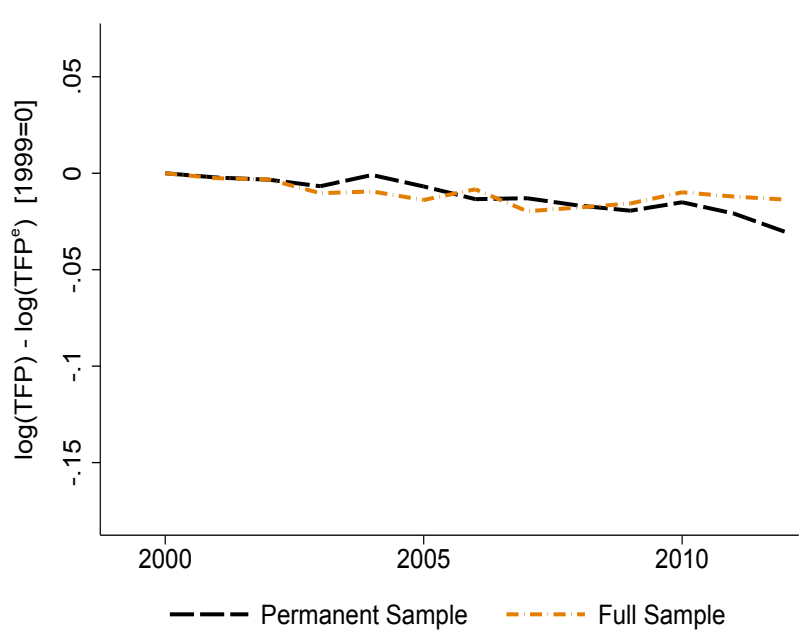

(d) France

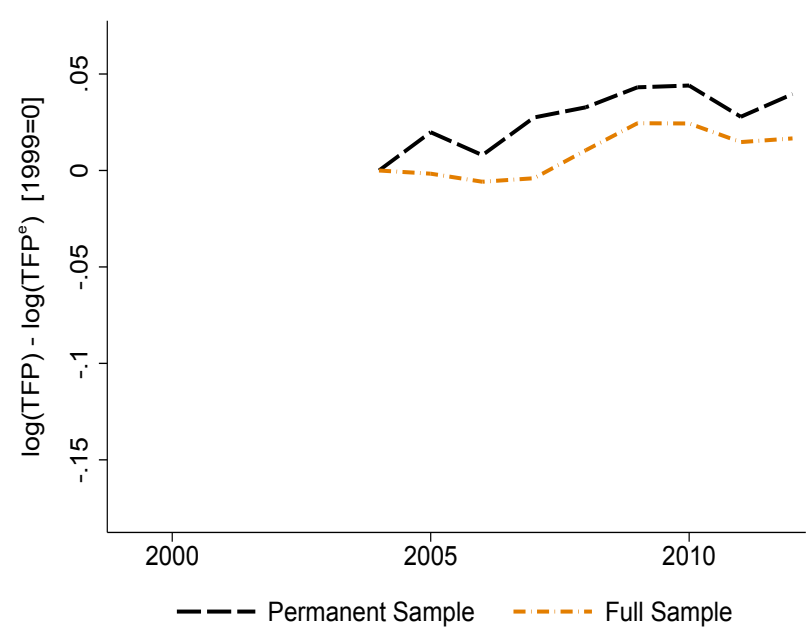

(f) Norway

Figure 15: Evolution of TFP Relative to Efficient Level 
and balance sheet data. Using this calibrated model, we illustrate how the decline in the real interest rate that started in the early to mid 1990s generates transitional dynamics that are similar to the dynamics of MRPK dispersion, TFP relative to its efficient level, and capital flows during the pre-crisis period.

Finally, we have documented that trends in the dispersion of the return to capital and in productivity losses from misallocation differ significantly between countries in South Europe and countries in the North. We find these differences suggestive, given that firms in the South are likely to operate in less well-developed financial markets. A more complete analysis of the differences between the South and the North remains a promising avenue for future research.

\section{References}

Ackerberg, D., K. Caves, and G. Frazer (2015): "Identification Properties of Recent Production Function Estimators," Econometrica, 83(6), 2411-51.

Aoki, K., G. Benigno, and N. Kiyotaki (2010): "Adjusting to Capital Account Liberalization," CEP Working Paper No. 1014.

Arellano, C., Y. Bai, and J. Zhang (2012): "Firm Dynamics and Financial Development," Journal of Monetary Economics, 59, 533-49.

Asker, J., A. Collard-Wexler, and J. De Loecker (2014): "Dynamic Inputs and Resource (Mis)Allocation," Journal of Political Economy, 122(5), 1013-63.

Bachmann, R., R. Caballero, and E. Engel (2013): "Aggregate Implications of Lumpy Investment: New Evidence and a DSGE Model," American Economic Journal: Macroeconomics, 5(4), 29-67.

Banerjee, A., and E. Duflo (2005): "Growth Theory Through the Lens of Development Economics," in Handbook of Economic Growth, ed. by P. Aghion, and S. Durlauf, pp. 473-552. Elsevier.

Bartelsman, E., J. Haltiwanger, and S. Scarpetta (2013): "Cross-Country Differences in Productivity: The Role of Allocation and Selection," American Economic Review, 103(1), $305-34$. 
Benigno, G., and L. Fornaro (2014): "The Financial Resource Curse," Scandinavian Journal of Economics, 116(1), 58-86.

Blanchard, O. (2007): "Adjustment Within the Euro. The Difficult Case of Portugal," Portuguese Economic Journal, 6(1), 1-21.

Bloom, N., M. Floetotto, N. Jaimovich, I. Saporta-Eksten, and S. Terry (2012): "Really Uncertain Business Cycles," NBER Working Paper No. 18245.

Buera, F., J. P. Kaboski, and Y. Shin (2011): "Finance and Development: A Tale of Two Sectors," American Economic Review, 101(5), 1964-2002.

Buera, F., and B. Moll (2015): "Aggregate Implications of a Credit Crunch: The Importance of Heterogeneity," American Economic Journal: Macroeconomics, 7(3), 1-42.

Buera, F., And Y. Shin (2016): "Productivity Growth and Capital Flows: The Dynamics of Reforms," American Economic Journal: Macroeconomics, Forthcoming.

Cette, G., J. Fernald, and B. Mojon (2016): "The Pre-Great Recession Slowdown in Productivity," European Economic Review, 88, 3-20.

Dias, D., C. Marques, and C. Richmond (2014): "Misallocation and Productivity in the Lead Up to the Eurozone Crisis," Working Paper, Bank of Portugal.

European Central Bank (2013): "Survey on the Access to Finance of Small and MediumSized Enterprises In the Euro Area," ECB Report.

Fernald, J., and B. Neiman (2011): "Growth Accounting with Misallocation: Or, Doing Less with More in Singapore," American Economic Journal: Macroeconomics, 3, 29-74.

Fernandez-Villaverde, J., L. Garicano, and T. Santos (2013): "Political Credit Cycles: The Case of the Eurozone," Journal of Economic Perspectives, 27(3), 145-66.

Foster, L., J. Haltiwanger, and C. Syverson (2008): "Reallocation, Firm Turnover, and Efficiency: Selection on Productivity or Profitability?," American Economic Review, 98(1), $394-425$.

Garcia-Santana, M., E. Moral-Benito, J. Pijoan-Mas, and R. Ramos (2016): "Growing Like Spain: 1995-2007,” Working Paper, Bank of Spain.

Gilchrist, S., J. Sim, and E. Zakrajsek (2013): "Misallocation and Financial Market Frictions: Some Direct Evidence From the Dispersion in Borrowing Costs," Review of Economic Dynamics, 16, 159-76. 
Guner, N., G. Ventura, And Y. Xu (2008): "Macroeconomic Implications of SizeDependent Policies," Review of Economic Dynamics, 11, 721-44.

Hsieh, C.-T., And P. Klenow (2009): "Misallocation and Manufacturing TFP in China and India," Quarterly Journal of Economics, 124(4), 1403-448.

Hsieh, C.-T., And B. Olken (2014): "The Missing "Missing Middle"," Journal of Economic Perspectives, 28, 89-108.

Johnson, S., And T. Mitton (2003): "Cronyism and Capital Controls: Evidence From Malaysia," Journal of Financial Economics, 67, 351-92.

Kalemli-Ozcan, S., B. Sorensen, C. Villegas-Sanchez, V. Volosovych, and S. Yesiltas (2015): "How to Construct Nationally Representative Firm Level Data from the ORBIS Global Database," NBER Working Paper No. 21558.

Kenrig, M. (2015): "The Cyclical Nature of the Productivity Distribution," Working Paper, University of Texas at Austin.

Khwaja, A., And A. Mian (2005): "Do Lenders Favor Politically Connected Firms? Rent Provision in an Emerging Financial Market," Quarterly Journal of Economics, 120(4), 1371411.

Kiyotaki, N., And J. Moore (1997): "Credit Cycles," Journal of Political Economy, 105(2), $211-48$.

LAgos, R. (2006): “A Model of TFP," Review of Economic Studies, 73, 983-1007.

Larrain, M., and S. Stumpner (2013): "Financial Reforms and Aggregate Productivity: The Microeconomic Channels," Working Paper, Columbia University.

Levinsohn, J., And A. Petrin (2003): "Estimating Production Functions Using Inputs to Control for Unobservables," Review of Economic Studies, 70(2), 317-42.

MendozA, E. (2010): "Sudden Stops, Financial Crises, and Leverage," American Economic Review, 100(5), 1941-66.

Midrigan, V., And D. Y. Xu (2014): "Finance and Misallocation: Evidence from Plant-Level Data," American Economic Review, 104(2), 422-58.

Moll, B. (2014): "Productivity Losses from Financial Frictions: Can Self-Financing Undo Capital Misallocation?," American Economic Review, 104(10), 3186-221. 
Oberfield, E. (2013): "Productivity and Misallocation During a Crisis: Evidence from the Chilean Crisis of 1982," Review of Economic Dynamics, 16, 100-19.

Olley, S., And A. Pakes (1996): "The Dynamics of Productivity in the Telecommunications Equipment Industry," Econometrica, 64(6), 1263-97.

Peters, M. (2013): "Heterogeneous Mark-Ups, Growth and Endogenous Misallocation," Working Paper, Yale University.

Reis, R. (2013): "The Portuguese Slump and Crash and the Euro Crisis," Brookings Papers on Economic Activity, 1, 143-210.

Restuccia, D., and R. Rogerson (2008): "Policy Distortions and Aggregate Productivity with Heterogeneous Plants," Review of Economic Dynamics, 11(4), 707-20.

Sandleris, G., And M. Wright (2014): "The Costs of Financial Crises: Resource Misallocation, Productivity and Welfare in Argentina 2001/02," Scandinavian Journal of Economics, 116(1), 87-127.

Wooldridge, J. (2009): "On Estimating Firm-Level Production Functions Using Proxy Variables to Control for Unobservables," Economics Letters, 104(3), 112-4. 


\title{
Capital Allocation and Productivity in South Europe
}

\author{
Online Appendix \\ Gita Gopinath Sebnem Kalemli-Ozcan Loukas Karabarbounis Carolina Villegas-Sanchez
}

February 2017

\section{A Data Cleaning and Summary Statistics}

Our dataset combines firm-level information across different BvD products (ORBIS disk 2005, ORBIS disk 2009, ORBIS disk 2013, AMADEUS online 2010 from WRDS, and AMADEUS disk 2014). We work only with unconsolidated accounts. We clean the data in four steps. First, we clean the data of basic reporting mistakes. Second, we verify the internal consistency of balance sheet information. The first two steps are implemented at the level of the total economy. Third, we do a more specific quality control on variables of interest for firms in the manufacturing sector. Finally, we winsorize variables.

\section{A.1 Cleaning of Basic Reporting Mistakes}

We implement the following steps to correct for basic reporting mistakes:

1. We drop firm-year observations that have missing information on total assets and operating revenues and sales and employment.

2. We drop firms if total assets are negative in any year, or if employment is negative or greater than 2 millions in any year, or if sales are negative in any year, or if tangible fixed assets are negative in any year.

3. We drop firm-year observations with missing, zero, or negative values for materials, operating revenue, and total assets.

4. We drop firm-year observations with missing information regarding their industry of activity. 


\section{A.2 Internal Consistency of Balance Sheet Information}

We check the internal consistency of the balance sheet data by comparing the sum of variables belonging to some aggregate to their respective aggregate. We construct the following ratios:

1. The sum of tangible fixed assets, intangible fixed assets, and other fixed assets as a ratio of total fixed assets.

2. The sum of stocks, debtors, and other current assets as a ratio of total current assets.

3. The sum of fixed assets and current assets as a ratio of total assets.

4. The sum of capital and other shareholder funds as a ratio of total shareholder funds.

5. The sum of long term debt and other non-current liabilities as a ratio of total non-current liabilities.

6. The sum of loans, creditors, and other current liabilities as a ratio of total current liabilities.

7. The sum of non-current liabilities, current liabilities, and shareholder funds as a ratio of the variable that reports the sum of shareholder funds and total liabilities.

After we construct these ratios, we estimate their distribution for each country separately. We then exclude from the analysis extreme values by dropping observations that are below the 0.1 percentile or above the 99.9 percentile of the distribution of ratios.

\section{A.3 Further Quality Checks for Manufacturing Firms}

After the implementation of the basic cleaning steps in the total economy sample we turn to examine the quality of the variables for firms in the manufacturing sector used in our analysis. At each stage, we provide the number of dropped observations for the Spanish sample. We start with $1,127,566$ observations that correspond to 149,779 firms in the Spanish manufacturing sector.

1. Age. We construct the variable "age" of the firm as the difference between the year of the balance sheet information and the year of incorporation of the firm plus one. We drop 
firms that report dates of incorporation that imply non-positive age values. This step reduces the observations in our sample by 35 .

2. Liabilities. As opposed to listed firms, non-listed firms do not report a separate variable "Liabilities." For these firms we construct liabilities as the difference between the sum of shareholder funds and liabilities ("SHFUNDLIAB") and shareholder funds or equity ("SHFUNDS"). We drop observations with negative or zero values. This step reduces the observations in our sample by 1,374 .

We could also have computed liabilities as the sum of current liabilities and non-current liabilities. However, we find that there are more missing observations if we follow this approach. Nevertheless, for those observations with non-missing information we compare the value of liabilities constructed as the difference between SHFUNDLIAB and SHFUNDS and the value of liabilities constructed as the sum of current and non-current liabilities. We look at the ratio of the first measure relative to the second measure. Due to rounding differences the ratio is not always exactly equal to one and so we remove only firm-year observations for which this ratio is greater than 1.1 or lower than 0.9 . This step reduces the observations in our sample by 1,349 .

We drop firm-year observations with negative values for current liabilities, non-current liabilities, current assets, loans, creditors, other current liabilities, and long term debt. This step reduces the observations in our sample by 40. Finally, we drop observations for which long term debt exceeds total liabilities. This step reduces the observations in our sample by 44 .

3. Net Worth. We construct net worth as the difference between total assets ("TOTASSTS") and total liabilities. This variable should be equal to the variable SHFUNDS provided by the BvD. We drop observations that violate this identity. This step reduces the observations in our sample by 32 .

4. Wage Bill. We drop firm-year observations with missing, zero, or negative values for the wage bill. This step reduces the observations in our sample by 20,571 . 
5. Capital Stock. We construct our measure of the capital stock as the sum of tangible fixed assets and intangible fixed assets and, therefore, we drop observations with negative values for intangible fixed assets. This step reduces the observations in our sample by 2,176. We drop observations with missing or zero values for tangible fixed assets. This step reduces the observations in our sample by 42,744 . We drop firm-year observations when the ratio of tangible fixed assets to total assets is greater than one. This step reduces the observations in our sample by 4,921. We drop firm-year observations with negative depreciation values. This step reduces the observations in our sample by 1 .

6. Capital-Labor Ratio. Next, we examine the quality of the capital to the wage bill variable. We first drop firms if in any year they have a capital to wage bill ratio in the bottom 0.1 percent of the distribution. This step reduces the observations in our sample by 5,801 . After we remove the very high extreme values of this ratio there is a very positively skewed distribution of the ratio and, therefore, we drop observations with ratios higher than the 99.9 or lower than the 0.1 percentile. This step reduces the observations in our sample by 1,836 .

7. Equity. We drop observations with negative SHFUNDS (equity or shareholders funds). This step reduces the observations in our sample by 123,208 . We drop observations in the bottom 0.1 percentile in the ratio of other shareholders funds (that includes items such as reserve capital and minority interests) to TOTASSTS. This step reduces the observations in our sample by 925 .

8. Leverage Ratios. We calculate the ratios of tangible fixed assets to shareholder funds and the ratio of total assets to shareholder funds and drop extreme values in the bottom 0.1 or top 99.9 percentile of the distribution of ratios. This step reduces the observations in our sample by 3,555 .

9. Value Added. We construct value added as the difference between operating revenue and materials and drop negative values. This step reduces the observations in our sample by 3,966 . We construct the ratio of wage bill to value added and drop extreme values in 
the bottom 1 percentile or the top 99 percentile. This step reduces the observations in our sample by 18,362. In this case we choose the 1 and 99 percentiles as thresholds to drop variables because the value of the ratio at the 99 percentile exceeds 1 . In addition, we drop firm-year observations if the ratio is greater than 1.1. This step reduces the observations in our sample by 11,629 .

The final sample for Spain has 884,997 firm-year observations, corresponding to 124,993 firms in the manufacturing sector. This is what we call the "full sample" in our analysis. The "permanent sample" is a subset of the full sample, consisting of firms with identifiers that are observed continuously for all years between 1999 and 2012. The permanent sample has 193,452 observations, corresponding to 13,818 firms.

\section{A.4 Winsorization}

We winsorize at the 1 and the 99 percentile variables such as value added, tangible fixed assets, wage bill, operating revenue, materials, total assets, shareholder funds, fixed assets, the sum of tangible and intangible fixed assets (capital), other fixed assets, and total liabilities. We winsorize at the 1 and the 99 percentile all of our estimated firm productivity variables and the productivity residuals from an $\mathrm{AR}(1)$ process used to construct our uncertainty measures. Similarly, we winsorize at the 1 and the 99 percentile net worth, cash flow to total assets, and sales to total assets. In addition, we winsorize at the 0.1 and 99.9 percentile the MRPK and the MRPL before calculating our dispersion measures to make our dispersion measures less sensitive to outliers. Finally, we winsorize at the 2 and the 98 percentile the net investment to lagged capital ratio used in our regressions because this ratio has a very long right tail.

\section{A.5 Industry Classifications}

Industry classifications changed from the NACE 1.1 revision to the NACE 2 revision in 2008. To match industry classifications, we start from the official Eurostat correspondence table that maps NACE 1.1 codes to NACE 2 codes. Often there is no one-to-one match between industries in the official correspondence table. When multiple NACE 2 codes are matched to a given NACE 1.1 code, we map the NACE 1.1 code to the first NACE 2 code provided in the official table. In many 
cases the first code is the most closely related industry to the one in NACE 1.1 classification. As

an example, consider the NACE 1.1 code "10.20: Mining and agglomeration of lignite." This code is matched to three NACE 2 codes: "5.2: Mining of lignite," "9.90: Support activities for other mining and quarrying," and "19.20: Manufacture of refined petroleum products." We match "10.20: Mining and agglomeration of lignite" to "5.20: Mining of lignite." Finally, when industries are completely missing from the official correspondence tables, we manually match codes by reading the descriptions of the codes.

\section{A.6 Summary Statistics}

Table A.1 presents summary statistics for all countries in our dataset. Except for employment, all entries in the table are in millions of euros. Value added, wage bill, total assets, and total liabilities are deflated with gross output price indices at the two digits industry level with a base year of 2005. For France and Norway we do not have these price deflators at the two digits and, therefore, we deflate with the price index for total manufacturing. The capital stock is the sum of tangible and intangible fixed assets and is deflated with the economy-wide price of investment goods. For each year, we first calculate means and standard deviations without weighting across all firms and industries. Entries in the table denote the means and standard deviations averaged across all years in each country.

\section{A.7 Coverage and Size Distribution}

Table A.2 presents coverage statistics for the wage bill relative to the wage bill reported in Eurostat's SBS for all countries. The coverage is high and averages from roughly 60 to more than 90 percent of the coverage observed in Eurostat. The exception is Germany, for which we have roughly one-third of the wage bill starting in 2006. The entry for France in 2008 is missing because of a missing observation in Eurostat. Generally, we obtain slightly higher coverage when we calculate similar statistics based on gross output and somewhat lower coverage when we calculate similar statistics based on employment.

Table A.3 reports the share of economic activity accounted for by firms belonging in three size categories in 2006 for all countries in our sample. Each panel presents a different measure 
Table A.1: Summary Statistics of Selected Variables

\begin{tabular}{|c|c|c|c|c|c|}
\hline \multirow[b]{2}{*}{ Country } & \multirow[b]{2}{*}{ Statistic } & \multicolumn{2}{|c|}{ Permanent Sample } & \multicolumn{2}{|r|}{ Full Sample } \\
\hline & & Mean & Standard Deviation & Mean & Standard Deviation \\
\hline \multirow[t]{6}{*}{ Spain } & Value Added & 1.23 & 3.00 & 2.16 & 4.08 \\
\hline & Employment & 24.87 & 138.73 & 42.07 & 234.69 \\
\hline & Wage Bill & 0.54 & 1.19 & 0.91 & 1.58 \\
\hline & Capital Stock & 0.89 & 2.47 & 1.47 & 3.20 \\
\hline & Total Assets & 2.66 & 7.10 & 4.52 & 9.32 \\
\hline & Total Liabilities & 1.54 & 4.12 & 2.40 & 5.22 \\
\hline \multirow[t]{6}{*}{ Italy } & Value Added & 2.73 & 5.31 & 4.76 & 6.81 \\
\hline & Employment & 36.12 & 171.25 & 55.75 & 156.40 \\
\hline & Wage Bill & 0.86 & 1.62 & 1.49 & 2.07 \\
\hline & Capital Stock & 1.36 & 3.17 & 2.35 & 4.04 \\
\hline & Total Assets & 5.31 & 11.4 & 9.10 & 14.30 \\
\hline & Total Liabilities & 3.73 & 7.75 & 5.95 & 9.51 \\
\hline \multirow[t]{6}{*}{ Portugal } & Value Added & 0.75 & 1.91 & 3.54 & 8.50 \\
\hline & Employment & 22.83 & 71.51 & 39.19 & 152.09 \\
\hline & Wage Bill & 0.30 & 0.65 & 1.60 & 3.51 \\
\hline & Capital Stock & 0.51 & 1.49 & 1.39 & 4.37 \\
\hline & Total Assets & 1.65 & 4.43 & 5.03 & 14.70 \\
\hline & Total Liabilities & 1.00 & 2.65 & 3.18 & 9.27 \\
\hline \multirow[t]{6}{*}{ Germany } & Value Added & 18.90 & 38.80 & 37.60 & 52.20 \\
\hline & Employment & 183.47 & 554.55 & 320.62 & 620.60 \\
\hline & Wage Bill & 7.39 & 14.40 & 14.40 & 19.20 \\
\hline & Capital Stock & 6.41 & 15.80 & 12.80 & 21.60 \\
\hline & Total Assets & 26.40 & 64.30 & 53.50 & 87.80 \\
\hline & Total Liabilities & 16.40 & 40.80 & 32.40 & 55.80 \\
\hline \multirow[t]{6}{*}{ France } & Value Added & 2.53 & 7.46 & 3.33 & 8.47 \\
\hline & Employment & 39.51 & 399.07 & 48.43 & 280.92 \\
\hline & Wage Bill & 0.95 & 2.52 & 1.26 & 2.85 \\
\hline & Capital Stock & 0.66 & 2.40 & 0.85 & 2.73 \\
\hline & Total Assets & 3.07 & 10.20 & 4.04 & 11.60 \\
\hline & Total Liabilities & 1.80 & 6.04 & 2.24 & 6.71 \\
\hline \multirow[t]{6}{*}{ Norway } & Value Added & 2.71 & 7.38 & 0.98 & 2.17 \\
\hline & Employment & 29.76 & 122.32 & 28.34 & 76.94 \\
\hline & Wage Bill & 1.26 & 3.11 & 0.38 & 0.74 \\
\hline & Capital Stock & 1.08 & 3.80 & 0.64 & 1.63 \\
\hline & Total Assets & 3.95 & 12.90 & 2.09 & 4.93 \\
\hline & Total Liabilities & 2.56 & 8.27 & 1.21 & 2.88 \\
\hline
\end{tabular}


Table A.2: Coverage in Wage Bill Relative to Eurostat (Manufacturing Industries)

\begin{tabular}{lcccccc}
\hline \hline & & & & & \\
& Spain & Italy & Portugal & Germany & France & Norway \\
\hline & & & & & & \\
\hline 1999 & 0.69 & 0.59 & & & & \\
2000 & 0.71 & 0.63 & & & 0.70 & \\
2001 & 0.73 & 0.62 & & & 0.72 & \\
2002 & 0.75 & 0.69 & & & 0.75 & \\
2003 & 0.74 & 0.68 & & & 0.73 & \\
2004 & 0.75 & 0.71 & & & 0.71 & 0.66 \\
2005 & 0.74 & 0.72 & & & 0.71 & 0.67 \\
2006 & 0.74 & 0.73 & 0.91 & 0.34 & 0.72 & 0.71 \\
2007 & 0.74 & 0.73 & 0.94 & 0.34 & 0.73 & 0.73 \\
2008 & 0.72 & 0.84 & 0.97 & 0.28 & $\mathrm{~N} / \mathrm{A}$ & 0.65 \\
2009 & 0.72 & 0.81 & 0.96 & 0.28 & 0.71 & 0.85 \\
2010 & 0.73 & 0.83 & 0.96 & 0.30 & 0.73 & 0.82 \\
2011 & 0.74 & 0.86 & 0.97 & 0.28 & 0.75 & 0.82 \\
2012 & 0.71 & 0.85 & 0.96 & 0.25 & 0.73 & 0.87 \\
& & & & & & \\
\hline \hline
\end{tabular}

of economic activity, namely employment, wage bill, and gross output. Within each panel, the first three rows report the measures from ORBIS-AMADEUS and the next three rows report the measures from Eurostat. As with the case of Spain, Table A.3 illustrates that our sample for other countries is also broadly representative in terms of contributions of small and medium sized firms to economic activity.

\section{B TFP Losses With Alternative Output Elasticities}

In this appendix we show that the trends in TFP losses that we estimate do not change meaningfully under a variety of alternative assumptions about the elasticity of output with respect to capital $\alpha_{s, t}$. Figure A.1 summarizes our results. In the left panel we show results for the permanent sample of firms and in the right panel we show results for the full sample of firms.

In each case, the black line shows changes relative to 1999 in the difference in $\log (\mathrm{TFP})$ relative to its efficient level, constructed with equation (10), under the baseline assumption of a constant across time and industries $\alpha=0.35$. We present estimated changes in TFP losses 
Table A.3: Share of Total Manufacturing Economic Activity By Size Class (2006)

\begin{tabular}{|c|c|c|c|c|c|c|c|}
\hline & & Spain & Italy & Portugal & Germany & France & Norway \\
\hline \multicolumn{8}{|c|}{ Employment } \\
\hline \multirow{3}{*}{ ORBIS-AMADEUS } & 1-19 employees & 0.24 & 0.13 & 0.25 & 0.05 & 0.10 & 0.18 \\
\hline & 20-249 employees & 0.50 & 0.55 & 0.53 & 0.32 & 0.35 & 0.47 \\
\hline & $250+$ employees & 0.26 & 0.32 & 0.22 & 0.63 & 0.56 & 0.35 \\
\hline \multirow[t]{3}{*}{ Eurostat (SBS) } & 0-19 employees & 0.31 & 0.40 & 0.32 & 0.15 & 0.19 & 0.20 \\
\hline & 20-249 employees & 0.43 & 0.38 & 0.49 & 0.32 & 0.34 & 0.42 \\
\hline & $250+$ employees & 0.26 & 0.22 & 0.19 & 0.53 & 0.47 & 0.38 \\
\hline \multicolumn{8}{|c|}{ Wage Bill } \\
\hline \multirow[t]{3}{*}{ ORBIS-AMADEUS } & 1-19 employees & 0.19 & 0.11 & 0.18 & 0.01 & 0.08 & 0.14 \\
\hline & 20-249 employees & 0.47 & 0.53 & 0.50 & 0.33 & 0.30 & 0.43 \\
\hline & $250+$ employees & 0.34 & 0.36 & 0.32 & 0.67 & 0.61 & 0.43 \\
\hline \multirow{3}{*}{ Eurostat (SBS) } & 0-19 employees & 0.20 & 0.22 & 0.21 & 0.07 & 0.14 & 0.15 \\
\hline & 20-249 employees & 0.43 & 0.44 & 0.49 & 0.26 & 0.31 & 0.41 \\
\hline & $250+$ employees & 0.37 & 0.34 & 0.30 & 0.67 & 0.55 & 0.44 \\
\hline \multicolumn{8}{|c|}{ Gross Output } \\
\hline \multirow[t]{3}{*}{ ORBIS-AMADEUS } & 1-19 employees & 0.14 & 0.12 & 0.12 & 0.06 & 0.05 & 0.11 \\
\hline & 20-249 employees & 0.42 & 0.49 & 0.43 & 0.27 & 0.23 & 0.40 \\
\hline & 250+ employees & 0.45 & 0.40 & 0.46 & 0.67 & 0.72 & 0.49 \\
\hline \multirow[t]{3}{*}{ Eurostat (SBS) } & 0-19 employees & 0.14 & 0.20 & 0.14 & 0.06 & 0.09 & 0.13 \\
\hline & 20-249 employees & 0.38 & 0.41 & 0.42 & 0.22 & 0.27 & 0.36 \\
\hline & $250+$ employees & 0.49 & 0.39 & 0.43 & 0.72 & 0.64 & 0.51 \\
\hline
\end{tabular}

under three alternative assumptions about the elasticity $\alpha_{s, t}$ which we always calculate as one minus the labor share. The dark orange line shows our estimates when we construct $\alpha_{s, t}$ using the labor share from our firm-level dataset in Spain at the four-digit and year level. The blue line uses an $\alpha_{s, t}$ estimated from U.S. labor share data at the two digits available in KLEMS. The red 


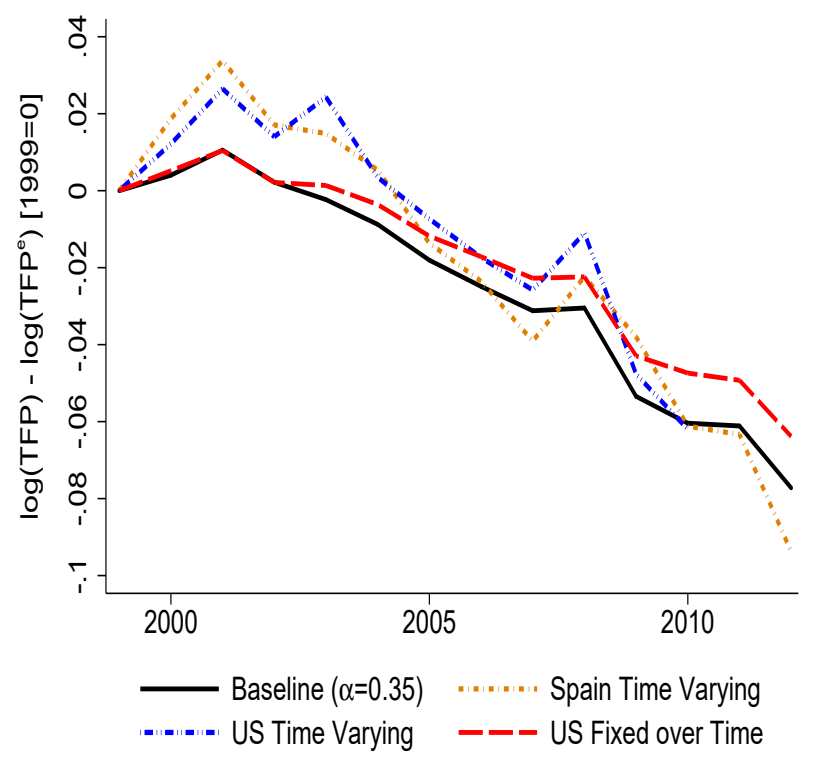

(a) Permanent Sample

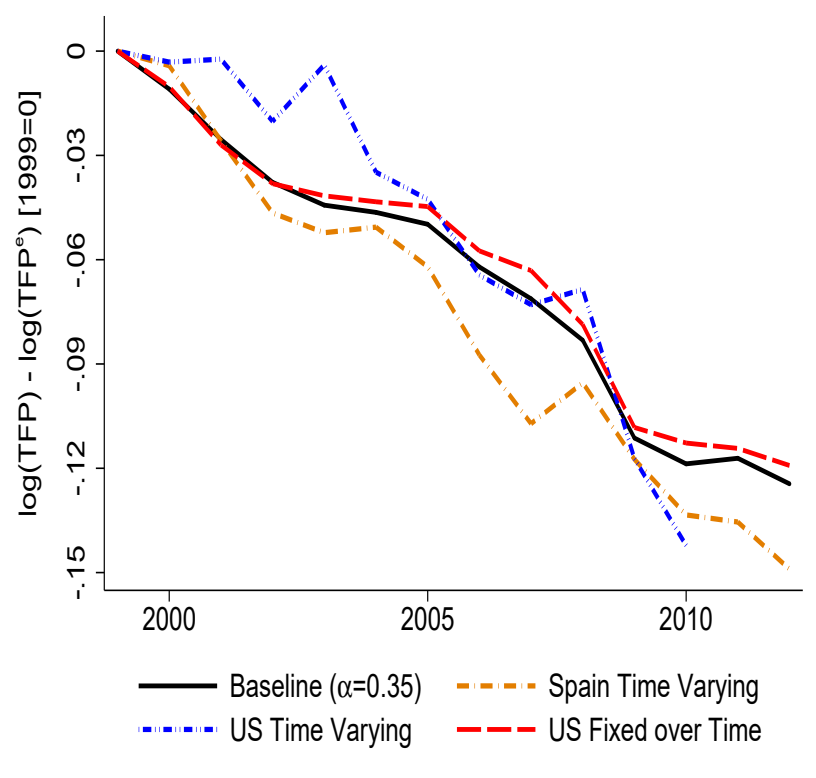

(b) Full Sample

Figure A.1: TFP Losses with Alternative Output Elasticities

line uses a time-invariant $\alpha_{s}$ estimated from U.S. labor share data at the two digits available in KLEMS. While there are year-to-year differences across the various series, the estimated trend in the TFP loss either in the pre-recession period (1999-2007) or in the full sample (1999-2012) does not change significantly under these alternative assumptions on the value of the output elasticity $\alpha_{s, t}$.

\section{Microfoundations of Borrowing Constraint}

In this appendix we present a microfoundation and some details underlying the size-dependent borrowing constraint that we use in our analysis. We begin by extending the logic underlying the borrowing constraint $b \leq \theta k$ used in the literature (Moll, 2014; Midrigan and Xu, 2014; Buera and Moll, 2015) to derive the size-dependent borrowing constraint in equation (16). In recursive form, the value of a firm that chooses to not default is:

$$
V^{N}\left(b, k, z^{P}, z^{T}, \mathbf{X}\right)=\max _{b^{\prime}, k^{\prime}, \ell, p}\left\{U(c)+\beta \mathbb{E} V\left(b^{\prime}, k^{\prime}, z^{P},\left(z^{T}\right)^{\prime}, \mathbf{X}^{\prime}\right)\right\}
$$


subject to the production function $y=Z k^{\alpha} \ell^{1-\alpha}$, the demand function $y=p^{-\varepsilon}$, and the budget constraint:

$$
c+k^{\prime}+(1+r) b+\frac{\psi\left(k^{\prime}-k\right)^{2}}{2 k}=p y-w \ell+(1-\delta) k+b^{\prime} .
$$

The value of a firm that chooses to default is:

$$
V^{D}\left(b, k, z^{P}, z^{T}, \mathbf{X}\right)=\max _{b^{\prime}, k^{\prime}, \ell, p}\left\{U(c)+\beta \mathbb{E} V\left(b^{\prime}, k^{\prime}, z^{P},\left(z^{T}\right)^{\prime}, \mathbf{X}^{\prime}\right)\right\}
$$

subject to the production function $y=Z k^{\alpha} \ell^{1-\alpha}$, the demand function $y=p^{-\varepsilon}$, and the budget constraint:

$$
c+k^{\prime}+\left(1+r-\mu_{0}\right) b+\underbrace{\mu_{1}(1-\delta) k+\mu_{2} \Psi(k)-\mu_{3} k}_{C(k): \text { net cost of default }}+\frac{\psi\left(k^{\prime}-k\right)^{2}}{2 k}=p y-w \ell+(1-\delta) k+b^{\prime} .
$$

Parameter $\mu_{0}$ is the fraction of the face value of debt that firms can default, $\mu_{1}$ is the fraction of capital lenders can seize in case of default, $\mu_{2}$ parameterizes adjustment costs from disruption in production in case of default, and $\mu_{3}$ parameterizes other benefits of default (e.g. default on labor payments). We note that if a firm defaults on a fraction $\mu_{0}$ of the face value of its debt, it can still access the financial market next period and borrow an amount $b^{\prime}$.

Because of the limited enforcement of contracts, lenders extend credit to firms up to the point where firms have no incentive to default in equilibrium:

$$
V^{N} \geq V^{D} \Longrightarrow b \leq \underbrace{\left(\frac{\mu_{1}(1-\delta)-\mu_{3}}{\mu_{0}}\right)}_{\theta_{0}} k+\underbrace{\left(\frac{\mu_{2}}{\mu_{0}}\right)}_{\theta_{1}} \Psi(k) .
$$

Using $a=k-b$, we can rewrite the collateral constraint as:

$$
k \leq \underbrace{\left(\frac{\mu_{0}}{\mu_{0}-\mu_{1}(1-\delta)+\mu_{3}}\right)}_{\lambda_{0}} a+\underbrace{\left(\frac{\mu_{2}}{\mu_{0}-\mu_{1}(1-\delta)+\mu_{3}}\right)}_{\lambda_{1}} \Psi(k) .
$$

Finally, we place parameter restrictions to ensure that (off-equilibrium) default is costly, i.e. $C(k) \geq 0$. For our particular parameterization with $\Psi(k)=\exp (k)-1$, the cost of default is:

$$
C(k)=\mu_{1}(1-\delta) k+\mu_{2}(\exp (k)-1)-\mu_{3} k,
$$

with

$$
C^{\prime}(k)=\mu_{1}(1-\delta)+\mu_{2} \exp (k)-\mu_{3},
$$




$$
C^{\prime \prime}(k)=\mu_{2} \exp (k)>0 .
$$

Because $C(0)=0$ and $C^{\prime \prime}(k)>0$, we obtain $C(k) \geq 0$ if $C^{\prime}(0) \geq 0 \Longleftrightarrow \mu_{1}(1-\delta)+\mu_{2}-\mu_{3} \geq 0$. Substituting the $\mu$ parameters out, we obtain that if $\lambda_{0}+\lambda_{1} \geq 1$ then $C(k) \geq 0$ for all $k$.

\section{Production Function Estimates}

In this appendix we discuss estimates of the production function. We estimate the production function separately for each two-digit industry $s$ :

$$
\log y_{i t}=d_{t}(s)+\beta^{\ell}(s) \log \ell_{i t}+\beta^{k}(s) \log k_{i t}+\log Z_{i t}+\epsilon_{i t},
$$

where $d_{t}(s)$ is a time fixed effect, $y_{i t}$ denotes nominal value added divided by the two-digit output price deflator, $\ell_{i t}$ denotes the wage bill divided by the same output price deflator, and $k_{i t}$ denotes the (book) value of fixed assets divided by the aggregate price of investment goods. In equation (A.7), $\beta^{\ell}(s)$ denotes the elasticity of value added with respect to labor and $\beta^{k}(s)$ denotes the elasticity of value added with respect to capital. These elasticities vary at 24 industries defined by their two-digit industry classification. Our estimation uses the methodology developed in Wooldridge (2009) and we refer the reader to his paper for details of the estimation process.

Given our estimated elasticities $\hat{\beta}^{\ell}(s)$ and $\hat{\beta}^{k}(s)$, we then calculate firm $(\log )$ productivity as $\log Z_{i t}=\log y_{i t}-\hat{\beta}^{\ell}(s) \log \ell_{i t}-\hat{\beta}^{k}(s) \log k_{i t}$.

In Table A.4 we present summary statistics for the sum of the elasticities $\hat{\beta}^{l}(s)+\hat{\beta}^{k}(s)$ estimated from regression (A.7) separately in each country. Our estimates look reasonable as the sum of elasticities is close to 0.80 . Because we do not observe prices at the firm level, these elasticities are more appropriately defined as revenue elasticities. In the presence of markups, these estimates are lower bounds for the true elasticities in the production function. With a constant returns to scale production function, we would estimate a sum of elasticities equal to 0.80 when the markup equals 20 percent.

The summary statistics in Table A.4 exclude industries for which at least one of the coefficients estimated with the Wooldridge (2009) extension of the Levinsohn and Petrin (2003) procedure results in a zero, negative, or missing value. Across 6 countries for which we separately estimate elasticities at the two-digit industry level we have few such industries (2 in Spain, 4 in 
Table A.4: Summary Statistics of Production Function Estimation

\begin{tabular}{lcccccc}
\hline \hline Sum of Elasticities & Spain & Italy & Portugal & Germany & France & Norway \\
& & & & & & \\
\hline & & & & & & \\
Mean & 0.80 & 0.71 & 0.79 & 0.85 & 0.82 & 0.76 \\
Median & 0.80 & 0.70 & 0.77 & 0.84 & 0.83 & 0.76 \\
Max & 0.91 & 0.81 & 0.87 & 1.03 & 0.90 & 0.90 \\
Min & 0.75 & 0.59 & 0.72 & 0.74 & 0.62 & 0.58 \\
Standard Deviation & 0.04 & 0.04 & 0.05 & 0.07 & 0.06 & 0.07 \\
& & & & & & \\
\hline \hline
\end{tabular}

Italy, 6 in Portugal, 3 in Germany, 2 in France, and 5 in Norway). Typically, these industries have a very small number of firms and account for a negligible fraction of total manufacturing activity. Therefore, we do not drop them from our analysis.

\section{E Additional Model Results}

In this appendix we present additional model results. In Appendix E.1 we compare the micro moments in the various models to the moments estimated from the full sample of firms. In Appendix E.2 we give more details about the firm-level regressions we presented in the main text. Finally, in Appendix E.3 we presents details of the various extensions to the baseline HeF model that we described in the main text.

\section{E.1 Firm-Level Moments in the Full Sample of Firms}

In Table A.5 we show the moments in the data for both the permanent sample of firms ("PS" column) and the full sample of firms ("FS" column). Most of the moments are of similar magnitude across samples. Panel E shows that using the moments in the full sample of firms rather than the moments from the permanent sample of firms would not change our conclusions about the relative fit of models. 
Table A.5: Firm-Level Moments: Permanent vs. Full Sample (1999-2007)

\begin{tabular}{|c|c|c|c|c|c|}
\hline Moment & PS & FS & HeF & HoF & NoF \\
\hline \multicolumn{6}{|c|}{$\underline{\text { A. Distributional Moments }}$} \\
\hline 1. $\mathrm{SD}(\log Z)$ & 0.37 & 0.38 & 0.38 & 0.38 & 0.38 \\
\hline 2. $\mathrm{SD}(\log \ell)$ & 1.13 & 1.21 & 0.80 & 0.74 & 0.71 \\
\hline 3. $\mathrm{SD}(\log k)$ & 1.52 & 1.70 & 0.91 & 0.75 & 0.66 \\
\hline 4. Top $20 \%$ Share of Aggregate Labor & 0.69 & 0.73 & 0.63 & 0.59 & 0.58 \\
\hline 5. Top $20 \%$ Share of Aggregate Capital & 0.79 & 0.84 & 0.71 & 0.61 & 0.56 \\
\hline \multicolumn{6}{|c|}{ B. Within-Firm Moments } \\
\hline 6. Coefficient of $\left(k^{\prime}-k\right) / k$ on $\log Z$ & 0.10 & 0.11 & 0.10 & 0.10 & 0.10 \\
\hline 7. Coefficient of $\left(k^{\prime}-k\right) / k$ on $\log a$ & 0.09 & 0.09 & 0.04 & 0.27 & 0.01 \\
\hline 8. Coefficient of $\left(k^{\prime}-k\right) / k$ on $\log k$ & -0.46 & -0.63 & -0.07 & -0.46 & -0.19 \\
\hline 9. Coefficient of $\left(b^{\prime}-b\right) / k$ on $\log Z$ & -0.38 & -0.48 & -0.04 & -0.06 & 0.03 \\
\hline 10. Coefficient of $\left(b^{\prime}-b\right) / k$ on $\log a$ & 0.15 & 0.14 & 0.09 & 0.72 & 0.02 \\
\hline 11. Coefficient of $\left(b^{\prime}-b\right) / k$ on $\log k$ & -0.34 & -0.54 & 0.07 & -0.74 & -0.22 \\
\hline \multicolumn{6}{|c|}{ C. Cross-Sectional Moments } \\
\hline 12. Fraction Borrowing & 0.90 & 0.91 & 0.90 & 0.90 & 1.00 \\
\hline 13. Coefficient of $b / k$ on $\log k$ & 0.15 & 0.23 & 0.15 & 0.03 & 0.00 \\
\hline 14. $\operatorname{Corr}(\log Z, \log k)$ & 0.62 & 0.52 & 0.88 & 0.89 & 0.91 \\
\hline 15. $\operatorname{Corr}(\log Z, \log a)$ & 0.75 & 0.65 & 0.84 & 0.90 & 0.43 \\
\hline 16. Corr $(\log \mathrm{MRPK}, \log Z)$ & 0.03 & 0.05 & -0.08 & 0.28 & 0.51 \\
\hline 17. Corr $(\log \mathrm{MRPK}, \log k)$ & -0.62 & -0.68 & -0.54 & -0.18 & 0.10 \\
\hline 18. Corr $(\log$ MRPK, $\log a)$ & -0.14 & -0.14 & -0.36 & -0.15 & 0.20 \\
\hline \multicolumn{6}{|c|}{ D. Model Evaluation (Permanent Sample) } \\
\hline 19. Root Mean Squared Error & & & 0.28 & 0.35 & 0.41 \\
\hline 20. Mean Absolute Error & & & 0.22 & 0.29 & 0.34 \\
\hline \multicolumn{6}{|c|}{ E. Model Evaluation (Full Sample) } \\
\hline 21. Root Mean Squared Error & & & 0.37 & 0.41 & 0.47 \\
\hline 22. Mean Absolute Error & & & 0.30 & 0.34 & 0.40 \\
\hline
\end{tabular}


Table A.6: Firm-Level Investment and Debt Decisions in the Data (Spain, 1999-2007)

\begin{tabular}{|c|c|c|c|}
\hline Dependent Variable & Regressors & Permanent Sample & Full Sample \\
\hline \multirow[t]{6}{*}{$\left(k^{\prime}-k\right) / k$} & $\log Z$ & $0.10^{* * *}$ & $0.11^{* * *}$ \\
\hline & & $(0.011)$ & $(0.007)$ \\
\hline & $\log a$ & $0.09 * * *$ & $0.09 * * *$ \\
\hline & & $(0.006)$ & $(0.003)$ \\
\hline & $\log k$ & $-0.46^{* * *}$ & $-0.63^{* * *}$ \\
\hline & & $(0.005)$ & $(0.003)$ \\
\hline \multirow[t]{6}{*}{$\left(k^{\prime}-k\right) / k$} & $\log ($ Sales $/ k)$ & $0.13^{* * *}$ & $0.14^{* * *}$ \\
\hline & & $(0.008)$ & $(0.005)$ \\
\hline & Cash Flow $/ k$ & $0.04^{* * *}$ & $0.05^{* * *}$ \\
\hline & & $(0.007)$ & $(0.003)$ \\
\hline & $\log k$ & $-0.31^{* * *}$ & $-0.47^{* * *}$ \\
\hline & & $(0.008)$ & $(0.005)$ \\
\hline \multirow[t]{6}{*}{$\left(b^{\prime}-b\right) / k$} & $\log Z$ & $-0.38 * * *$ & $-0.48 * * *$ \\
\hline & & $(0.027)$ & $(0.022)$ \\
\hline & $\log a$ & $0.15^{* * *}$ & $0.14^{* * *}$ \\
\hline & & $(0.013)$ & $(0.009)$ \\
\hline & $\log k$ & $-0.34^{* * *}$ & $-0.54^{* * *}$ \\
\hline & & $(0.011)$ & $(0.010)$ \\
\hline \multirow[t]{6}{*}{$\left(b^{\prime}-b\right) / k$} & $\log ($ Sales $/ k)$ & $-0.45^{* * *}$ & $-0.49 * * *$ \\
\hline & & $(0.020)$ & $(0.014)$ \\
\hline & Cash Flow $/ k$ & $0.07^{* * *}$ & 0.00 \\
\hline & & $(0.020)$ & $(0.013)$ \\
\hline & $\log k$ & $-0.66^{* * *}$ & $-0.91^{* * *}$ \\
\hline & & $(0.019)$ & $(0.015)$ \\
\hline
\end{tabular}

\section{E.2 Firm-Level Regressions}

Table A.6 compares the investment and debt regressions using our regressors to similar regressions but with regressors more commonly used by the finance literature. All regressions include firm fixed effects and industry-year fixed effects. The regressors that we used in the main text are motivated by our theory in which productivity, net worth, and capital are the state variables that summarize firm capital and debt decisions.

As the table shows, using the sales to capital ratio instead of productivity and the cash flow 
Table A.7: Capital Growth and Initial Net Worth

\begin{tabular}{llcc}
\hline \hline Dependent Variable & Regressors & Permanent Sample & Full Sample \\
\hline$\left(k_{07}-k_{99}\right) / k_{99}$ & $\log Z_{99}$ & $1.14^{* * *}$ & $1.49^{* * *}$ \\
& & $(0.08)$ & $(0.06)$ \\
& $\log a_{99}$ & $0.17^{* * *}$ & $0.15^{* * *}$ \\
& & $(0.03)$ & $(0.02)$ \\
& $\log k_{99}$ & $-0.96^{* * *}$ & $-1.11^{* * *}$ \\
& & $(0.03)$ & $(0.03)$ \\
\hline$\left(b_{07}-b_{99}\right) / k_{99}$ & $\log Z_{99}$ & $1.12^{* * *}$ & $1.47^{* * *}$ \\
& & $(0.11)$ & $(0.10)$ \\
& $\log a_{99}$ & $0.20^{* * *}$ & $0.11^{* * *}$ \\
& & $(0.04)$ & $(0.03)$ \\
& $\log k_{99}$ & $-0.86^{* * *}$ & $-0.98^{* * *}$ \\
& & $(0.05)$ & $(0.04)$ \\
\hline \hline
\end{tabular}

to capital ratio instead of log net worth leads to highly similar results. With one exception, all coefficient signs are the same across the two types of regressions. All coefficients except for the coefficient on the cash flow to capital ratio in the debt regression in the full sample are statistically significant at the 1 percent level.

In the first panel of Table A.7 we present the standard errors in the regression described in Section 6.2. All coefficient estimates are statistically significant at the 1 percent level. In the second panel of the table we show the corresponding regression for debt. We find that, conditional on initial productivity and capital, firms with higher initial net worth accumulated more debt by 2007 .

\section{E.3 Details Related to Model Extensions}

In this appendix we discuss in more detail the five extensions of the baseline model presented in rows 5 to 9 of Table 6 in the main text. For each extension, Table A.8 in this appendix presents the firm-level moments shown in Table 4 in the main text.

Higher Adjustment Costs. In the model with higher adjustment costs we choose $\psi=7.6$ such that the model exactly reproduces the change in aggregate capital observed in the data 
between 1999 and 2007. All other parameters are kept constant at their values presented in Table 3.

Exogenous Labor Wedges. The labor wedge $\tau$ takes the form of a proportional tax that firms pay on their compensation to labor. Thus, if $w$ is the wage and $\ell$ is labor, the after-tax compensation to labor equals $(1+\tau) w l$. We rebate the tax revenue $\tau w \ell$ lump-sum to each firm and, as a result, taxes affect firm behavior only through production decisions.

The labor wedge is heterogeneous across firms and can take two values, $\tau=-\bar{\tau}$ and $\tau=$ $+\bar{\tau}$. It follows an exogenous first-order Markov process $\pi\left(\tau^{\prime} \mid \tau\right)$ that is independent of firm productivity and takes the values $\pi\left(\tau^{\prime}=\bar{\tau} \mid \tau=\bar{\tau}\right)=\pi\left(\tau^{\prime}=-\bar{\tau} \mid \tau=-\bar{\tau}\right)=\pi_{\tau}$. The process $\pi\left(\tau^{\prime} \mid \tau\right)$ is independent of calendar time and, as a result, MRPL dispersion is constant in the model.

We calibrate the values of $\bar{\tau}$ and $\pi_{\tau}$ to match two moments estimated from the permanent sample of firms. First, the standard deviation of $\log (\mathrm{MRPL})$ equals 0.30 . Second, the first-order autocorrelation coefficient of $\log (\mathrm{MRPL})$ estimated from a regression with firm and industryyear fixed effects equals 0.48. With 14 sample periods, we obtain the values $\bar{\tau}=0.29$ and $\pi_{\tau}=0.81$. Given the stochastic process of the MRPL and the values of all other parameters listed in Table 3 , we recalibrate $\left(\psi, \lambda_{0}, \lambda_{1}\right)=(2.3,1.01,0.05)$ such that the model matches exactly the same three moments targeted under the parameterization of our baseline HeF model.

Overhead Labor. As in Bartelsman, Haltiwanger, and Scarpetta (2013), we consider the production function:

$$
y_{i t}=Z_{i t} k_{i t}^{\alpha}\left(\ell_{i t}-\phi_{\ell}\right)^{1-\alpha}
$$

where $\phi_{\ell}$ denotes overhead labor. With this production function, all firms equalize the true marginal revenue product of labor to the common wage. However, the measured marginal revenue product of labor varies across firms. To see this, we write:

$$
\mathrm{MRPL}_{i t}:=\left(\frac{1-\alpha}{\mu}\right)\left(\frac{p_{i t} y_{i t}}{\ell_{i t}}\right)=\left(1-\frac{\phi_{\ell}}{\ell_{i t}}\right) w_{t} .
$$

From this equation we see that firms with higher labor also have higher measured MRPL. This is an appealing feature of the model because in the data firm size and measured $\log (\mathrm{MRPL})$ correlate positively. 
Table A.8: Firm-Level Moments: Model vs. Data (1999-2007)

Moment

\begin{tabular}{|c|c|c|c|c|c|c|c|c|c|}
\hline \multicolumn{10}{|c|}{ A. Distributional Moments } \\
\hline 1. $\mathrm{SD}(\log Z)$ & 0.37 & 0.38 & 0.38 & 0.38 & 0.38 & 0.38 & 0.38 & 0.38 & 0.38 \\
\hline 2. $\mathrm{SD}(\log \ell)$ & 1.13 & 0.80 & 0.74 & 0.71 & 0.88 & 0.96 & 0.51 & 0.83 & 0.80 \\
\hline 3. $\mathrm{SD}(\log k)$ & 1.52 & 0.91 & 0.75 & 0.66 & 1.11 & 0.93 & 0.91 & 1.34 & 0.92 \\
\hline 4. Top $20 \%$ Share of Agg. Labor & 0.69 & 0.63 & 0.59 & 0.58 & 0.69 & 0.64 & 0.47 & 0.65 & 0.63 \\
\hline 5. Top 20\% Share of Agg. Capital & 0.79 & 0.71 & 0.61 & 0.56 & 0.81 & 0.72 & 0.71 & 0.74 & 0.71 \\
\hline \multicolumn{10}{|c|}{ B. Within-Firm Moments } \\
\hline 6. Coeff. of $\left(k^{\prime}-k\right) / k$ on $\log Z$ & 0.10 & 0.10 & 0.10 & 0.10 & 0.03 & 0.10 & 0.10 & 0.10 & 0.10 \\
\hline 7. Coeff. of $\left(k^{\prime}-k\right) / k$ on $\log a$ & 0.09 & 0.04 & 0.27 & 0.01 & 0.02 & 0.05 & 0.04 & 0.05 & 0.05 \\
\hline 8. Coeff. of $\left(k^{\prime}-k\right) / k$ on $\log k$ & -0.46 & -0.07 & -0.46 & -0.19 & -0.01 & -0.10 & -0.07 & -0.13 & -0.12 \\
\hline 9. Coeff. of $\left(b^{\prime}-b\right) / k$ on $\log Z$ & -0.38 & -0.04 & -0.06 & 0.03 & -0.09 & -0.04 & -0.04 & -0.18 & -0.05 \\
\hline 10. Coeff. of $\left(b^{\prime}-b\right) / k$ on $\log a$ & 0.15 & 0.09 & 0.72 & 0.02 & 0.30 & 0.11 & 0.09 & 0.16 & 0.12 \\
\hline 11. Coeff. of $\left(b^{\prime}-b\right) / k$ on $\log k$ & -0.34 & 0.07 & -0.74 & -0.22 & 0.01 & 0.02 & 0.07 & 0.01 & 0.00 \\
\hline \multicolumn{10}{|c|}{ C. Cross-Sectional Moments } \\
\hline 12. Fraction Borrowing & 0.90 & 0.90 & 0.90 & 1.00 & 0.92 & 0.90 & 0.90 & 0.90 & 0.90 \\
\hline 13. Coeff. of $b / k$ on $\log k$ & 0.15 & 0.15 & 0.03 & 0.00 & 0.06 & 0.15 & 0.15 & 0.15 & 0.15 \\
\hline 14. $\operatorname{Corr}(\log Z, \log k)$ & 0.62 & 0.88 & 0.89 & 0.91 & 0.90 & 0.87 & 0.88 & 0.71 & 0.92 \\
\hline 15. Corr $(\log Z, \log a)$ & 0.75 & 0.84 & 0.90 & 0.43 & 0.91 & 0.85 & 0.84 & 0.58 & 0.87 \\
\hline 16. Corr $(\log$ MRPK, $\log Z)$ & 0.03 & -0.08 & 0.28 & 0.51 & -0.45 & -0.06 & -0.08 & -0.17 & -0.09 \\
\hline 17. Corr $(\log \mathrm{MRPK}, \log k)$ & -0.62 & -0.54 & -0.18 & 0.10 & -0.79 & -0.42 & -0.53 & -0.80 & -0.56 \\
\hline 18. Corr $(\log$ MRPK, $\log a)$ & -0.14 & -0.36 & -0.15 & 0.20 & -0.77 & -0.31 & -0.36 & -0.77 & -0.44 \\
\hline \multicolumn{10}{|c|}{ D. Model Evaluation } \\
\hline 19. Root Mean Squared Error & & 0.28 & 0.35 & 0.41 & 0.32 & 0.26 & 0.32 & 0.25 & 0.27 \\
\hline 20. Mean Absolute Error & & 0.22 & 0.29 & 0.34 & 0.27 & 0.20 & 0.25 & 0.20 & 0.22 \\
\hline
\end{tabular}

Notes: Columns give moments in the data, the baseline model with heterogeneous frictions (HeF), the model with homogeneous frictions $(\mathrm{HoF})$, the model without frictions ( $\mathrm{NoF})$, the model with higher adjustment costs (HAC), the model with exogenous labor wedges (LW), the model with overhead labor (OL), the model with unmeasured capital (UC), and the model with an alternative process for the real interest rate (APR). 
Next, we calibrate and simulate the model with overhead labor. In parallel to the model with exogenous labor taxes, we rebate $\phi_{\ell} w$ back to each firm. This allows us to make consistent comparisons between the model with overhead labor and our baseline model without MRPL dispersion. We calibrate jointly $\left(\psi, \lambda_{0}, \lambda_{1}\right)=(3.2,0.98,0.047)$ and $\phi_{\ell}=0.135$ to match four moments. The three moments are the same moments targeted in our baseline model. The fourth moment is the standard deviation of $\log$ (MRPL) which in the data equals 0.30. All other parameters are fixed to the values shown in Table 3 for the baseline model.

For the model with overhead labor, we define aggregate total factor productivity as $\mathrm{TFP}_{t}:=$ $Y_{t} /\left(K_{t}^{\alpha}\left(L_{t}-\phi_{\ell} N\right)^{1-\alpha}\right)$, where $\phi_{\ell} N$ denotes total overhead labor in the economy. That is, we do not allow overhead labor to artificially bias measured TFP in the model. We finally note that the model with overhead labor generates an increase in the dispersion of $\log (\mathrm{MRPL})$ over time.

Unmeasured Capital. For this extension, we consider the production function:

$$
y_{i t}=Z_{i t}\left(k_{i t}+q_{i t}\right)^{\alpha} \ell_{i t}^{1-\alpha}
$$

where $q_{i t}$ denotes measurement error in firms' effective capital. The measurement error could reflect either some types of intangible assets that are not well measured in the data (in which case $q_{i t}>0$ ) or overhead capital in the production function (in which case $q_{i t}<0$ ).

Write the true MRPK as:

$$
\overline{\operatorname{MRPK}}_{i t}:=\left(\frac{\alpha}{\mu}\right)\left(\frac{p_{i t} y_{i t}}{k_{i t}+q_{i t}}\right)=\left(1+\tau_{i t}^{k}\right)\left(r_{t}+\delta\right) .
$$

where $\tau_{i t}^{k}$ denotes the percent deviation of the true MRPK from the frictionless cost of capital $r_{t}+\delta$. As in our baseline analysis, the wedge $\tau_{i t}^{k}$ arises because of a binding borrowing constraint, risk in capital accumulation, and capital adjustment costs. Next, consider the measured MRPK:

$$
\operatorname{MRPK}_{i t}:=\left(\frac{\alpha}{\mu}\right)\left(\frac{p_{i t} y_{i t}}{k_{i t}}\right)=\left(1+\frac{q_{i t}}{k_{i t}}\right) \overline{\operatorname{MRPK}}_{i t}=\left(1+\frac{q_{i t}}{k_{i t}}\right)\left(1+\tau_{i t}^{k}\right)\left(r_{t}+\delta\right) .
$$

Equation (A.12) shows that $q_{i t}$ introduces an additional wedge between the frictionless cost of capital and the measured MRPK.

We parameterize the model as follows. Unmeasured capital can take two values, $-\bar{q}$ and $+\bar{q}$, that remain constant over time. We choose $\left(\psi, \lambda_{0}, \lambda_{1}\right)=(1.6,0.98,0.047)$ and $\bar{q}=0.18$ to match 
four moments. The three moments are the same moments targeted in our baseline model. The fourth moment is the standard deviation of $\log (\mathrm{MRPK})$ which in the data equals 0.88 . Similarly to the model with overhead labor, we tax lump-sum each firm an amount equal to $\left(r_{t}+\delta\right) q_{i t}$. Also, we define aggregate total factor productivity as $\operatorname{TFP}_{t}:=Y_{t} /\left(\left(K_{t}+\sum_{i} q_{i t}\right)^{\alpha} L_{t}^{1-\alpha}\right)$. That is, we do not allow the $q_{i t}$ input to artificially bias measured TFP in the model. All other parameters are fixed to the values shown in Table 3 for the baseline model.

Alternative $r$ Process. We assume that the initial decline in 1994 was an unexpected shock but that from that date firms expect the real interest rate to evolve according to an $\operatorname{AR}(1)$ process $r_{t}=\left(1-\rho^{r}\right) \bar{r}+\rho^{r} r_{t-1}+\sigma^{r} \epsilon_{t}^{r}$, where $\bar{r}$ denotes the mean real interest rate, $\rho^{r}$ denotes the persistence of the process, and $\sigma^{r}$ denotes the standard deviation of shocks to the real interest rate. In our sample period, we estimate $\bar{r}=0.03, \rho^{r}=0.50$, and $\sigma^{r}=0.0086$. We then calibrate $\left(\psi, \lambda_{0}, \lambda_{1}\right)=(3.1,1.02,0.042)$ to match the same three moments that we targeted in our baseline model. All other parameters are set at their baseline values shown in Table 3 .

\section{F Dispersion of the MRPK in a Simpler Model}

In this appendix we use a simpler model to derive in closed-form the response of the dispersion of the $\log (\mathrm{MRPK})$ to various shocks. In this simpler model we show that the dispersion of the MRPK increases when: (i) the cost of capital decreases; (ii) financial frictions increase; (iii) exogenous aggregate productivity or the demand shifter increase. All responses have the same sign as the responses generated by our richer model.

The environment is close to one considered by Midrigan and Xu (2014), Moll (2014), and Buera and Moll (2015). Similar to these papers, we assume that firms maximize the discounted present value of utility flows under perfect foresight about next-period's productivity. This assumption implies that debt and capital are perfect substitutes and effectively renders the choice of capital a static decision. A firm's budget constraint is:

$$
c+a^{\prime}=\pi\left(Z^{A} z, k\right)+(1+r) a-R k .
$$

where $c$ is consumption, $a$ is assets, $\pi$ is profits, $r$ is the interest rate, $k$ is capital, and $R=r+\delta$ denotes the cost of capital. 
The reduced-form profit function is given by:

$$
\pi\left(Z^{A} z, k\right)=\frac{Z^{A} z}{\eta} k^{\eta},
$$

where $Z^{A}$ is the aggregate component of productivity and $z$ denotes the idiosyncratic component of productivity (which lumps together both the transitory and the permanent component of idiosyncratic productivity). While for simplicity we call it productivity, the product $Z^{A} z$ represents a reduced-form for productivity, the demand shifter, and wages. The concavity of the profit function, $\eta<1$, can reflect a combination of decreasing returns to scale and a downward sloping demand for a firm's product. ${ }^{1}$ The marginal revenue product of capital is:

$$
\operatorname{MRPK}=Z^{A} z k^{\eta-1} .
$$

Following Midrigan and Xu (2014), Moll (2014), and Buera and Moll (2015), we specify the borrowing constraint as:

$$
k \leq \lambda a,
$$

where the parameter $\lambda \geq 1$ captures the degree of financial frictions. A lower $\lambda$ denotes more severe financial frictions. When $\lambda=1$, firms cannot borrow and have to self-finance capital accumulation. When $\lambda \rightarrow \infty$, there are no financial frictions in capital accumulation.

Unconstrained firms equalize the MRPK to the cost of capital $R=r+\delta$. The unconstrained level of capital is:

$$
k^{*}=\left(\frac{Z^{A} z}{R}\right)^{\frac{1}{1-\eta}},
$$

and so capital is given by $k=\min \left\{k^{*}, \lambda a\right\}$. Firms with productivity $z$ above some threshold $Z^{*}$ are constrained and can finance capital only equal to $\lambda a$. The cutoff productivity level is given by:

$$
Z^{*}=(\lambda a)^{1-\eta} \frac{R}{Z^{A}} .
$$

We denote the joint distribution of productivity and net worth at any particular point in time by $G(a, z)$. We denote the probability density function of productivity $z$ conditional on

\footnotetext{
${ }^{1}$ The assumption that $\eta<1$ is an important difference between our model in this section and some of the previous literature. If the profit function was linear, then firm size would only be pinned down by the borrowing constraint. Below we show that when all firms are constrained in the initial equilibrium, small changes in $R, \theta$, or $Z^{A}$ do not affect MRPK dispersion.
} 
assets $a$ by $f(z \mid a)$, the cumulative density function of $z$ conditional on $a$ by $F(z \mid a)$, and the marginal probability density function of $a$ by $g(a)$. We denote by $z_{L}$ and $z_{H}$ the lowest and highest levels of productivity.

The goal is to solve for changes in the variance of the $\log (\mathrm{MRPK})$ in response to changes the cost of capital $R$, financial frictions $\lambda$, and aggregate productivity or the demand shifter $Z^{A}$. Our solutions should be understood as the first period of an impulse response. We note that assets $a$ are predetermined at the period of the shock, which allows us to treat their distribution as given.

As a preliminary step for our comparative statics we calculate the following quantities:

$$
\begin{aligned}
& \log (\mathrm{MRPK})=\log \left(Z^{A} z\right)-(1-\eta) \log (k)=\left\{\begin{array}{ll}
\log (R), & \text { if } z \leq Z^{*} \\
\log \left(Z^{A} z \lambda^{\eta-1} a^{\eta-1}\right), & \text { if } z>Z^{*}
\end{array},\right. \\
& \mathbb{E} \log (\mathrm{MRPK})=\int_{a}\left[\int_{z_{L}}^{Z^{*}} \log (R) f(z \mid a) d z+\int_{Z^{*}}^{z_{H}} \log \left(Z^{A} z \lambda^{\eta-1} a^{\eta-1}\right) f(z \mid a) d z\right] g(a) d a
\end{aligned}
$$

We use these expectations to calculate the response of the variance $\operatorname{Var}(\log (\mathrm{MRPK}))$ to any shock $X$ :

$$
\frac{\partial \operatorname{Var}(\log (\mathrm{MRPK}))}{\partial X}=\frac{\partial \mathbb{E}\left[(\log (\mathrm{MRPK}))^{2}\right]}{\partial X}-2[\mathbb{E} \log (\mathrm{MRPK})] \frac{\partial[\mathbb{E} \log (\mathrm{MRPK})]}{\partial X} .
$$




\section{F.1 Changes in the Cost of Capital}

We consider how small changes in $R$ impact the dispersion of the MRPK. Using Leibniz's rule we obtain:

$$
\frac{\partial[\mathbb{E} \log (\mathrm{MRPK})]}{\partial R}=\int_{a}\left[\frac{F\left(Z^{*} \mid a\right)}{R}+\log (R) f\left(Z^{*} \mid a\right) \frac{\partial Z^{*}}{\partial R}-\log \left(Z^{A} Z^{*} \lambda^{\eta-1} a^{\eta-1}\right) f\left(Z^{*} \mid a\right) \frac{\partial Z^{*}}{\partial R}\right] g(a) d a .
$$

Note that the two last terms in the integral cancel out because at the cutoff $Z^{*}$ we have $R=Z^{A} Z^{*} \lambda^{\eta-1} a^{\eta-1}$. Therefore:

$$
\frac{\partial[\mathbb{E} \log (\mathrm{MRPK})]}{\partial R}=\frac{1}{R} \int_{a} F\left(Z^{*} \mid a\right) g(a) d a .
$$

Similarly:

$$
\frac{\partial \mathbb{E}\left[(\log (\mathrm{MRPK}))^{2}\right]}{\partial R}=\frac{2 \log (R)}{R} \int_{a} F\left(Z^{*} \mid a\right) g(a) d a .
$$

Plugging (A.24) and (A.25) into (A.23) we obtain:

$$
\frac{\partial \operatorname{Var}(\log (\mathrm{MRPK}))}{\partial R}=\left(\frac{2}{R}\right)(\log R-\mathbb{E} \log (\mathrm{MRPK})) \int_{a} F\left(Z^{*} \mid a\right) g(a) d a \leq 0 .
$$

The variance is weakly decreasing in $R$ because $\log R \leq \mathbb{E} \log (\mathrm{MRPK})$ and $F\left(Z^{*} \mid a\right) \geq 0$ at the initial point of differentiation. Note that the variance does not change in the limiting cases of no firm being initially constrained (i.e. $\log R=\mathbb{E} \log (\mathrm{MRPK})$ ) or all firms being initially constrained (i.e. $F\left(Z^{*} \mid a\right)=0$ ). Finally, we note that locally $R$ does not affect dispersion through the cutoff $Z^{*}$. This assumes that there is a smooth distribution of $z$ conditional on $a$ and that there are no mass points.

\section{F.2 Changes in Financial Frictions}

We consider how small changes in $\lambda$ impact the dispersion of the MRPK. We obtain:

$\frac{\partial[\mathbb{E} \log (\mathrm{MRPK})]}{\partial \lambda}=\int_{a}\left[\log (R) f\left(Z^{*} \mid a\right) \frac{\partial Z^{*}}{\partial \lambda}-\log \left(Z^{A} Z^{*} \lambda^{\eta-1} a^{\eta-1}\right) f\left(Z^{*} \mid a\right) \frac{\partial Z^{*}}{\partial \lambda}+\left(\frac{\eta-1}{\lambda}\right) \int_{Z^{*}}^{z_{H}} f(z) d z\right] g(a) d a$.

Note that the two first terms in the integral cancel out because at the cutoff $Z^{*}$ we have $R=Z^{A} Z^{*} \lambda^{\eta-1} a^{\eta-1}$. Therefore:

$$
\frac{\partial[\mathbb{E} \log (\mathrm{MRPK})]}{\partial \lambda}=\left(\frac{\eta-1}{\lambda}\right) \int_{a} \int_{Z^{*}}^{z_{H}} f(z) d z g(a) d a=\left(\frac{\eta-1}{\lambda}\right) \int_{a}\left(1-F\left(Z^{*} \mid a\right)\right) g(a) d a .
$$


We also have:

$$
\begin{array}{r}
\frac{\partial \mathbb{E}\left[(\log (\mathrm{MRPK}))^{2}\right]}{\partial \lambda}=\int_{a}\left[(\log (R))^{2} f\left(Z^{*} \mid a\right) \frac{\partial Z^{*}}{\partial \lambda}-\left(\log \left(Z^{A} Z^{*} \lambda^{\eta-1} a^{\eta-1}\right)\right)^{2} f\left(Z^{*} \mid a\right) \frac{\partial Z^{*}}{\partial \lambda}\right] g(a) d a \\
+\int_{a}\left[\int_{Z^{*}}^{z_{H}} \frac{2(\eta-1) \log \left(Z^{A} z \lambda^{\eta-1} a^{\eta-1}\right)}{\lambda} f(z) d z\right] g(a) d a .
\end{array}
$$

The first two terms cancel out and therefore this derivative can be simplified to:

$$
\frac{\partial \mathbb{E}\left[(\log (\mathrm{MRPK}))^{2}\right]}{\partial \lambda}=\left(\frac{2(\eta-1)}{\lambda}\right) \int_{a} \int_{Z^{*}}^{z_{H}} \log \left(Z^{A} z \lambda^{\eta-1} a^{\eta-1}\right) f(z) d z g(a) d a .
$$

or

$$
\frac{\partial \mathbb{E}\left[(\log (\mathrm{MRPK}))^{2}\right]}{\partial \lambda}=\left(\frac{2(\eta-1)}{\lambda}\right) \int_{a} \mathbb{E}\left(\log (\mathrm{MRPK}) \mid z>Z^{*}, a\right)\left(1-F\left(Z^{*} \mid a\right)\right) g(a) d a .
$$

Plugging (A.27) and (A.28) into (A.23) we finally obtain:

$$
\frac{\partial \operatorname{Var}(\log (\mathrm{MRPK}))}{\partial \lambda}=\left(\frac{2(\eta-1)}{\lambda}\right) \int_{a}\left[\mathbb{E}\left(\log (\mathrm{MRPK}) \mid z>Z^{*}, a\right)-\mathbb{E} \log (\mathrm{MRPK} \mid a)\right]\left(1-F\left(Z^{*} \mid a\right)\right) g(a) d a \leq 0 .
$$

The bracket is weakly positive because the expected marginal revenue product of capital is higher conditional on productivity being above $Z^{*}$. Given that $\eta<1$, the derivative of the variance is weakly negative.

\section{F.3 Changes in Aggregate Productivity or Demand}

We consider how small changes in $Z^{A}$ impact the dispersion of the MRPK. We obtain:

$$
\frac{\partial[\mathbb{E} \log (\mathrm{MRPK})]}{\partial Z^{A}}=\int_{a}\left[\log (R) f\left(Z^{*} \mid a\right) \frac{\partial Z^{*}}{\partial Z^{A}}-\log \left(Z^{A} Z^{*} \lambda^{\eta-1} a^{\eta-1}\right) f\left(Z^{*} \mid a\right) \frac{\partial Z^{*}}{\partial Z^{A}}+\left(\frac{1}{Z^{A}}\right) \int_{Z^{*}}^{z_{H}} f(z) d z\right] g(a) d a .
$$

Note that the two first terms in the integral cancel out because at the cutoff $Z^{*}$ we have $R=Z^{A} Z^{*} \lambda^{\eta-1} a^{\eta-1}$. Therefore:

$$
\frac{\partial[\mathbb{E} \log (\mathrm{MRPK})]}{\partial Z^{A}}=\left(\frac{1}{Z^{A}}\right) \int_{a} \int_{Z^{*}}^{z_{H}} f(z) d z g(a) d a=\left(\frac{1}{Z^{A}}\right) \int_{a}\left(1-F\left(Z^{*} \mid a\right)\right) g(a) d a .
$$

We also have:

$$
\begin{aligned}
\frac{\partial \mathbb{E}\left[(\log (\mathrm{MRPK}))^{2}\right]}{\partial Z^{A}}=\int_{a}\left[(\log (R))^{2} f\left(Z^{*} \mid a\right) \frac{\partial Z^{*}}{\partial Z^{A}}\right. & \left.-\left(\log \left(Z^{A} Z^{*} \lambda^{\eta-1} a^{\eta-1}\right)\right)^{2} f\left(Z^{*} \mid a\right) \frac{\partial Z^{*}}{\partial Z^{A}}\right] g(a) d a \\
& +\int_{a}\left[\int_{Z^{*}}^{z_{H}} \frac{2 \log \left(Z^{A} z \lambda^{\eta-1} a^{\eta-1}\right)}{Z^{A}} f(z) d z\right] g(a) d a .
\end{aligned}
$$


The first two terms cancel out and therefore this derivative can be simplified to:

$$
\frac{\partial \mathbb{E}\left[(\log (\mathrm{MRPK}))^{2}\right]}{\partial Z^{A}}=\left(\frac{2}{Z^{A}}\right) \int_{a} \int_{Z^{*}}^{z_{H}} \log \left(Z^{A} z \lambda^{\eta-1} a^{\eta-1}\right) f(z) d z g(a) d a .
$$

or

$$
\frac{\partial \mathbb{E}\left[(\log (\mathrm{MRPK}))^{2}\right]}{\partial Z^{A}}=\left(\frac{2}{Z^{A}}\right) \int_{a} \mathbb{E}\left(\log (\mathrm{MRPK}) \mid z>Z^{*}, a\right)\left(1-F\left(Z^{*} \mid a\right)\right) g(a) d a .
$$

Plugging (A.30) and (A.31) into (A.23) we finally obtain:

$$
\frac{\partial \operatorname{Var}(\log (\mathrm{MRPK}))}{\partial Z^{A}}=\left(\frac{2}{Z^{A}}\right) \int_{a}\left[\mathbb{E}\left(\log (\mathrm{MRPK}) \mid z>Z^{*}, a\right)-\mathbb{E} \log (\mathrm{MRPK} \mid a)\right]\left(1-F\left(Z^{*} \mid a\right)\right) g(a) d a \geq 0 .
$$

The bracket is weakly positive because the expected marginal revenue product of capital is higher conditional on productivity being above $Z^{*}$. Therefore, the derivative of the variance is weakly positive. 